NATIONAL LABORATORY

MANAGED BY UT-BATTELLE

FOR THE DEPARTMENT OF ENERGY

\title{
Preliminary Conceptual Design of Thick Concrete Nondestructive Evaluation Specimens
}

\section{April 2014}

\author{
Prepared by \\ Dwight Clayton \\ Kyle Hoegh \\ Lev Khazanovich \\ Mike Hileman
}

Approved for public release:

distribution is unlimited.

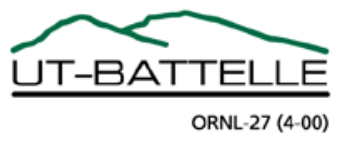




\section{DOCUMENT AVAILABILITY}

Reports produced after January 1, 1996, are generally available free via US Department of Energy (DOE) SciTech Connect.

Website http://www.osti.gov/scitech/

Reports produced before January 1, 1996, may be purchased by members of the public from the following source:

National Technical Information Service

5285 Port Royal Road

Springfield, VA 22161

Telephone 703-605-6000 (1-800-553-6847)

TDD 703-487-4639

Fax 703-605-6900

E-mail info@ntis.gov

Website http://www.ntis.gov/support/ordernowabout.htm

Reports are available to DOE employees, DOE contractors, Energy Technology Data Exchange representatives, and International Nuclear Information System representatives from the following source:

Office of Scientific and Technical Information

PO Box 62

Oak Ridge, TN 37831

Telephone 865-576-8401

Fax 865-576-5728

E-mail reports@osti.gov

Website http://www.osti.gov/contact.html

This report was prepared as an account of work sponsored by an agency of the United States Government. Neither the United States Government nor any agency thereof, nor any of their employees, makes any warranty, express or implied, or assumes any legal liability or responsibility for the accuracy, completeness, or usefulness of any information, apparatus, product, or process disclosed, or represents that its use would not infringe privately owned rights. Reference herein to any specific commercial product, process, or service by trade name, trademark, manufacturer, or otherwise, does not necessarily constitute or imply its endorsement, recommendation, or favoring by the United States Government or any agency thereof. The views and opinions of authors expressed herein do not necessarily state or reflect those of the United States Government or any agency thereof. 


\title{
Preliminary Conceptual Design of a Thick Concrete Nondestructive Evaluation Specimen
}

\author{
Dwight Clayton \\ Kyle Hoegh \\ Lev Khazanovich \\ Mike Hileman
}

Date Published: May 2014

Prepared by

OAK RIDGE NATIONAL LABORATORY

Oak Ridge, Tennessee 37831-6283

managed by

UT-BATTELLE, LLC

for the

US DEPARTMENT OF ENERGY

under contract DE-AC05-00OR22725 



\section{CONTENTS}

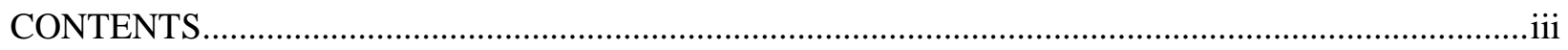

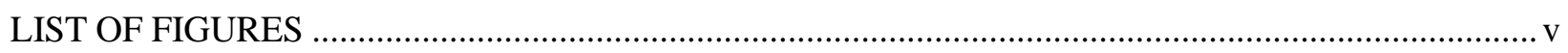

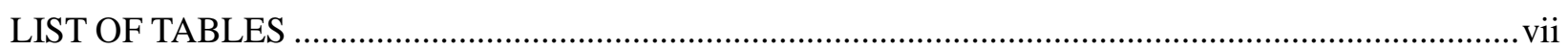

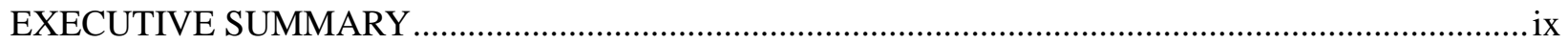

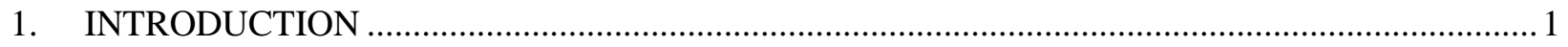

2. NEED FOR SUITABLE CONCRETE SPECIMENS …............................................................

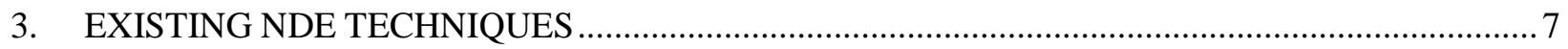

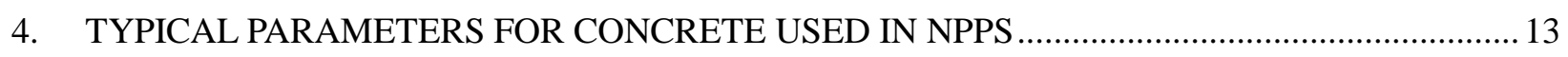

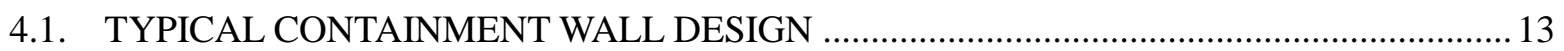

4.2. PREVIOUS CONCRETE FAILURES IN NPP CONTAINMENT STRUCTURES ................15

5. SPECIMENS WITH DEFECTS APPLICABLE FOR COMPARATIVE NDE …............................ 19

5.1. CONTAINMENT STRUCTURE CONCRETE SPECIMENS …......................................... 19

5.2. INFRASTRUCTURE CONCRETE SPECIMENS WITH NPP CONTAINMENT

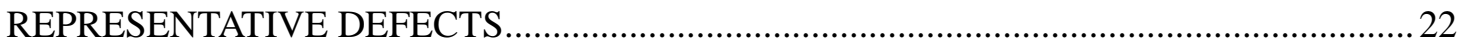

5.2.1. Federal Institute For Materials Research And Testing (Bam) In Berlin (Germany)...... 22

5.2.2. Nondestructive Evaluation Specimens From Journal Publications ............................... 23

5.2.3. Federal Highway Administration NDE Validation Center At The Turner-Fairbank

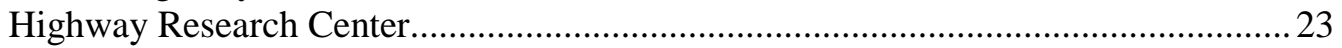

5.2.4. Specimen 1 - F-Shaped Free Standing Portable with Simulated Corrosion.................... 24

5.2.5. Specimen 2 - F-Shaped Bolt Down with Simulated Corrosion...................................... 25

5.2.6. Specimen 3 - F-Shaped Free Standing Portable with Embedded Voids .......................... 27

5.2.7. FLORIDA DEPARTMENT OF TRANSPORTATION NDE VALIDATION

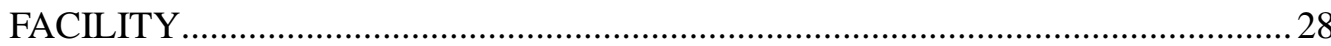

6. DESIGN REQUIREMENTS FOR A SUITABLE REPRESENTATIVE NPP CONCRETE

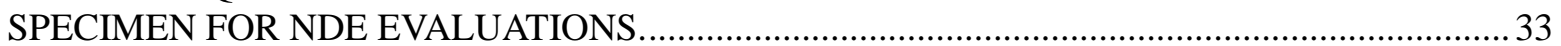

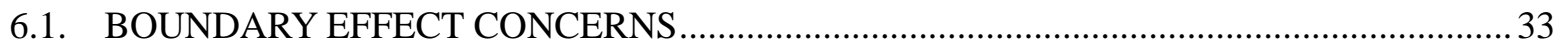

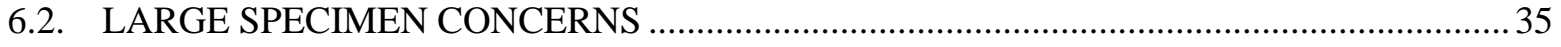

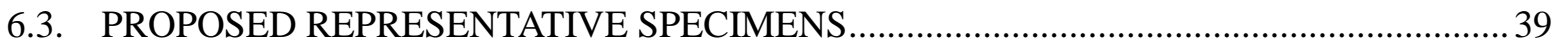

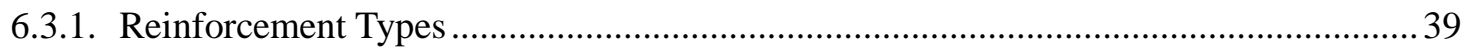

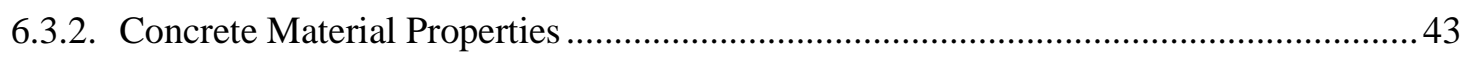

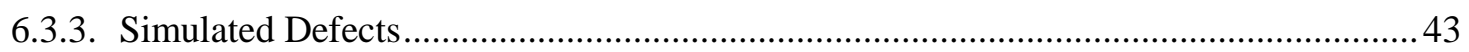

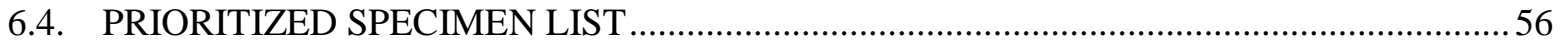

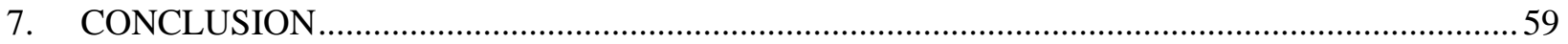

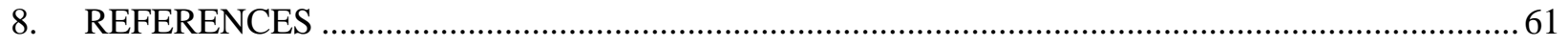





\section{LIST OF FIGURES}

Figure

Page

1

3

4

5

6

7

8

9

10

11

12

13

14

15

16

17

18

19

20

21

22

23

24

[A] Volumetric imaging of a reinforced concrete specimen with [B] simulated degradation during construction and a [C] clear indication of the increasingly degraded

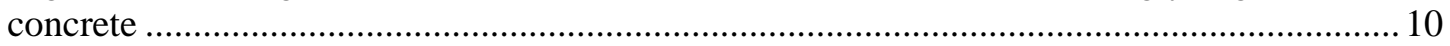

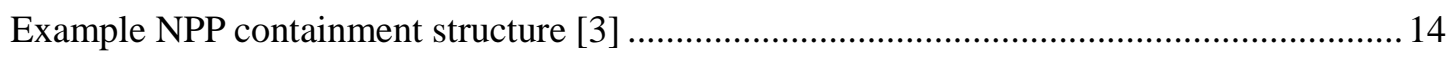

Delamination crack running from horizontal tendons at approximately $10 \mathrm{in}$. deep [A]

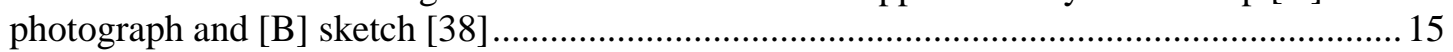

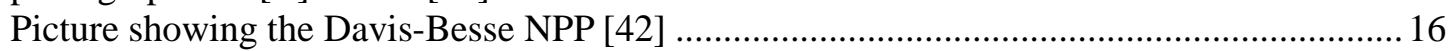

View of the Davis-Besse NPP layout and reinforcement scheme [42] .................................. 16

Laminar cracking at reinforcements from an interface cut out by hydrodemolition [42] ....... 17

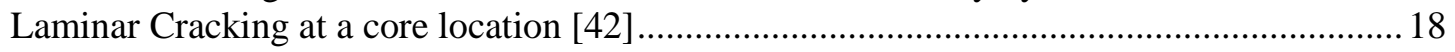

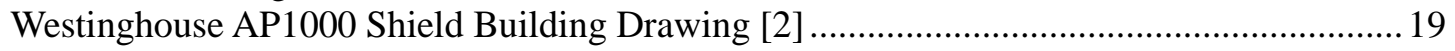

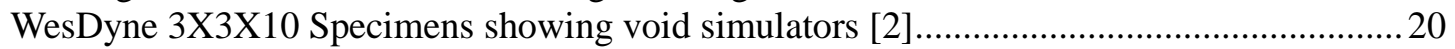

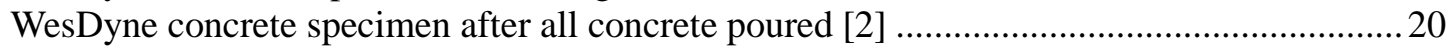

WesDyne Westinghouse AP1000 Shield Building NDE Evaluation Section [2] ..................... 21

NDE Evaluations being performed on AP1000 Shield Building Section[2] ............................ 21

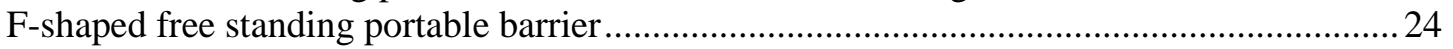

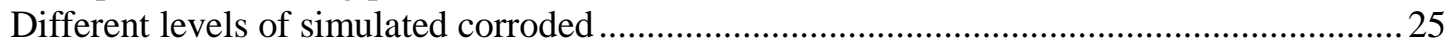

F-shaped bolt-down barrier with different levels of simulated ................................................. 25

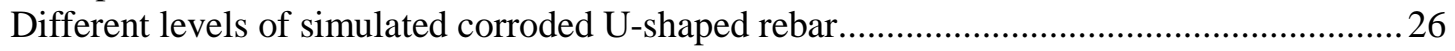

F-shaped bolt-down barrier fabrication with simulated corrosion ............................................26

F-shaped free standing portable barrier with simulated voids................................................ 27

Four concrete test specimens. Clockwise from top-left: rebar detection, steel post

tensioning duct evaluation, polypropylene post tensioning duct evaluation, and slab

thickness evaluation blocks in varying stages of design and construction [9].......................28

Orientation and relative location of rebar mats in Rebar Detection Block [5] ......................... 29

Installing the surface level pervious concrete prism and two short boards holding the triangular plates used to make the simulated cracks [8].

Three rebar pieces including the two moving specimens in Void and Flaw Detection

Block. The plastic caps marked with the black arrows both keep concrete out of the movement slot in the form boards and indicate which direction the rebar end is

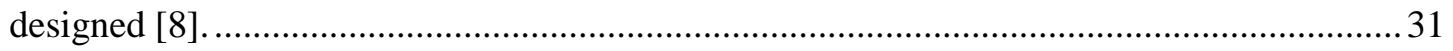

Beam Pattern from a Four Element Ultrasonic Array …...................................................... 33

[A] Picture of MIRA ultrasound scanner with an approximately 1 meter thick

reinforced concrete specimen with corresponding reconstructions that indicate the [B]

shallow features [C] deep features, and [D] all features....................................................... 34

Photograph of the abutment reinforced concrete specimen cast in the UMN Structures

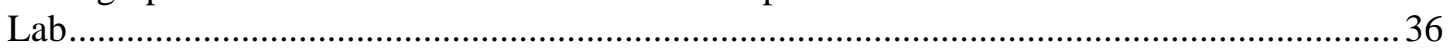

Design for a large reinforced concrete specimen in the UMN structures lab illustrating

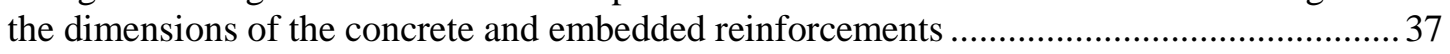

Formwork required to cast the abutment structure.............................................................. 38

Abutment block including details used to hold the block in place during loading and to

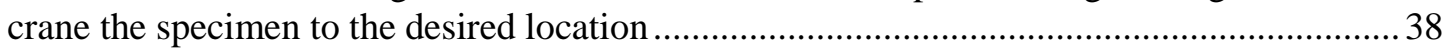

Concrete dimensions and reinforcement cross-section to simulate a NPP containment

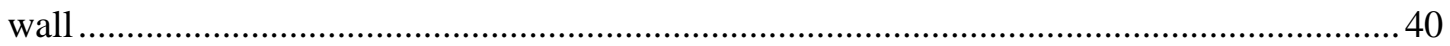

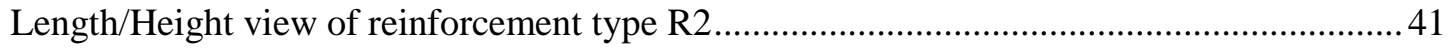

Length/Height view of reinforcement type R3 ................................................................. 42 
Height/depth view of the D1 defects outlined in Table 6

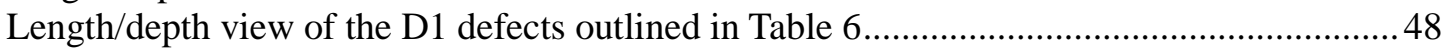

Length/height view of the D2 defects outlined in Table 7

Height/depth view of the D2 defects outlined in Table 7 ...........

Length/depth view of the D2 defects outlined in Table 7.

Length/height view of the D3 defects outlined in Table 8. 


\section{LIST OF TABLES}

Table

Page

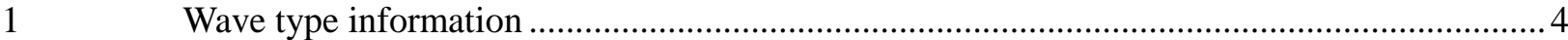

2 Summary of current NDE concrete measurement techniques............................................. 8

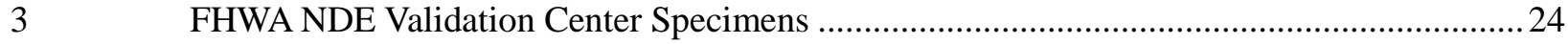

$4 \quad$ Corrosion simulation for each barrier section for Specimens 1 and 2.................................2 24

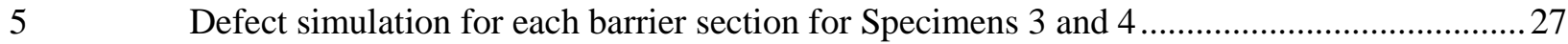

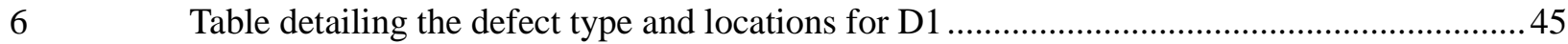

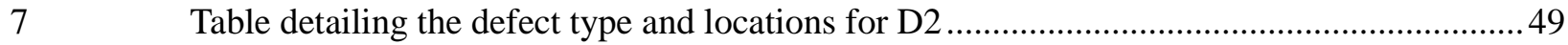

$8 \quad$ Table detailing the defect type and locations for D3 ......................................................... 53 



\section{EXECUTIVE SUMMARY}

Many important safety structures in a nuclear power plant (NPP) are constructed using concrete. The purpose of the U.S. Department of Energy Office of Nuclear Energy's Light Water Reactor Sustainability (LWRS) Program is to develop technologies and other solutions that can improve the reliability, sustain the safety, and extend the operating lifetimes of NPPs beyond 60 years [1]. In order to evaluate the current status of NPP structures, concrete inspection techniques must be developed and tested. Since in-service containment structures do not allow for destructive measures necessary to validate the accuracy of these inspection techniques, comparative testing of the various nondestructive evaluation (NDE) concrete measurement techniques will require concrete specimens with known material properties, voids, internal microstructure flaws, and reinforcement locations. This report examines the need and availability of large concrete specimens to allow comparative testing of various NDE techniques, and the structural characteristics necessary for the specimens to serve as relevant representations of actual concrete structures in commercial NPPs.

Many NDE concrete measurement techniques have been developed for relatively thin concrete structures ( $\sim 1 \mathrm{ft}$. thickness or less) such as those found in building construction and infrastructure applications (pavement, bridge decking, etc.). While these techniques have shown promise in their ability to nondestructively evaluate internal characteristics of thin concrete structures, their performance for evaluating NPP concrete structures (typically over $3 \mathrm{ft}$. thick and heavily reinforced) needs to be validated. The lack of readily available representative specimens creates a need to construct these specimens for performing NDE assessments, research, and training [2].

To determine the design requirements for a suitable representative NPP concrete specimen for NDE, it was necessary to evaluate currently available NDE techniques and their suitability for the examination of known materials and characteristics of typical NPP structures. It was also necessary to examine previous NPP structure failures and the processes that lead to the degradation of these structures to compile a thorough list of structural flaws for inclusion in the test specimens. These assessments identified a series of issues and limitations.

- Although current NDE techniques provided a baseline performance showing many of them generally perform well when used on relatively thin concrete structures, each method has some limitations and it remains to be seen how these techniques will perform on thick, heavily reinforced concrete structures such as those in commercial NPPs.

- Examination of typical NPP structure characteristics revealed the need for testing specimens much larger and more heavily reinforced than specimens currently available.

- Examination of previous NPP structure failures shows that degradation in the form of cracking, spalling, and general deterioration is commonly observed defects. Delamination cracks or gaps near layers of reinforcement are also observed.

- Examination of recent NDE test specimens with intentional voids and flaws helped to show limitations of current NDE techniques allowed preliminary testing of techniques to overcome these limitations. These specimens also allowed testing of the techniques needed to create realistic flaws and to simulate defects created by construction methods.

- Examination of beamforming techniques and multi-transducer array techniques proved useful for overcoming acoustic interference effects encountered near specimen boundaries and in regions with complex reinforcement structure. These volumetric imaging techniques make it possible to detect structures at longer depths that may be obstructed by reinforcement at nearer depths.

Based current volumetric imaging techniques and results from previous studies, along with the challenges associated with thick reinforced concrete sections identified in this report, a prioritized list of conceptual designs of concrete specimens fabricated to represent NPP concrete structures for use in NDE instrumentation and evaluation comparisons are proposed. 



\section{INTRODUCTION}

Materials issues are a key concern for the existing nuclear reactor fleet as material degradation can lead to increased maintenance, increased downtime, and increased risk. Extending reactor life to 60 years and beyond will likely increase susceptibility and severity of known forms of degradation [2][3]. New mechanisms of materials degradation are also possible. A multitude of concrete-based structures are typically part of a light water reactor (LWR) plant to provide foundation, support, shielding, and containment functions. Concrete has been used in the construction of nuclear power plants (NPPs) due to three primary properties; its low cost, structural strength, and ability to shield radiation. Examples of concrete structures important to the safety of LWR plants include the containment building, spent fuel pool, and cooling towers. Use in these structures has made concrete's long-term performance crucial for the safe operation of commercial NPPs. This creates the need to be able to nondestructively evaluate the current subsurface concrete condition of aging concrete material in NPP containment structures.

The size and complexity of NPP containment structures and heterogeneity of Portland cement concrete (PCC) make characterization of the degradation extent a difficult task. Unlike most metallic materials, reinforced concrete is a composite with a relatively low density matrix, a mixture of Portland cement, fine aggregate or sand, aggregate, water, admixtures, and a high density reinforcement (typically 5 percent in NPP containment structures), made up of steel rebar or tendons. NPPs have been typically built with local cement and aggregate fulfilling the design specifications regarding strength, workability, and durability, but as a consequence each plant's concrete composition is unique and complex. In addition, NPP's concrete structures are often inaccessible, containing large volumes and massively thick concrete structures exposed to different environments (moisture, temperature) and a diversity of degradation mechanisms (high temperatures, radiation exposure, chemical reactions and other physical mechanisms) at different plant sites, all of which add to the complexity of determining the integrity/quality of the concrete [2][3].

Specially designed and fabricated test specimens can provide realistic flaws that are similar to actual flaws in terms of how they interact with a particular NDE technique. Artificial test blocks allow the isolation of certain testing problems as well as the variation of certain parameters. Because of the controlled conditions in the laboratory, the number of unknown variables can be decreased, which makes it possible to focus on specific aspects, investigate them in detail, and gain further information on the capabilities and limitations of the methods. To minimize artifacts caused by boundary effects, the dimensions of the specimens should not be too compact. Representative large heavily reinforced PCC specimens would allow for comparative testing to evaluate the state-of-the-art in NDE in this area and to identify additional developments necessary to address the challenges potentially found in NPPs. These types of specimens would also be useful for calibration and validation of new technology and processing techniques. 



\section{NEED FOR SUITABLE CONCRETE SPECIMENS}

Comparative testing of the various NDE concrete measurement techniques will require concrete specimens with known material properties, voids, internal microstructure flaws, and reinforcement locations. Ideally, commercial NPPs undergoing the decommissioning process would be used for NDE comparison, since there are certain characteristics of NPP structures that are difficult to replicate [4]. They are also exposed to known degradation mechanisms including different levels of radiation, temperature, and chemical reactions that provide the most realistic concrete aging specimens. Concrete fabricated some 40 to 50 years ago is difficult to reproduce using fabricated test blocks, since old cements were generally coarser than present-day cement. Fine cements set and hydrate quickly, generating a high heat release at an early age that can cause thermal cracking and potentially delayed ettringite formation if not cured correctly and the original admixture (plasticizer, etc.) may no longer be available [5]-[7]. Exclusive use of commercial NPPs to evaluate the effectiveness of NDE techniques is not feasible for a variety of reasons. Commercial NPPs do not always provide access to be able to collect data using all potential NDE techniques. Destructive forensic activities necessary to validate discrepancies and limitations in the NDE results are also not typically feasible. Alternative methods such as transporting NPP samples to a laboratory environment could theoretically provide the necessary access and forensic capabilities. However, the lateral dimensions required to mitigate boundary effects for NDE specimens of over $3 \mathrm{ft}$. thick, often makes transportation of specimens impractical.

Other than NPPs, there are not many applications where critical concrete structures are as thick and heavily reinforced, entities that are interested in performing NDE on thick and reinforced concrete structures. Research reactors such as the High Flux Isotope Reactor (HFIR) located at Oak Ridge National Laboratory (ORNL) possess thick, heavily reinforced concrete structures. However, these structures are not as extensive as those of commercial NPPs. This creates a need to construct specimens for performing NDE assessments, research, and training.

The environment where specimens are constructed should represent the access conditions of an inservice containment structure for evaluation of techniques requiring only one-sided testing. Since it is not feasible to build specimens that are to the scale of in-service structures, compact sample specimens must be built while still replicating the NDE needs of real structures. This includes minimizing artifacts caused by boundary effects. Although significant NDE research has been conducted on thin Portland Cement Concrete (PCC) structures to assess pavement, bridge deck, and other infrastructure applications, construction of large reinforced concrete specimens specifically for NDE comparisons is less common [2][3]. Comparative studies have shown various NDE techniques to be successful in identifying the types of internal characteristics of interest, requiring only one sided access [8]-[17]. However, these applications are typically conducted to evaluate thin sections ( $1 \mathrm{ft}$. in thickness), while NPP containment walls are often much thicker (over $3 \mathrm{ft}$. in thickness). Even though previous results for thinner structures show promise in the ability to nondestructively evaluate internal characteristics, the results need to be validated for thicker and more heavily reinforced structures. There are two major NDE challenges associated with the fabrication and evaluation of thicker structures:

- Low signal-to-noise ratio with greater depths due to heterogeneous material such as PCC with a dense and complex arrangement of reinforcements.

- Effects from vertical boundaries at similar distances to the region of interest (ROI).

A brief background on elastic wave propagation which is a common technique used to nondestructively interrogate concrete structures allows for a discussion of these challenges. When exposed to a short duration external impact, concrete reacts approximately like an elastic solid medium where the distortion and subsequent movements in the concrete can then be described using three general modes of wave propagation categorized by the coverage and direction of particle motion with respect to propagation direction: P-waves, S-waves, and R-waves. The compression (also known as longitudinal or primary) waves (P-waves) have particle motion parallel with the direction of wave propagation. The 
transverse (also known as shear) waves (S-waves) have particle motion perpendicular to the wave propagation direction. The Rayleigh waves (R-waves) have retrograde elliptical particle motion. The Rwaves propagate along the surface, whereas the P- and S-waves propagate throughout the body of the solid in a hyperbolic nature [18]. The reflection of P- and S-waves depends on changes in acoustic impedance from internal characteristics of concrete structures. P- and S- waves are useful in evaluating internal characteristics of concrete structures with only one-sided access because changes in subsurface properties such as flaws, inclusions, or layer boundaries cause reflections back to the surface.

If concrete is approximated as an isotropic and elastic medium, the relationship between elastic parameters (Modulus, Poisson's ratio), density, and wave velocity in concrete has the form shown in equation 1 through 3 [14]:

$$
\begin{aligned}
& C_{P}=\sqrt{\frac{E(1-\mu)}{(1-\mu)(1-2 \mu) \rho}} \\
& C_{S}=\sqrt{\frac{E}{2(1+\mu) \rho}} \\
& C_{R}=C_{S} \frac{0.87+1.12 \mu}{1+\mu}
\end{aligned}
$$

Equation 1

Equation 2

Equation 3

Where $E$ is Young's modulus of elasticity, $\mu$ is Poisson's ratio, $\rho$ is density, $C_{P}$ is the compression or pressure wave (P-wave) velocity, $C_{S}$ is the transverse or shear wave ( $\mathrm{S}$-wave) velocity, and $C_{R}$ is the Rayleigh wave (R-wave) velocity. Assuming the S-wave response is being evaluated and a typical value for Poisson's ratio in concrete, $\mu=0.2$, the velocity of the other wave types has the following relationship with respect to shear waves:

$$
C_{S}=0.61 C_{P}=1.09 C_{R}
$$

Equation 4

Table 1 gives additional information including the particle motion, relative wave speeds, and energy content of the various wave types [18].

Table 1. Wave type information

\begin{tabular}{|c|c|c|c|c|}
\hline Wave Type & Particle Motion & $\begin{array}{c}\text { Propagation } \\
\text { Medium }\end{array}$ & $\begin{array}{c}\text { Relative Wave } \\
\text { Speed, } \boldsymbol{\mu}=\mathbf{0 . 2}\end{array}$ & $\begin{array}{c}\text { Energy Content } \\
\mathbf{\%}\end{array}$ \\
\hline P-wave & $\begin{array}{c}\text { Parallel to } \\
\text { propagation } \\
\text { direction }\end{array}$ & $\begin{array}{c}\text { Solid, liquid, or } \\
\text { gas body wave }\end{array}$ & 0.61 & 7 \\
\hline S-wave & $\begin{array}{c}\text { Perpendicular to } \\
\text { propagation } \\
\text { direction }\end{array}$ & Solid body wave & 1 & 26 \\
\hline R-wave & \begin{tabular}{c} 
Retrograde elliptical \\
\hline
\end{tabular} & Surface wave & 1.09 & 67 \\
\hline
\end{tabular}


A few observations can be made from these relationships with regard to use of elastic waves for evaluation of thick reinforced concrete structures. Since acoustic impedance is positively correlated to the stiffness of the material, elastic waves are extremely proficient at characterizing interfaces such as cracks, voids, or delamination where the change in acoustic impedance from concrete to air is extremely high. However, since PCC is comprised of air voids and aggregates, elastic waves can also experience significant attenuation that limits the penetration depth. For example, since the P-wave has the lowest amount of energy from a point source impact, it may not achieve the necessary penetration depth required to characterize the thick concrete specimen due to the low energy content. However, the ability to propagate in all medium types may provide air coupled possibilities [13]. S-waves have significantly higher energy content allowing for greater penetration depth in heterogeneous mediums such as concrete. However, they require a solid material for propagation creating a need for ground coupling. Moreover, because they have a similar in velocity to R-waves, boundary effect interference may be a problem.

The Elastodynamic Finite Integration Technique (EFIT), developed at the University of Kassel, is an effective tool in investigating both the penetration depth and boundary effect challenges for evaluation of thick reinforced concrete structures [19]. This tool has been used to compare elastic wave propagation in a $2 \mathrm{D}$ concrete model assuming $0 \%$ and $1 \%$ air porosity from a $200 \mathrm{kHz}$ center frequency point source. It was reported that the reflections from simulated inclusions and back wall reflections were less clear with porosity and the signal-to-noise ratio decreased with depth. While evaluation based on lower frequency content may resolve this difficulty, the general trend of increased attenuation and a decreased signal-tonoise ratio with depth holds true. Therefore, the same internal defects that can be identified in thin concrete structures may require improved filtering or processing techniques to identify the same defect at a greater depth due to the decreased signal-to-noise ratio. This is especially true for heavily reinforced concrete structures where scattering and reflection of the wavefront occurs at the boundaries between concrete and steel [20]. Decreasing signal-to-noise ratio with depth is a significant challenge that needs to be addressed for effective nondestructive characterization of aging concrete material in NPP containment structures.

Unlike the loss of signal-to-noise ratio with greater penetration depth problem, which needs to be addressed solely by the NDE technique, the boundary effect problem is less of an issue for in-service inspection of commercial NPP containment structures where lateral boundaries are less prevalent. However, boundary effects are more critical for thicker concrete structures with regards to specimen design. For many NDE techniques, the first reflected wave received is assumed to be from internal changes in acoustic impedance, or the rear surface, assuming the structure is infinitely expanded in lateral direction. This assumption is generally valid for evaluation of continuous structures such as NPP containment walls and for internal interrogation of specimens of thin structures such as bridge decks or pavements. However, thicker concrete structure specimens require higher restrictions for allowable vertical boundaries to use this assumption and properly represent NPP containment structures. If a vertical boundary is located sufficiently close to the sensor position in relation to the depth of interrogation interest, reflections of surface and body waves are present within the same time window [21]. In these cases, the boundary effects must either be eliminated through specimen design, or be taken into account in time-domain signal and spectrum analysis to mitigate systematic errors.

Since the ability of each NDE technique to account for boundary effects is not critical for in-service inspection, it is preferable to design the specimen to mitigate boundary effects, which are also representative of the lack of vertical boundaries for NPP containment structures. The exact lateral dimensions required of the specimen for this assumption to be valid are directly related to the region of interest (ROI) depth - often the thickness of the specimen - and the NDE technique used. For example, a NDE technique based on point source elastic wave propagation used to evaluate a $3 \mathrm{ft}$ long, $3 \mathrm{ft}$ tall, $4 \mathrm{ft}$. thick specimen of a containment wall may have difficulty detecting a defect at $3 \mathrm{ft}$. depth due to boundary effects. However, the same technique may be able to detect the same defect when testing an in-service containment wall where the boundary effects do not affect the measurements. 
Since specimens should be designed to test the ability of the technique to mitigate boundary effects, the most extreme case, evaluation of S-waves from a point source, should be taken into account for specimen design considerations. This is considered the most extreme case since a point source creates elastic waves with a full 180 degree divergence, and the S-wave velocity is very similar to the surface Rwave velocity, which also contains the highest energy content, as noted in Table 1 . In this case, the distance from the source location to the rear surface must be the minimum dimension. This type of challenge was investigated using 3D EFIT simulation of a point-source elastic wave field in a $2 \times 1.5 \times 0.5$ $\mathrm{m}^{3}$ steel-reinforced concrete model with polystyrene inclusions [18]. Considering the energy content of R-waves shown in Table 1, it follows that the study reported the circular R-wave reflected by the lateral boundaries in the simulation to lead to geometrical effects in time-domain signal and spectrum analysis. These boundary effects can cause systematic errors in internal flaw detection or thickness determination. This need to mitigate boundary effects creates transportation challenges for the use of concrete specimens removed from operating reactors to accommodate an increased lateral to depth dimension ratio that allows for representative testing.

Fortunately, concrete specimens can be fabricated under laboratory conditions to control various properties as substitutes for specimens obtained from nuclear structures. Fabricated test blocks allow the isolation, as well as the variation of certain test parameters. Under controlled laboratory conditions, the number of variables can be decreased making it possible to investigate specific defects in detail as well as gain further information on the capabilities and limitations of the techniques. The laboratory environment also allows for forensic investigation of the specimen in locations where there is suspected discrepancies in as-built characteristics compared to as-designed features. A conceptual design of various reinforced PCC specimens for construction is proposed to address the limitations discussed in this section. 


\section{EXISTING NDE TECHNIQUES}

The type of NDE techniques used for testing should be accommodated in the conceptual specimen design. In-service inspection programs for NPP structures have the primary goal of ensuring that the structures have sufficient margins to continue to perform in a reliable and safe manner. A secondary goal is to identify environmental stressors or aging factor effects before they reach sufficient intensity to potentially degrade structural components. One of the conditions of all operating licenses for watercooled power reactors in the U. S. is that the primary reactor containment shall meet the containment leakage test requirements set forth in Appendix J, "Primary Reactor Containment Leakage Testing for Water-Cooled Power Reactors,” to Title 10, “Energy,” Part 50 of the Code of Federal Regulations (10 CFR 50).

NDE techniques are not typically employed as part of the in-service inspection and testing of containments. NDE of containment structures is generally conducted to determine if degradation has occurred or to quantify degradation that is known to be present. Table 2 summarizes the traditional NDE techniques for measuring concrete degradation [2]. 
Table 2. Summary of current NDE concrete measurement techniques

\begin{tabular}{|c|c|c|}
\hline NDE Technique & Advantages & Disadvantages \\
\hline Visual Inspection & Simple, fast & Relies on experience \\
\hline Ground-Penetrating Radar & $\begin{array}{l}\text { Rapid; non-contact; can obtain } \\
\text { depth and thickness measurements; } \\
\text { good at locating embedded metals } \\
\text { and fluids }\end{array}$ & $\begin{array}{l}\text { Limited depth of penetration } \\
(0.6 \mathrm{~m}) \text {; subjective to data } \\
\text { interpretation; cannot see behind } \\
\text { metal }\end{array}$ \\
\hline Ultrasonic - general & $\begin{array}{l}\text { Thickness measurement; } \\
\text { embedded metal location; imaging } \\
\text { capability }\end{array}$ & $\begin{array}{l}\text { See below different ultrasonic } \\
\text { techniques }\end{array}$ \\
\hline Ultrasonic Pulse Velocity & $\begin{array}{l}\text { Can be one-sided measurement } \\
\text { (indirect transmission); void/defect } \\
\text { location; simple }\end{array}$ & $\begin{array}{l}\text { Requires transmitter and } \\
\text { receiver }\end{array}$ \\
\hline Ultrasonic Pulse Echo & $\begin{array}{l}\text { Single transducer; can be } \\
\text { multi-sensor array }\end{array}$ & $\begin{array}{l}\text { Speed of sound in concrete } \\
\text { being tested must be measured }\end{array}$ \\
\hline $\begin{array}{l}\text { Ultrasonic Coda Wave } \\
\text { Interferometry }\end{array}$ & $\begin{array}{l}\text { Quite useful for detecting } \\
\text { changes and monitoring damage }\end{array}$ & $\begin{array}{l}\text { Does not appear to locate } \\
\text { defects; requires high signal-to- } \\
\text { noise ratio in the field }\end{array}$ \\
\hline Impact Echo & $\begin{array}{l}\text { Simple; can locate large voids } \\
\text { and delaminations in plate }\end{array}$ & $\begin{array}{l}\text { Results can be difficult to } \\
\text { interpret }\end{array}$ \\
\hline Acoustic Emission & $\begin{array}{l}\text { Can provide real-time feedback } \\
\text { on crack propagation }\end{array}$ & $\begin{array}{l}\text { Can only detect change in } \\
\text { state; high variability in signal } \\
\text { strength; background noise can } \\
\text { have sufficient effect on the } \\
\text { measurement }\end{array}$ \\
\hline Infrared Thermography & $\begin{array}{l}\text { Area testing technique; good } \\
\text { for finding near-surface voids }\end{array}$ & $\begin{array}{l}\text { Requires a thermal gradient } \\
\text { through the concrete }\end{array}$ \\
\hline Radiographic & $\begin{array}{l}\text { Deep penetration; visualization } \\
\text { of density changes }\end{array}$ & $\begin{array}{l}\text { Requires access to both sides } \\
\text { of the concrete being tested; costly; } \\
\text { safety concerns }\end{array}$ \\
\hline Half-Cell Potential & $\begin{array}{l}\text { quick; simple; qualitative } \\
\text { information on steel rebar risk of } \\
\text { corrosion }\end{array}$ & $\begin{array}{l}\quad \text { Relative readings; subjective to } \\
\text { data interpretation; rebar being } \\
\text { tested must be exposed; steel } \\
\text { coatings can be problematic; } \\
\text { complicated if saturated with water }\end{array}$ \\
\hline Polarization Resistance & $\begin{array}{l}\text { Measures instantaneous metal } \\
\text { corrosion rate }\end{array}$ & $\begin{array}{l}\text { Polarized area of metal surface } \\
\text { being tested must be known; } \\
\text { requires direct connection to metal }\end{array}$ \\
\hline Electrical Resistivity & $\begin{array}{l}\quad \text { Indirect measurement of } \\
\text { concrete’s porosity and the } \\
\text { connectivity of pores; can be used } \\
\text { to detect wet areas in concrete; } \\
\text { measures resistivity }\end{array}$ & $\begin{array}{l}\text { One point method requires } \\
\text { direct connection to rebar }\end{array}$ \\
\hline
\end{tabular}


Ultrasonic testing techniques have a wide range of applications including thickness measurement, locating steel reinforcement and tendon ducts, and characterization of surface cracks. It also shows promise for investigating grouting conditions inside grouted tendon ducts. Unlike electromagnetic waves, acoustic waves are capable of penetrating metal components such as liners [22]. Ultrasonic techniques can also use the Synthetic Aperture Focusing Technique (SAFT) to produce an image when multiple impulse time histories are combined.

Coda wave interferometry (CWI) is a technique that allows one to observe differences in the coda portion of the recorded waveform of a diffuse field. When an ultrasonic wave is emitted into a concrete specimen, the heterogeneous nature of the concrete causes the wave to become highly scattered and a diffuse field is created. A diffuse field consists of two parts, the first arrival and the diffuse portions, which includes the late coda contribution. Diffuse waves undergo multiple scattering, which causes them to arrive much later than the first arrival. However, diffuse waves are much more sensitive to small changes in the concrete medium and carry more information than the first arrival. CWI compares two different time series of coda waves, the stressed state and unstressed state, and determines the degree of correlation. Comparing the difference between the two states allows one to monitor damage progression in the concrete specimen [23]. There are two types of CWI: the doublet technique and the stretching technique. The stretching technique is the more advanced of the two and is more commonly used. In this technique, the time axis is stretched or compressed until it has much in common with a reference time signal. Since time and velocity are proportional, the relative velocity can be calculated from the scaling factor. CWI appears to be quite useful for detecting changes and monitoring the progression of damage in concrete. However, it does not seem to be able to locate defects. It also requires a high signal-to-noise ratio to be effective in the field [23].

Ultrasonic pulse echo uses the same impulse echo principle as radar. Ultrasonic waves are reflected at interfaces where acoustic impedance differs, and the propagation time to the interface and back can be measured to learn about the interior of the structure. This technique is a bit more flexible than ultrasonic pulse velocity because it only requires one transducer that both transmits and receives. This means it also only requires access to one side of the structure, which is invaluable in an environment such as a NPP. The one drawback to this technique is that the speed of sound in the concrete to be tested must be known before testing can begin. This often, but not always, requires drilling cores for testing [24]. Ultrasonic pulse echo can benefit from the use of multi-sensor arrays. These arrays typically use 10-40 sensors that can both transmit and receive. Only one transducer acts as the transmitter at a time, while the rest act as receivers. Once the first has transmitted, the next sensor becomes the transmitter. This cycle continues until each transducer has acted as a transmitter. Multi-sensor arrays are quite promising in that they offer an increased sensing area as well as increased depth of penetration, reportedly up to $2 \mathrm{~m}$ [25].

To perform accurate cross-sectional and 3D reconstruction of PCC in more complex environments, Kirchoff-based migration - most notably SAFT - has been used for locating material degradation and defects under these conditions [26]-[30]. Although the traditional SAFT technique is simple and heuristically formulated, when combined with the use of dry-point contact (DPC) low-frequency $(\sim 50 \mathrm{kHz}) \mathrm{S}$-wave ultrasonic transducers, this technology has been successfully used for evaluation of various concrete infrastructure [31][32]. Further generalization using phase information has improved evaluation of reinforcements in bridge decks using ultrasonic pulse-echo data applied along a single axis of symmetry [33].

Extension of the pulse-echo hardware for multiple channel linear array technology provides added redundancy in evaluating PCC aging and defects. This technology, applied with traditional SAFT, qualitatively detects PCC defects at the level of reinforcement [34]. Extending the SAFT reconstruction for overlapping virtual arrays allows for detection of PCC degradation below reinforcements [35]. The signature analysis technique from Schubert and Kohler [18] has been generalized for quantitative PCC flaw and degradation detection using the reconstruction results of ultrasonic linear array signals [36]. 
A recent study conducted by ORNL and various NDE research teams provides a baseline performance indication of various NDE techniques in evaluating reinforced PCC structures [8]. The study showed the various techniques generally perform well. However, the results of the study also identified that advanced signal processing techniques should be developed to improve the performance of NDE on thick aging concrete structures such as LWRs. The results of this study are summarized here to provide the design needs for the conceptual design of the larger, more heavily reinforced structure presented in this report. For the limited size of the test specimens utilized and the types of internal structure and anomalies existing within each specimen, the state-of-the-art techniques - Ground Penetrating Radar (GPR), aircoupled and semi-coupled ultrasonic, as well as two versions of ultrasonic linear array - perform reasonably well. Figure 1[A] shows an example result of how volumetric imaging tools are used to evaluate simulated concrete degradation. Figure 1[B] shows construction of simulated increasing concrete degradation by disturbing the concrete during the hardening process on one end of the reinforcement. Figure $1[\mathrm{C}]$ shows a zoomed in view of the volumetric imaging in the leftmost reinforcement showing a clear indication of the increasingly degraded concrete through the widening blue image within the reconstruction at the depth of the reinforcement and width of the degradation.

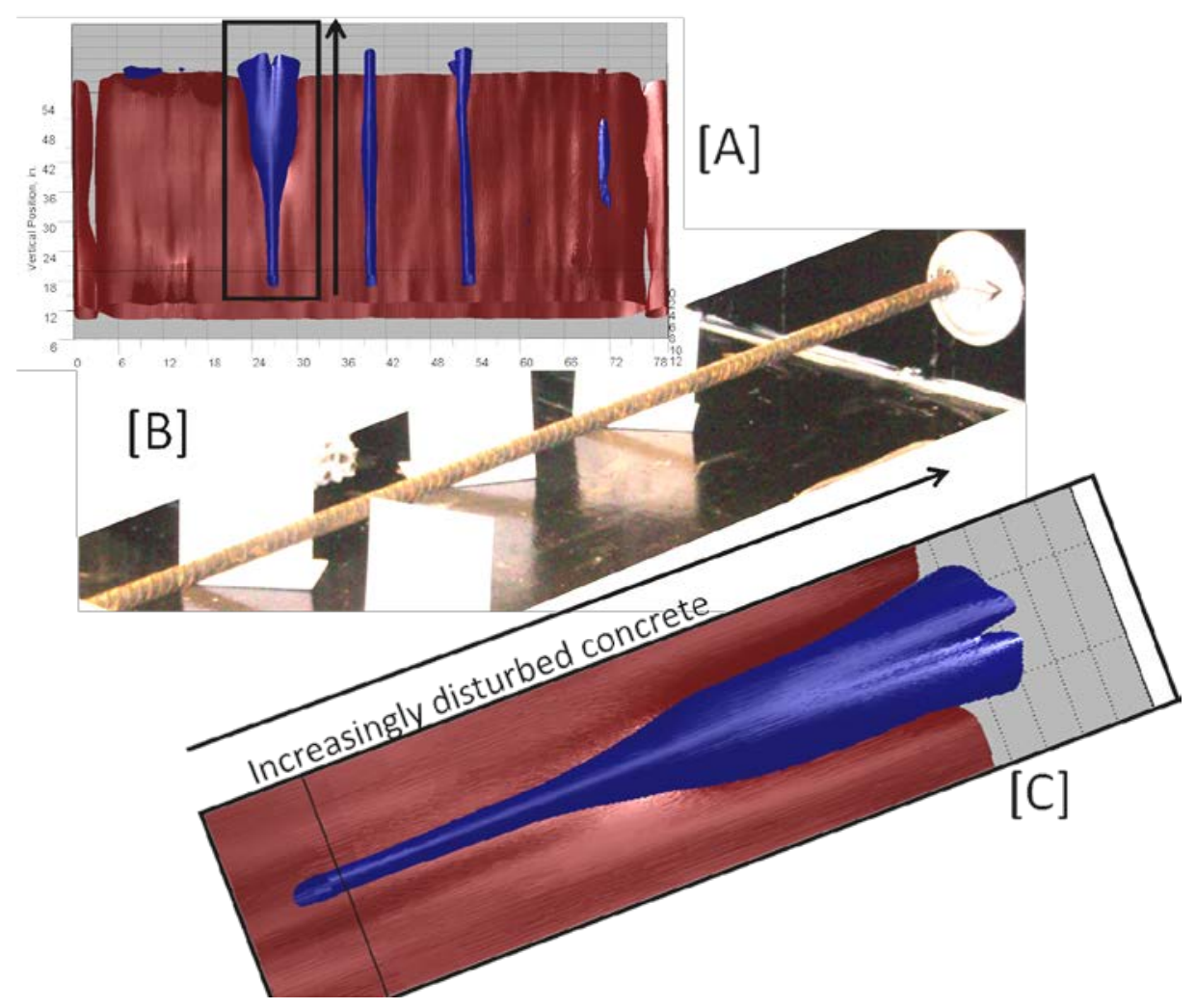

Fig. 1 [A] Volumetric imaging of a reinforced concrete specimen with [B] simulated degradation during construction and a $[\mathrm{C}]$ clear indication of the increasingly degraded concrete 
However, each technique has some limitations and it remains to be seen how each of these techniques will perform on thick, heavily reinforced concrete structures such as those in commercial NPPs. Once a representative test specimen, such as the conceptual design presented in this report, is fabricated with internal structure and anomalies, such as those in the specimens from [8], this comparative testing can be performed on that specimen. The baseline of performance established in [8] for the different ultrasonic techniques can then be applied and compared to performance on the thick heavily reinforced specimen. Development of advanced signal processing algorithms may be important to the performance of these techniques when applied to thick, heavily reinforced concrete structures like those in commercial NPPs. The specimen designed in this report should be critical in directing these developments, especially towards addressing the decreasing signal-to-noise ratio with depth. 



\section{TYPICAL PARAMETERS FOR CONCRETE USED IN NPPS}

\subsection{TYPICAL CONTAINMENT WALL DESIGN}

The concrete structures in NPPs are thick in cross section and heavily reinforced with steel. Fig. 2 illustrates one type of NPP concrete and steel reinforced containment structure with the following specifications [4]:

- Wall Thickness: $3-4$ feet

- Dome Thickness: 3 feet

- Floor Thickness: If there are rock anchors (2 feet), if not 10 feet

- Inside Diameter: 150 feet

- Liner Thickness: $1 / 4$ to $3 / 8$ inch

- Height: 150 to 200 feet

- Volume: $2.5 \times 10^{6}$ cubic feet

- Liner Material: Carbon Steel

- Containment shape: vertical right cylinder with hemispherical or shallow dome

- Concrete Cover over Bottom Liner: 2 to 3 feet

- $\quad$ Reinforcing Material: Mild Steel

— \# 18 rebars (2.257 inch diameter, $4.00 \mathrm{in}^{2}$ cross sectional area)

— \# 8 rebars (1.000 inch diameter, 0.79 in $^{2}$ cross sectional area)

In this typical containment structure, the upper reinforced concrete containment is typically three and a half feet thick with two layers of \#18 steel reinforcing bars on 12 inch centers vertically and horizontally on each face at a distance of 6 inches from each face of a containment structure ranging from 150 to 200 feet tall with a diameter of approximately 150 feet. The lower cylindrical walls of the containment are even larger in order to carry the entire dead load, including the upper containment, to the base slab. The walls are at least four feet thick with \#18 vertical bars at 12 inches spacing for each face and \#18 horizontal bars on both sides of the vertical reinforcing; the ties are made of \#8 bars. 

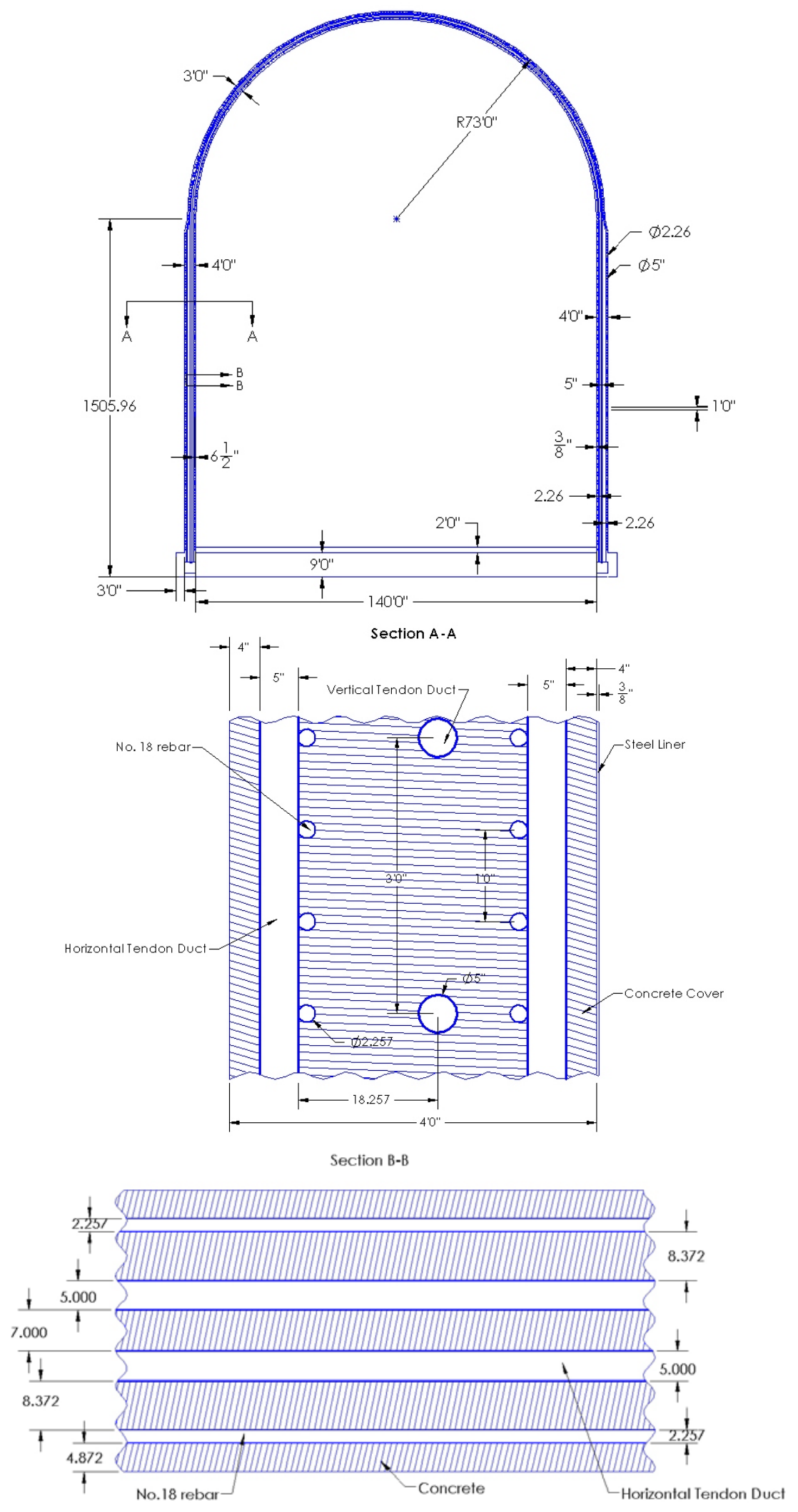

Fig. 2. Example NPP containment structure [3] 


\subsection{PREVIOUS CONCRETE FAILURES IN NPP CONTAINMENT STRUCTURES}

Ideally, from a NDE point of view, the NPP specimen should have realistic and known distress. There are a few representative sections that have experienced known distress. Concrete defects observed in power plant containment structures are tabulated by Braverman et al. [37]. It is observed that degradation in the form of cracking, spalling, and general deterioration were commonly observed defects, and the technique of identification was typically visual inspection. Delamination in the form of stresscorrosion cracks at the level of reinforcements is also generally a concern for the nuclear containment structures [38]-[41].

Fig. 3 shows in-situ the cross-section of the Crystal River Nuclear Plant (CR3) containment structure with tendon ducts and reinforcements where a delamination gap was observed in the vertical plane of the horizontal tendons, approximately ten inches from the outer surface, of the CR3 containment wall [38]. One form of subsurface defect (delamination at the level of tendon ducts) that is possible for this type of containment structure can be observed from Fig. 3.

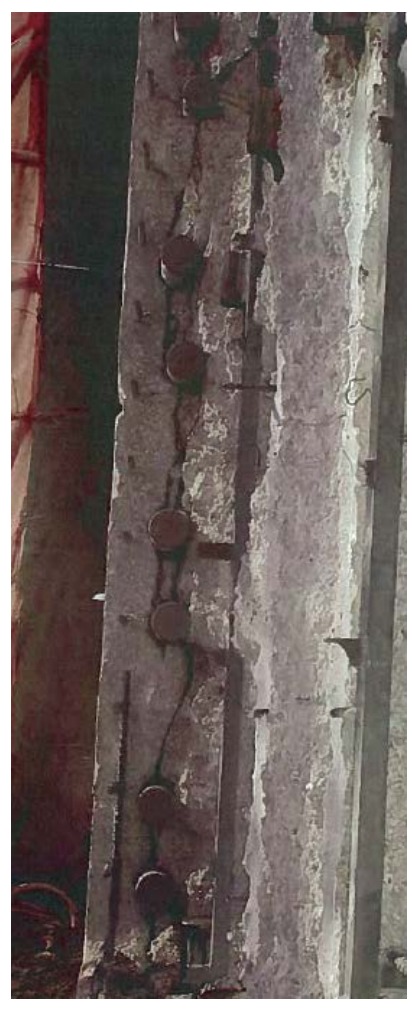

[A]

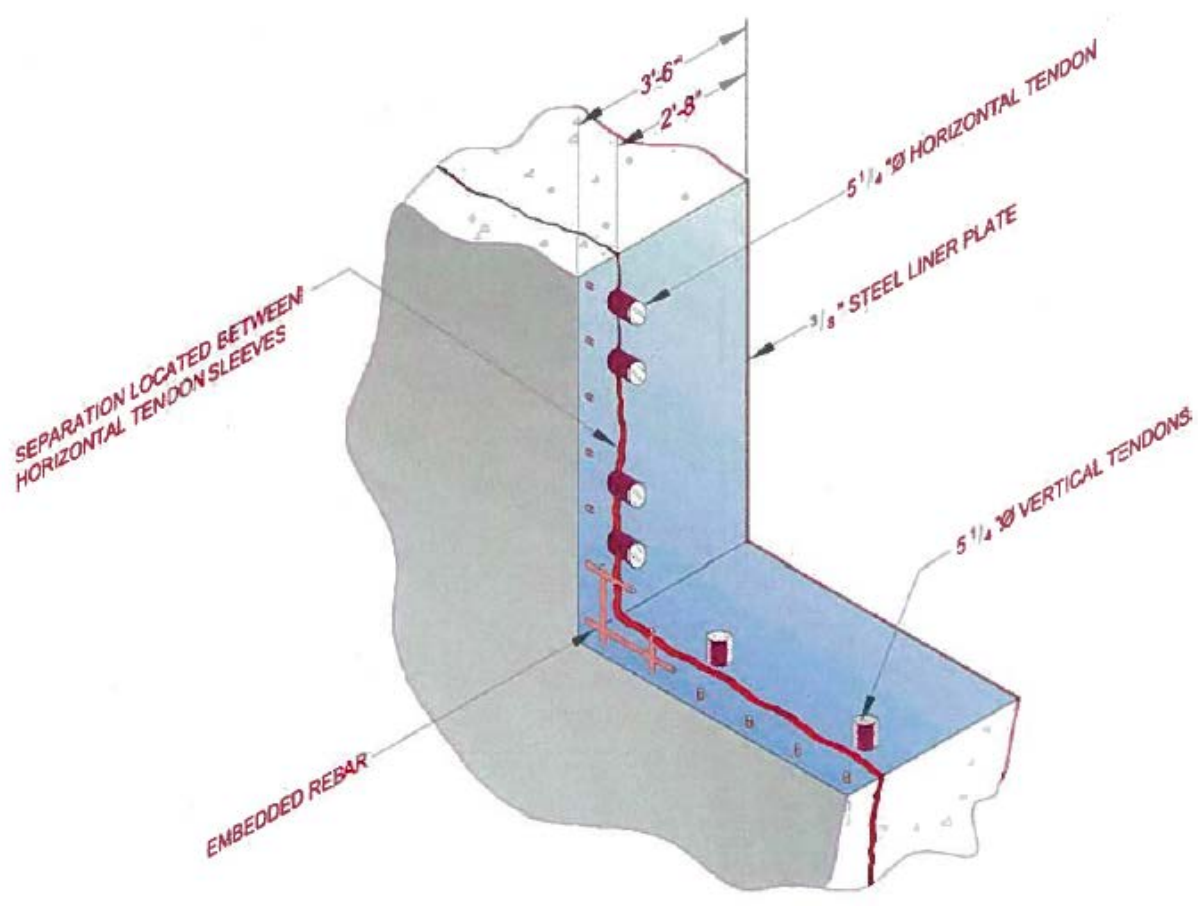

$[B]$

Fig. 3. Delamination crack running from horizontal tendons at approximately $10 \mathrm{in}$. deep [A] photograph and [B] sketch [38]

Fig. 4 shows the Davis-Besse NPP [42]. Fig. 5 shows the general layout of the structure with reinforcements. Fig. 6 shows example laminar subsurface cracking at the depth of the reinforcement. This interface was visible due to hydro demolition to create an opening in the shield building, and the crack width is possibly larger than the delaminated condition prior to the cutting. Core bore specimens, such as that shown in Fig. 7, shows the crack condition unaffected by the hydro demolition process. 


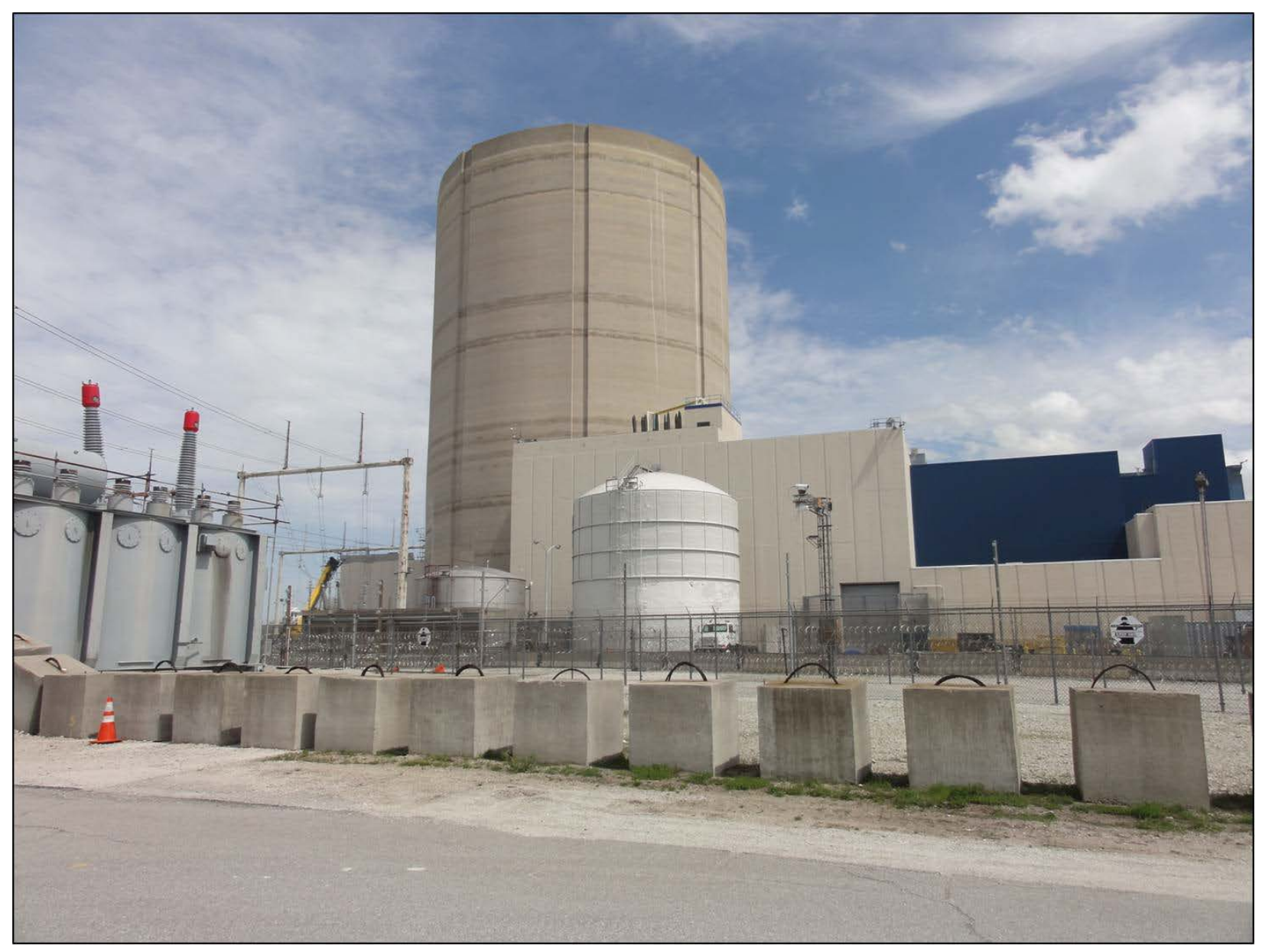

Fig. 4. Picture showing the Davis-Besse NPP [42]

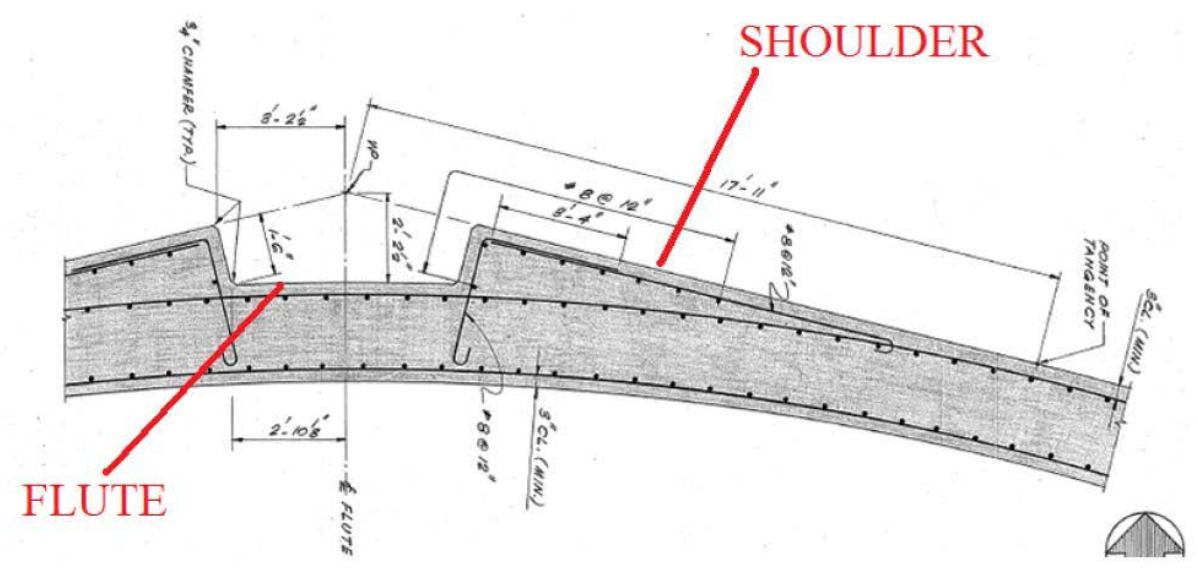

Fig. 5. View of the Davis-Besse NPP layout and reinforcement scheme [42] 


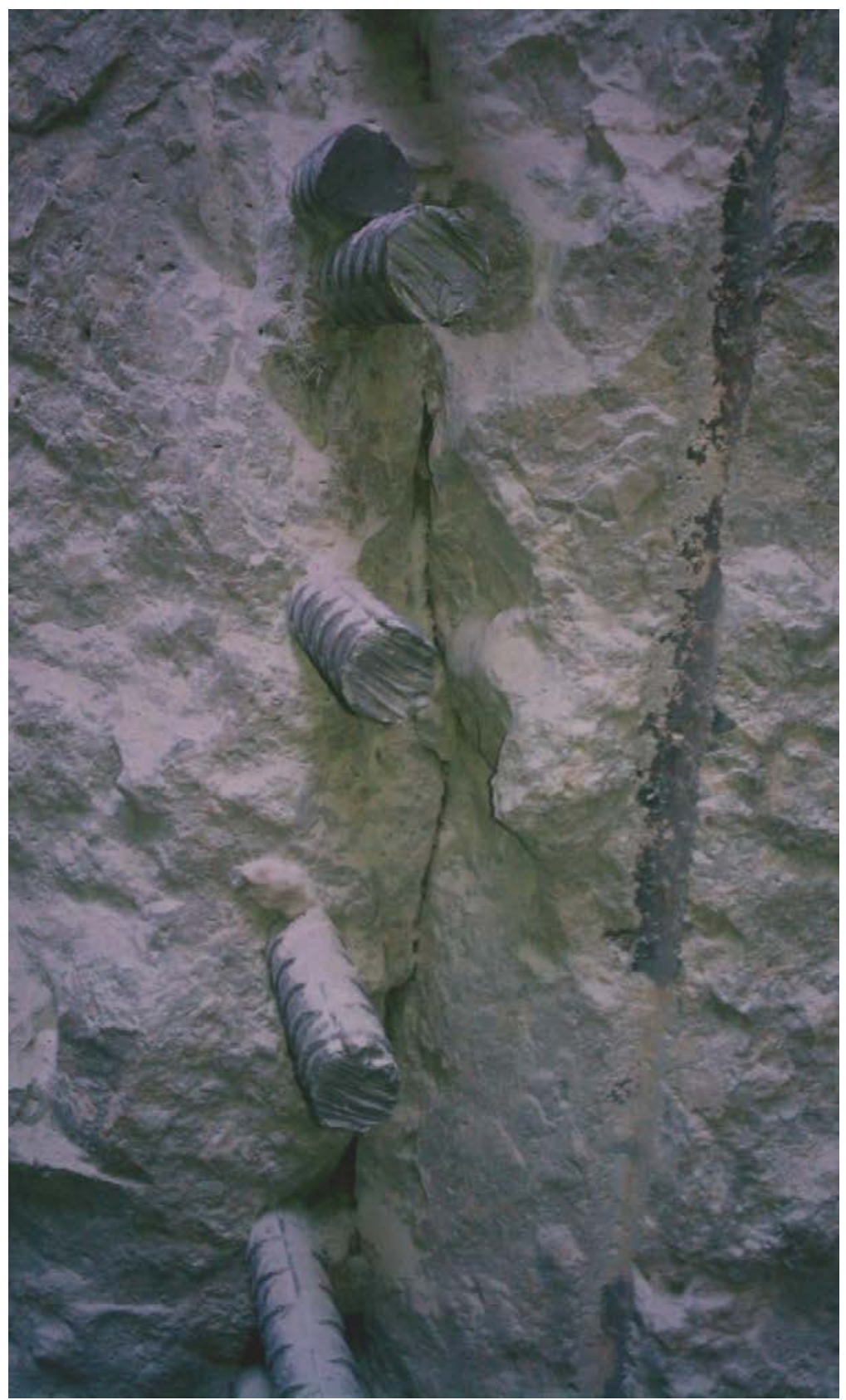

Fig. 6. Laminar cracking at reinforcements from an interface cut out by hydrodemolition [42] 


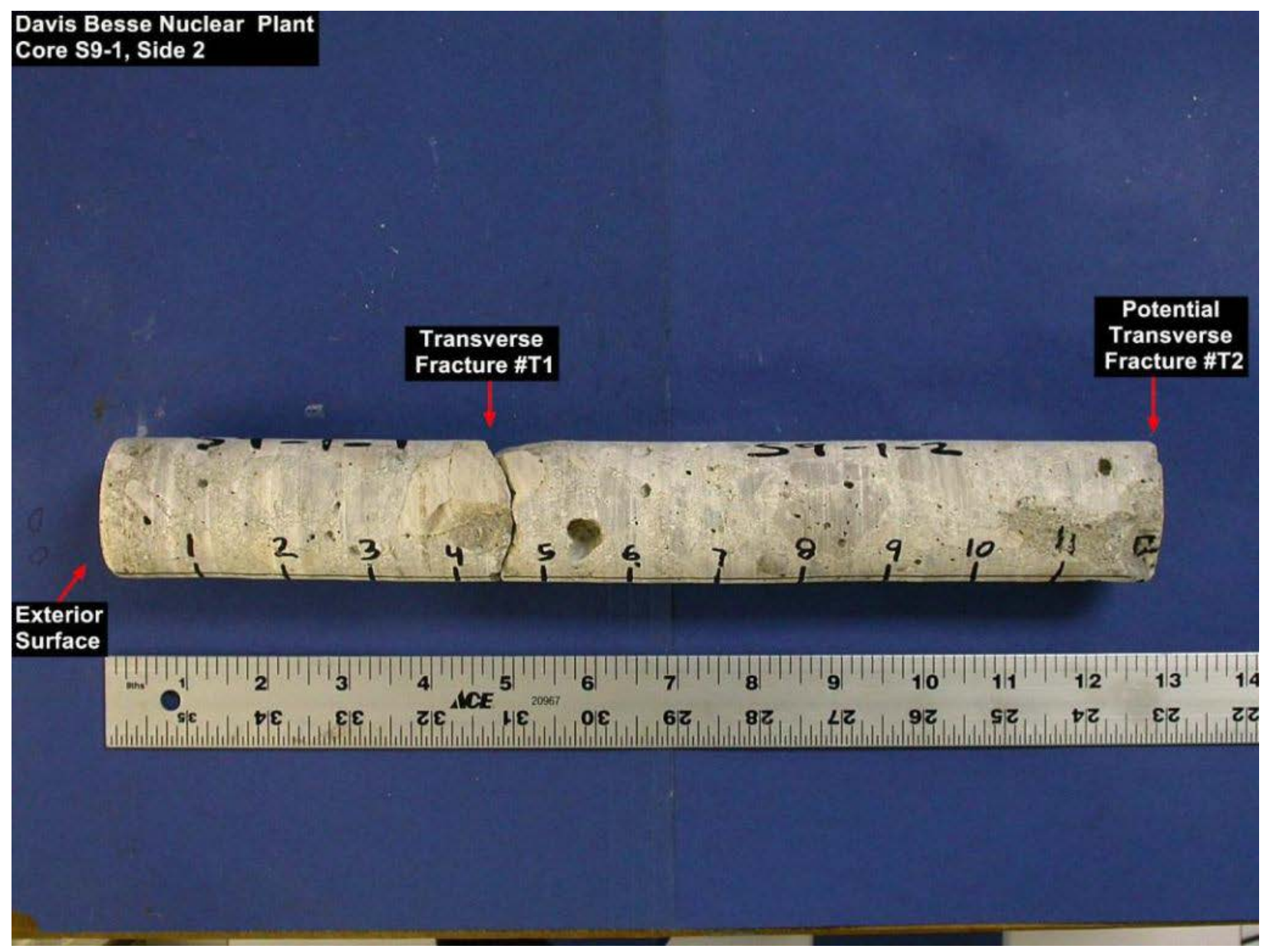

Fig. 7. Laminar Cracking at a core location [42]

However, as detailed in ORNL/TM-2013/223 [3] and discussed in the "Need for Suitable Concrete Specimens" section, there are problems associated with use of in-service specimens for validation of NDE methods. The acquisition of such specimens can be prohibitive due to the costs of transporting such a large concrete structure, lack of on-site access for research teams to collect data for comparative testing, lack of an ability to verify internal characteristics, and, in some cases, problems with transfer of ownership for a potentially radioactive specimen [2][3]. This leads to the lack of readily available specimens of thick and heavily reinforced concrete for performing NDE evaluations, research and training. 


\section{SPECIMENS WITH DEFECTS APPLICABLE FOR COMPARATIVE NDE}

To determine what concrete specimens are suitable and available in the United States for NDE of NPP concrete, ORNL utilized its contacts established through the LWRS Concrete NDE Workshop conducted in August 2013 [2].

\subsection{CONTAINMENT STRUCTURE CONCRETE SPECIMENS}

Wesdyne Corporation is working with Westinghouse in certifying the AP1000 containment, which is a non-traditional, sectional, steel and concrete containment structure shown in Fig. 8 [2].

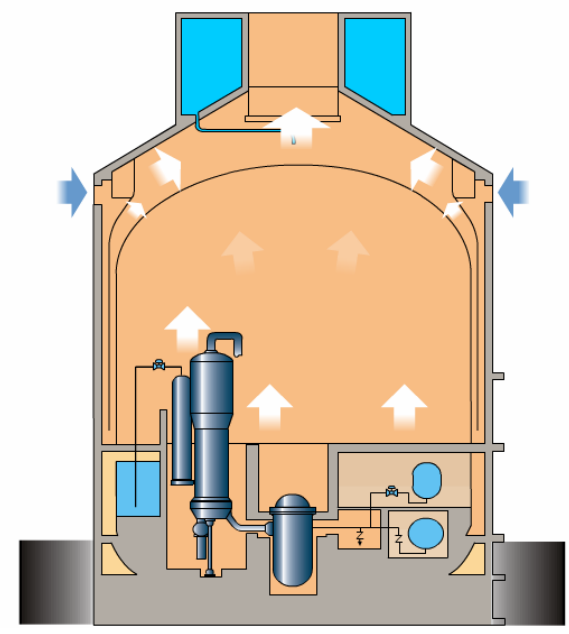

Fig. 8. Westinghouse AP1000 Shield Building Drawing [2]

The Westinghouse Shield Building was constructed of 30 -foot by 30 -foot sections of pre-assembled steel forms. These steel forms have 1-inch thick steel inner and outer walls which are separated by 3 feet of space which will be filled with concrete. The inner and outer steel walls are connected by steel struts and there are partial length concrete anchors attached to both the inner and outer steel walls. These preassembled steel forms are welded together forming the shield building. Concrete is then continuously poured into the three foot space to provide rigidity, shielding, and impact (airplane) protection.

Initially, WesDyne fabricated a 3 foot wide by 3 foot deep by 10 foot long concrete specimen to use for NDE evaluations. This specimen is shown in Fig. 9 and Fig. 10. The 1-inch thick inner and outer steel walls along with the steel cross struts and partial length concrete anchors can be seen in Fig. 9. Fig. 10 illustrates the specimen after all the concrete was poured. WesDyne evaluated the ultrasonic and impulse-echo NDE techniques using this specimen and found the physical dimensions limit the testing being performed. Presumably, the limitations involved difficulties accounting for the boundary effects described in the previous sections. Therefore, the decision to fabricate a full 30 foot by 30 foot Shield Building section was made. 


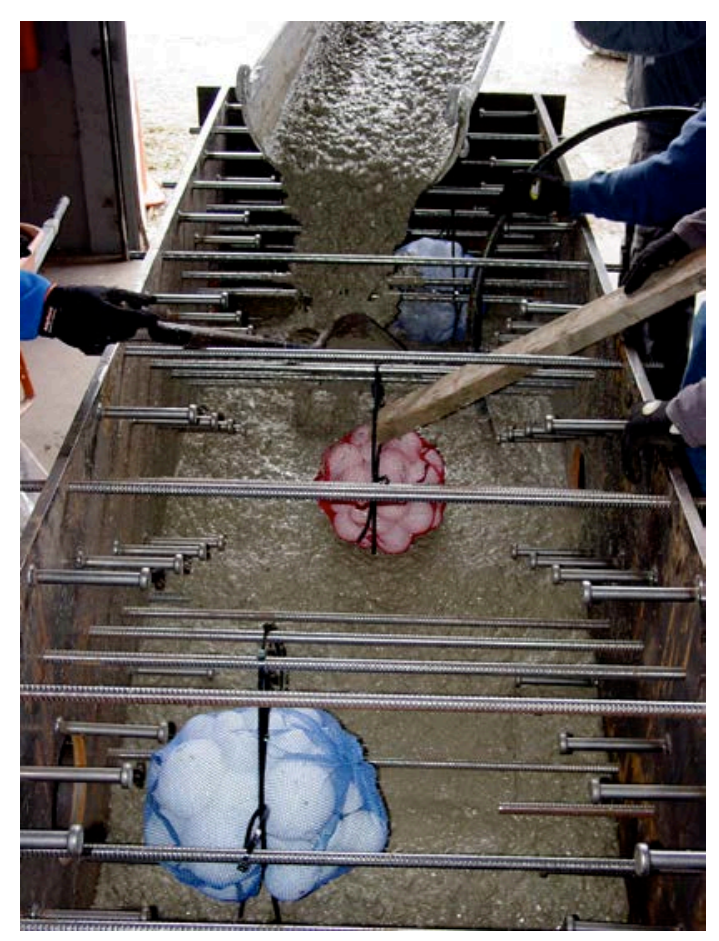

Fig. 9. WesDyne 3X3X10 Specimens showing void simulators [2]

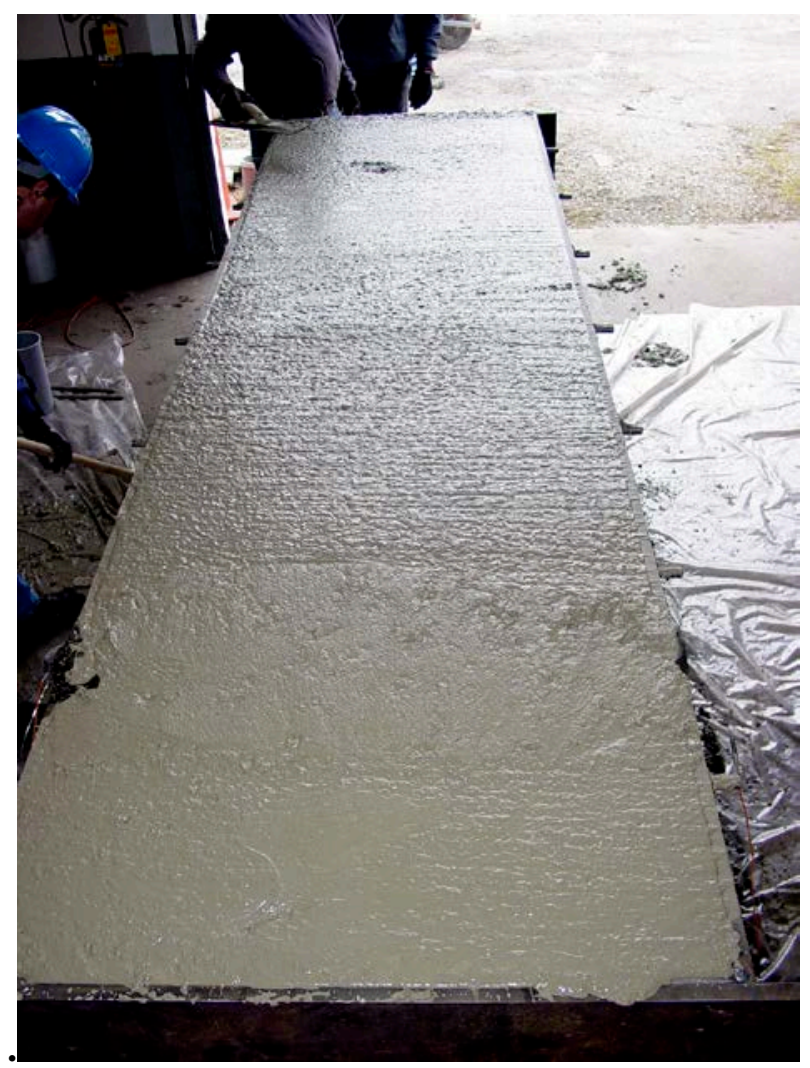

Fig. 10. WesDyne concrete specimen after all concrete poured [2] 
The WesDyne single 30-foot by 30-foot shield building section for NDE is shown in Fig. 11 and Fig. 12. Shrinkage of the poured concrete away from the inner and outer steel walls during curing of the concrete was of concern because any air gap will prohibit NDE of the concrete from the external steel faces of the walls. In this section, WesDyne again tied plastic mesh bags containing foam balls to a limited number of specific steel cross struts before the concrete was poured to simulate voids within the concrete.

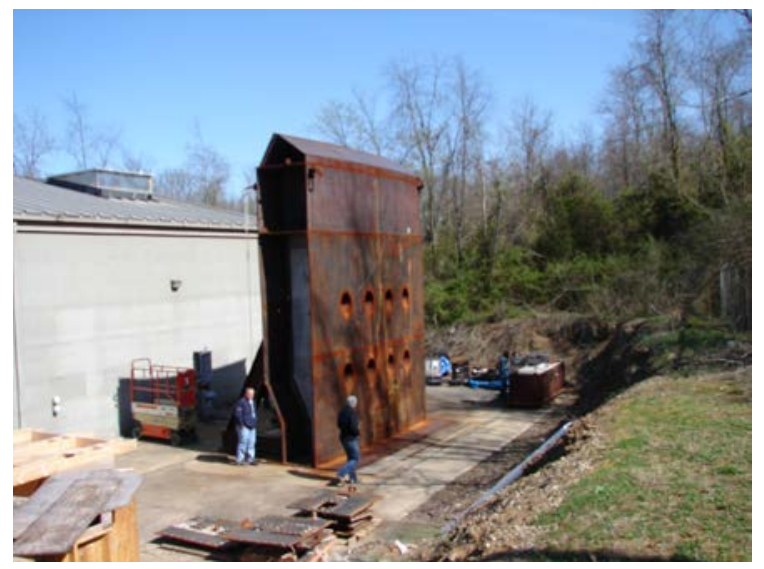

Fig. 11. WesDyne Westinghouse AP1000 Shield Building NDE Evaluation Section [2]

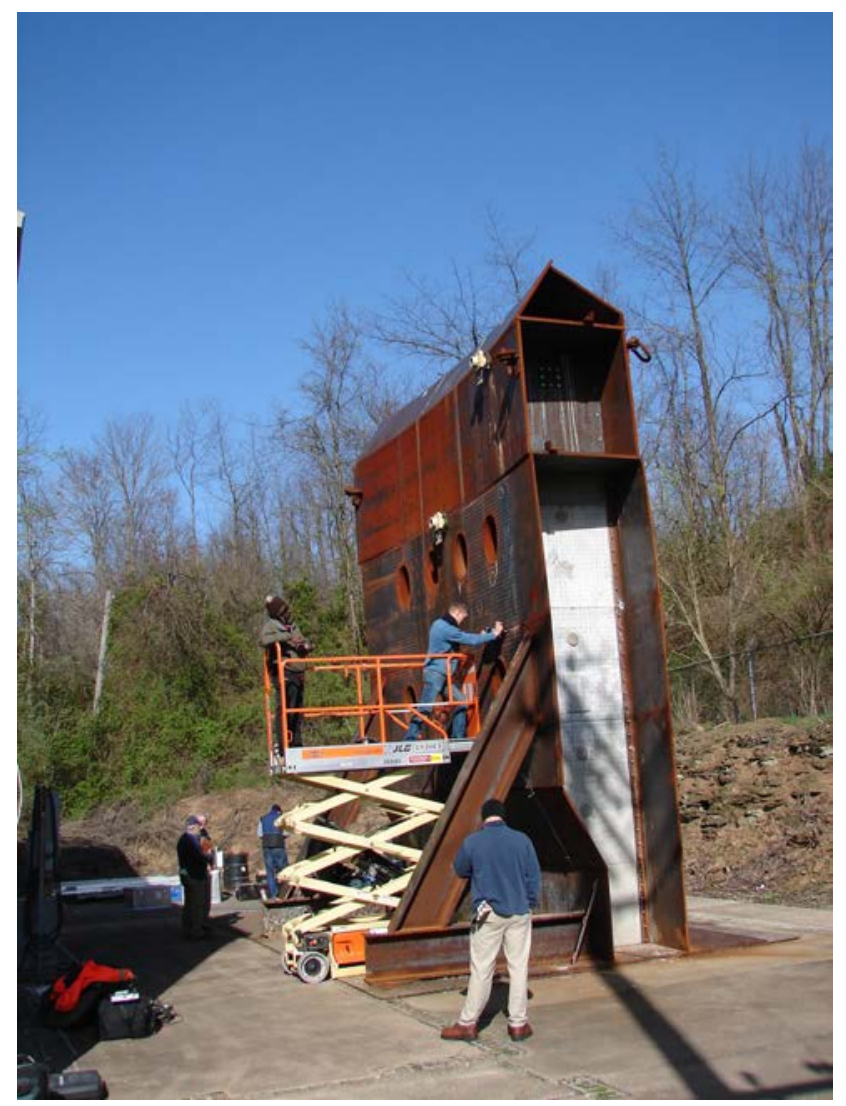

Fig. 12. NDE Evaluations being performed on AP1000 Shield Building Section[2] 
The Shield Building section, which WesDyne fabricated, is the top section of the Shield Building containing the cooling ducts which cool the reactor in case of emergency. They chose to fabricate this section due to the interference cooling ducts have on the flow of concrete into the section. All of the sections of the Shield Building below this section where of reduced thickness [2]. WesDyne evaluated the ultrasonic and impact-echo techniques of NDE on this fabricated section and was able to detect the formed-in void simulations. However, there was also shrinkage of the concrete away from the steel inner and outer walls, which is problematic for NDE at locations where shrinkage occurred.

These types of concrete specimens are useful for NDE testing, technology evaluation, and technician training, but the WesDyne specimen was scheduled for demolition in 2013. While the 3' x 3' x 10' specimen can be shipped by truck, the 30' x 30' AP1000 Shield Building section would be impractical to ship by any means and must be used at its current location at WesDyne’s Watts' Mill Service Center in Pittsburg, Pennsylvania. While both of these specimens are typical of AP1000 Shield Building construction, they are not typical of earlier nuclear power reactor shield building construction and the void simulators were not in line with the desired defect simulators in this report.

\subsection{INFRASTRUCTURE CONCRETE SPECIMENS WITH NPP CONTAINMENT REPRESENTATIVE DEFECTS}

The industry typically performing NDE on concrete structures is the bridge and roadway industry. While bridge and roadway structures are thinner and typically contain less steel reinforcement, they provide a good base of NDE research to support their field NDE programs to detect, identify, and repair concrete failures. A summary of concrete structures in this discipline specifically designed for the purposes of NDE validation is given here.

\subsubsection{Federal Institute For Materials Research And Testing (Bam) In Berlin (Germany)}

In 2002, a Large Concrete Slab (LCS) was designed and constructed at the Federal Institute for Materials Research and Testing (BAM) in Berlin (Germany) [17]. BAM has accomplished major achievements in research and development (R\&D) in regards to NDE of concrete structures [2]. There is a great variety of mostly artificial but also field-removed test blocks addressing various testing problems. Other large-scale test blocks are located at their secondary test site in Horstwalde (Germany), outside of Berlin. Practical experience in NDE for more than ten years and urgent research topics from investigations and applications defined the construction of the LCS. The concrete slab has an area of $10 \mathrm{x}$ $4 \mathrm{~m}^{2}$ with a regular thickness of $30 \mathrm{~cm}$. The large dimensions of the specimen are necessary to minimize boundary effects on the measured signals and to establish well-defined defects with varying properties [17].

The concrete slab is partitioned into two sections, one section containing tendon ducts with different diameters and grouting defects along the pre-stressing steel and the other section providing areas with varying thickness and voids. Auxiliary elements like thermo-elements, water inlet, and reinforcement mats are implemented to allow for a detailed testing. The thickness of the slab was also varied in geometry and dimension along with the following parameters:

- Reduced slab thickness from $30 \mathrm{~cm}$ to $25 \mathrm{~cm}$ and $20 \mathrm{~cm}$

- Variation of the geometry

- Slant backside from $30 \mathrm{~cm}$ down to $15 \mathrm{~cm}$

- Roughness of the backside surface

- Variation of the slab thickness

- Compaction fault/honeycombing simulation

- Grouting faults in tendon ducts 
BAM was the testing site for another reinforced concrete specimen with embedded defects for NDE purposes in the form of a standing wall [14]. Polystyrene cuboids were embedded to simulate voids and compaction faults in concrete. It should be noted that some of the Polystyrene bodies tilted orientation during construction due to buoying upwards during concreting. The conceptual specimen presented in this report should account for this difficulty in construction so any movement from the desired position can be limited.

\subsubsection{Nondestructive Evaluation Specimens From Journal Publications}

Various test blocks have also been constructed for evaluation of impact echo [11]-[13]. In addition to various grouting, delamination, and other defects, Popovics et al. simulated internal voids by embedding 300 and $100 \mathrm{~mm}$ diameter soft foam blocks. The foam blocks were secured to the wire mesh with tie wire [13]. Asano et al. fabricated approximately 8 in. concrete slab specimens with disk shaped artificial defects (styrene, thickness: $0.5 \mathrm{~cm}$ ) [12]. The concrete size was chosen to be large enough not to be affected by elastic wave reflection from the sides. The diameters of artificial defects were $5,10,15,20$, 30 , and $50 \mathrm{~cm}$ with depths of 3, 5, 7, and $10 \mathrm{~cm}$ from the surface. Yehia et al. created a specimen for detection of concrete bridge deck defects using various NDE techniques [10]. This included void simulation using PVC pipes running through the specimen removed to leave a void behind. Crack simulation was conducted by embedding Plexiglas of different lengths and thicknesses.

\subsubsection{Federal Highway Administration NDE Validation Center At The Turner-Fairbank Highway Research Center}

The Federal Highway Administration (FHWA) NDE Validation Center is tasked with validating commercial concrete NDE systems for use by state inspectors on highway structures. Their tasking was established by the National Bridge Inspection Program (NBIP) through the Federal Highway Act of 1968 which required states to periodically inventory and inspect all highway structures on the federal aid system. Since then, Congress has expanded this inspection program to include all structures on public roads, including those not on the federal aid system. This mandate by Congress is the reason states have their massive inspection, rating, and inventory programs [43].

While visual inspection has been the principal technique for inspecting bridges, a number of NDE technologies such as infrared thermographic imaging, ground penetrating radar (GPR) imaging, laserradar scanning, acoustic emission monitors, electromagnetic acoustic transducers, embedded corrosion microsensors, and vibrometers are also being used. The NDE Validation Center was established by the FHWA in 1996 and is the only center in the world dedicated entirely to the evaluation and validation of NDE technologies for highway structures.

In August of 2008, a tractor-trailer fatally crashed through a bridge barrier on the William Preston Lane, Jr. Memorial Bridge in Maryland after a section of the bridge barrier was dislodged due to the impact. Investigations of this incident revealed significant corrosion of the anchor bolts, which attached the bridge railing to the bridge deck. However, this corrosion was not visible during inspections before the accident. As a result, the FHWA NDE Validation Center has been investigating the feasibility of using four NDE technologies, GPR, ultrasonic pulse-echo, digital radiography and infrared thermal imaging to develop bridge inspection methods to augment visual inspections. To this end, the Center procured five specimens from Smith-Midland, a cast concrete products manufacturer in Midland, Virginia as shown in Table 3. 
Table 3. FHWA NDE Validation Center Specimens

\begin{tabular}{|c|l|l|}
\hline Specimen & \multicolumn{1}{|c|}{ Description } & \multicolumn{1}{c|}{ Defect } \\
\hline 1 & F-Shaped Free Standing Portable & Simulated Corrosion \\
\hline 2 & F-Shaped Bolt Down & Simulated Corrosion \\
\hline 3 & F-Shaped Free Standing Portable & Embedded Voids \\
\hline 4 & F-Shaped Bolt-Down & Embedded Voids \\
\hline 5 & Bridge Deck Slab & Embedded Voids \\
\hline
\end{tabular}

\subsubsection{Specimen 1 - F-Shaped Free Standing Portable With Simulated Corrosion}

Fig. 13 shows the dimensions of Specimen 1, which is an F-shaped Free Standing Portable Barrier which is 12 feet long and 2 feet 8 inches high. This custom fabricated barrier has three specially prepared sections of \#5 rebar through the middle of the barrier as well as wire mesh attached to the rebar. The 12 foot length of the barrier was segmented into six 2 foot sections as shown in the figure. Over each 2 foot section of rebar, the diameter was machined to simulate different levels of corrosion as identified in Table 4 and shown in Fig. 14.

Table 4. Corrosion simulation for each barrier section for Specimens 1 and 2

\begin{tabular}{|c|l|}
\hline Section Identification & Corrosion Simulation \\
\hline a & No Corrosion \\
\hline b & Mild Corrosion \\
\hline c & $5 \%$ Diameter Reduction \\
\hline d & $10 \%$ Diameter Reduction \\
\hline e & $25 \%$ Diameter Reduction \\
\hline f & $50 \%$ diameter Reduction \\
\hline
\end{tabular}

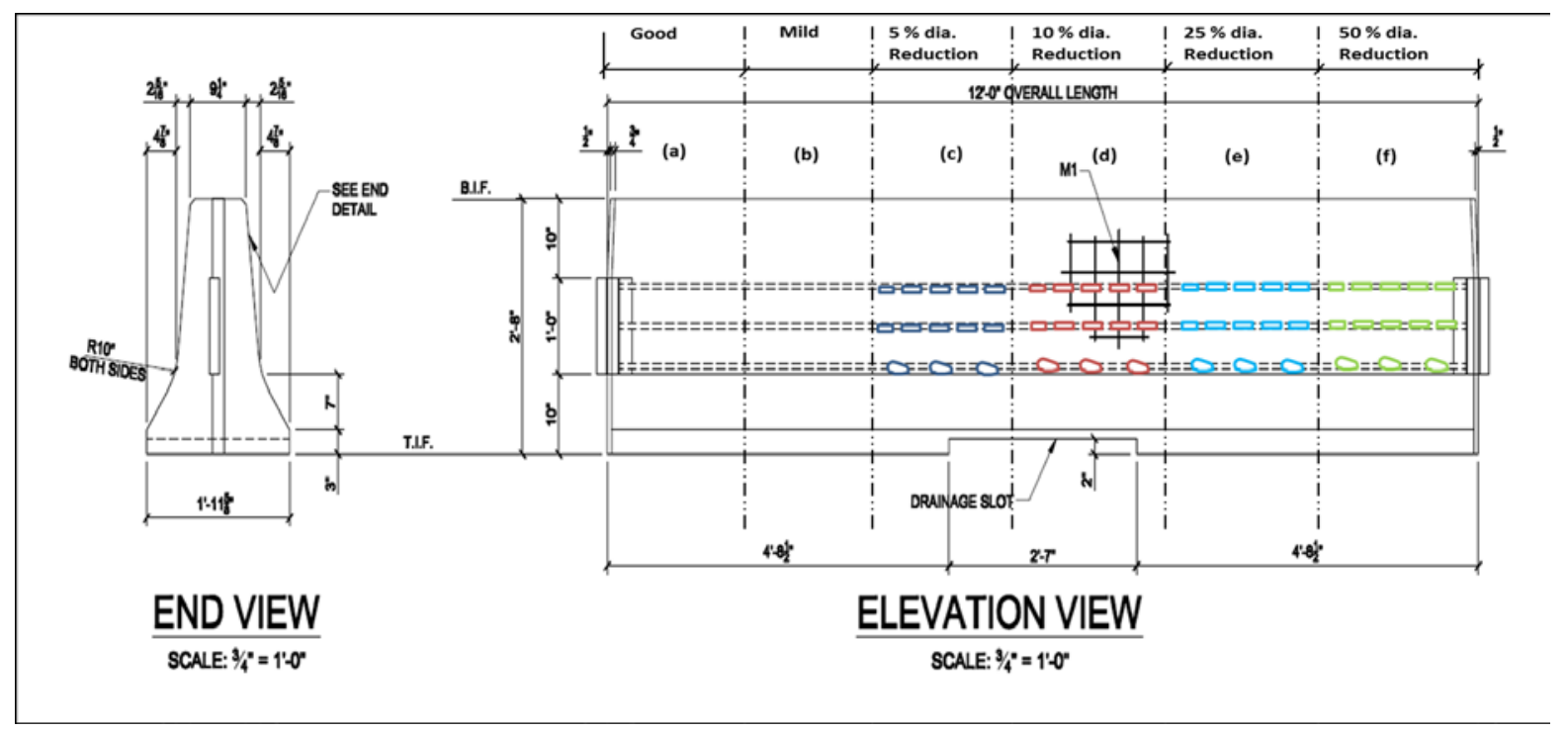

Fig. 13. F-shaped free standing portable barrier 

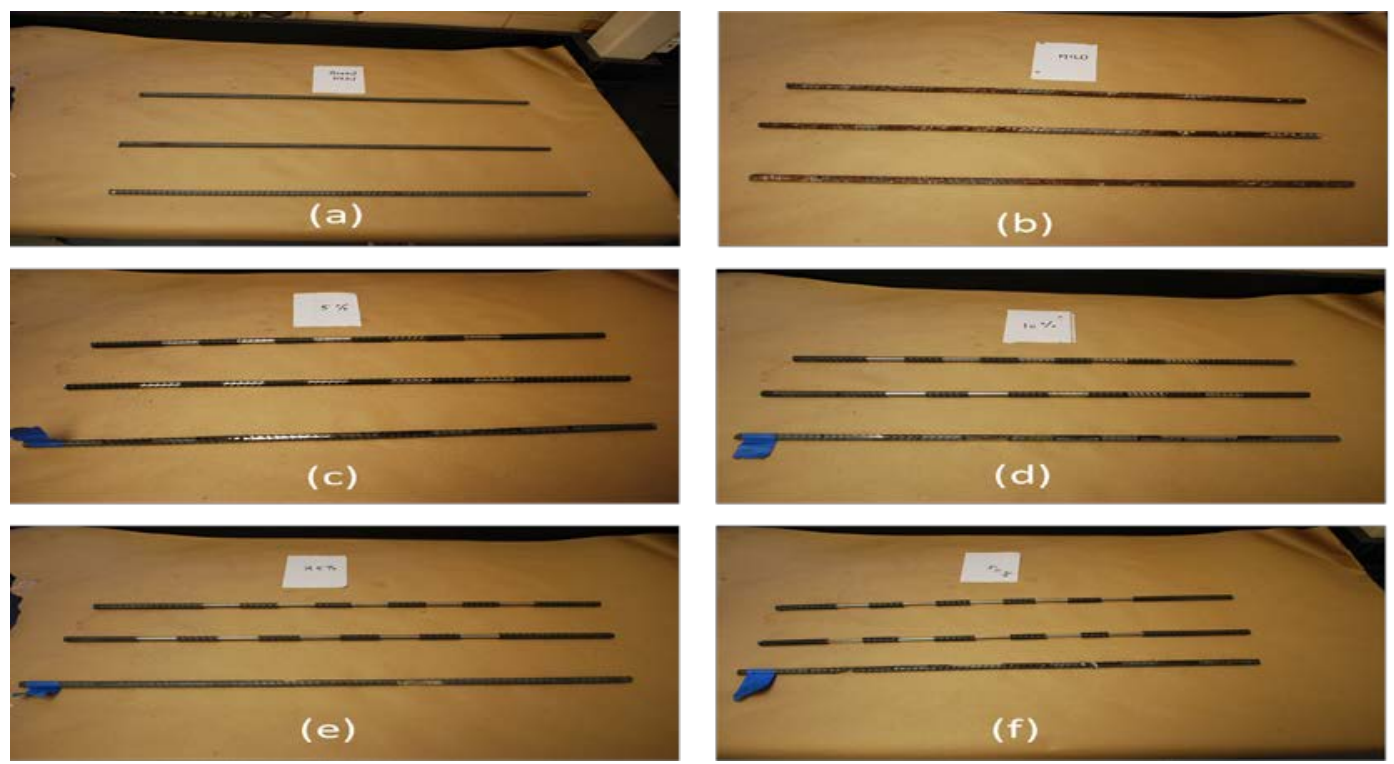

Fig. 14. Different levels of simulated corroded

\subsubsection{Specimen 2 - F-Shaped Bolt Down With Simulated Corrosion}

Fig. 15 shows the dimensions of Specimen 2, which is an F-shaped Bolt Down Barrier 12 feet long and 2 feet 8 inches high. This custom fabricated barrier has three specially prepared sections of \#4 rebar through the middle of the barrier and twelve U-shaped sections of \#5 rebar placed every foot as shown in the end view of Fig. 15. Photos of the U-shaped rebar are shown in Fig. 16 and Fig. 17. The 12 foot length of the barrier was segmented into six 2 foot sections as shown in the figure. All \#4 rebar sections were full diameter, but varying amounts of the diameter of the U-shaped rebar was machined to simulate different levels of corrosion as identified in Table 2.

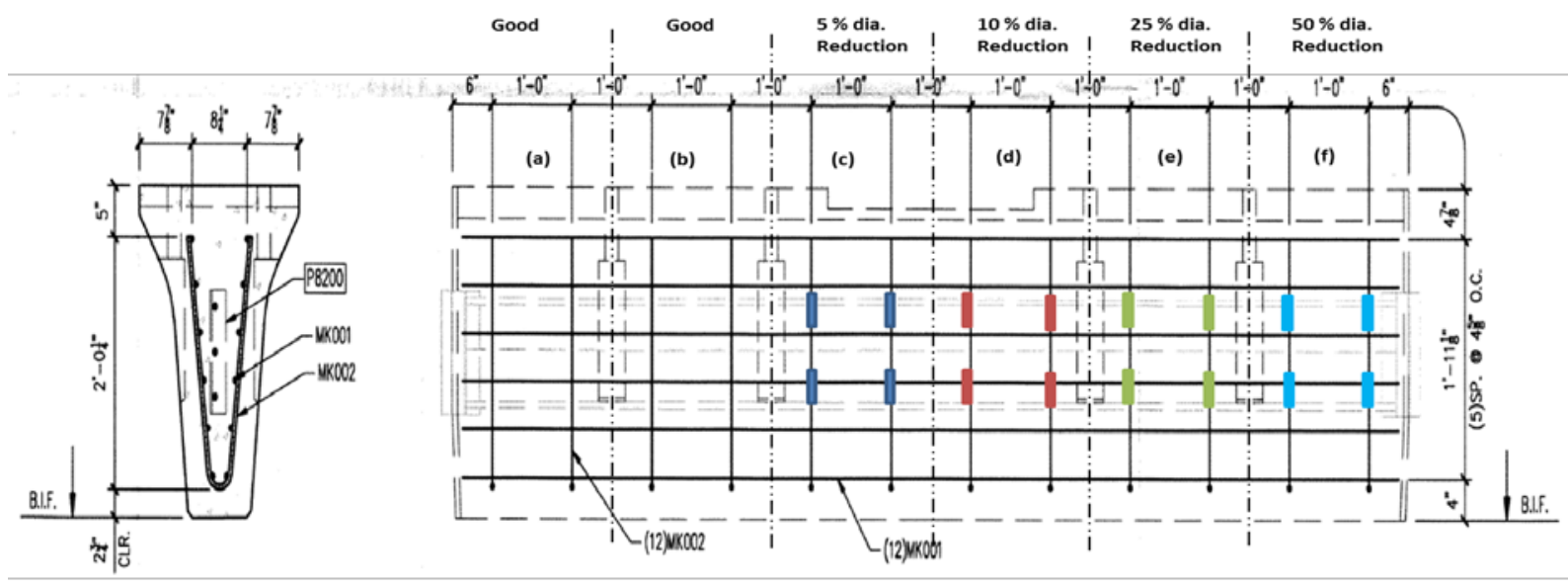

END VIEW

ELEVATION VIEW

Fig. 15. F-shaped bolt-down barrier with different levels of simulated 

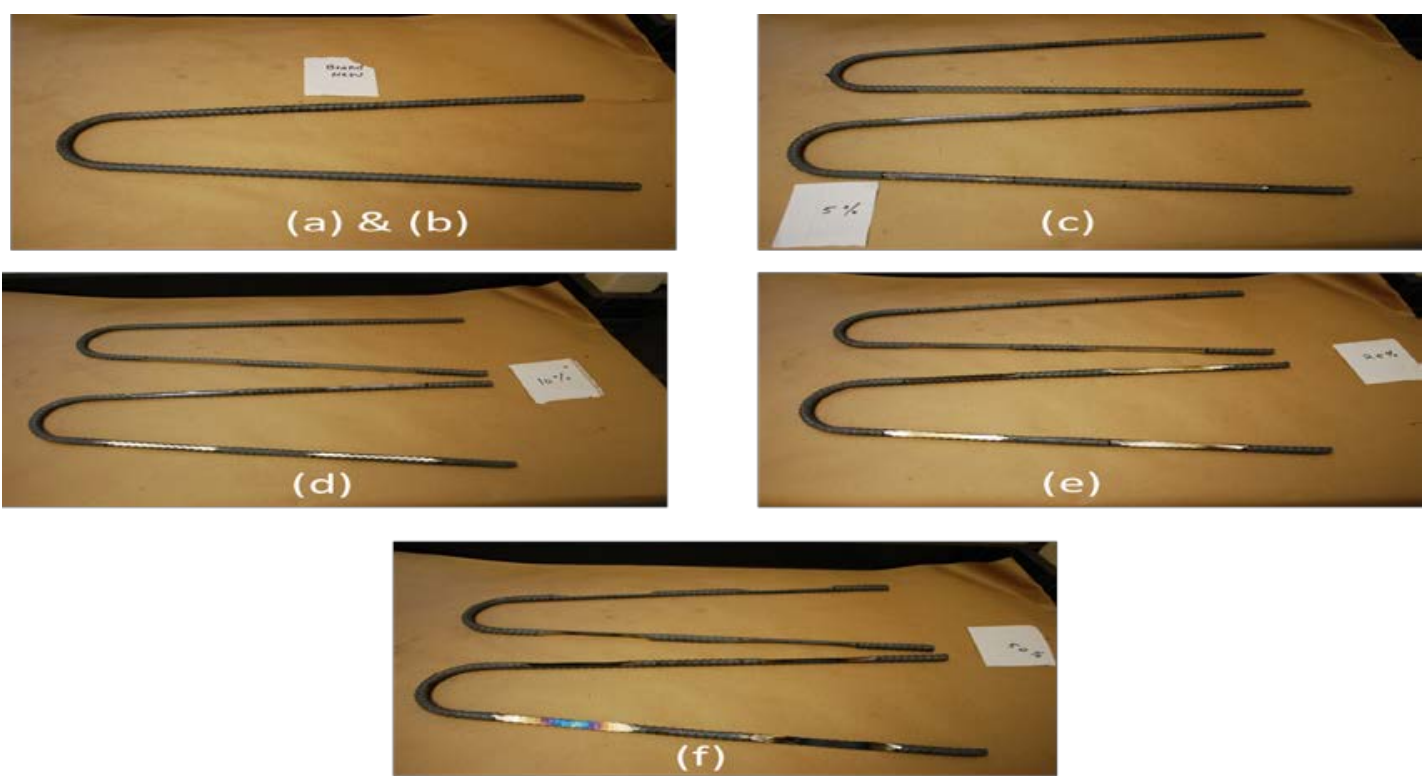

Fig. 16. Different levels of simulated corroded U-shaped rebar

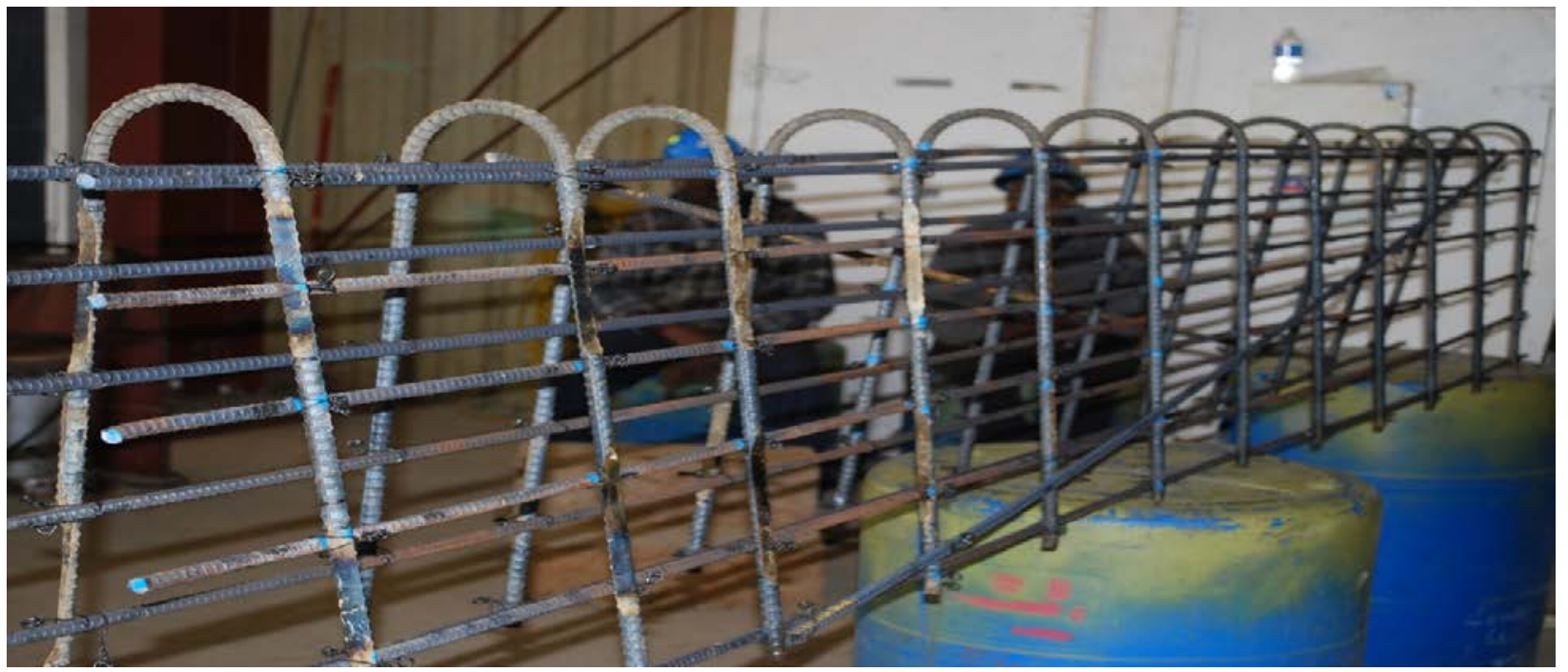

Fig. 17. F-shaped bolt-down barrier fabrication with simulated corrosion 


\subsubsection{Specimen 3 - F-Shaped Free Standing Portable with Embedded Voids}

Fig. 18 shows the dimensions of Specimen 3, an F-shaped Free Standing Portable Barrier 12 feet long and 2 feet 8 inches high. This custom fabricated barrier has three specially prepared \#5 rebar sections through the middle of the barrier as well as wire mesh attached to the rebar. The 12 foot length of the barrier was segmented into six 2 foot sections as shown in the figure. Over each 2 foot section of rebar, hollow balls, loose gravel and foam of different shapes and sizes were attached to the wire mesh to simulate voids, segregation, and delamination of different shapes and sizes respectively as identified in Table 5. A photo of F-shaped freestanding portable barrier fabrication is shown in Fig. 18.

Table 5. Defect simulation for each barrier section for Specimens 3 and 4

\begin{tabular}{|c|l|}
\hline Section Identification & Defect Simulation \\
\hline a & Control \\
\hline b & Hollow balls to simulate voids \\
\hline c & Foam to simulate voids \\
\hline d & Foam to simulate delamination \\
\hline e & Foam balls to simulate voids \\
\hline f & Gravel to simulate segregation \\
\hline
\end{tabular}

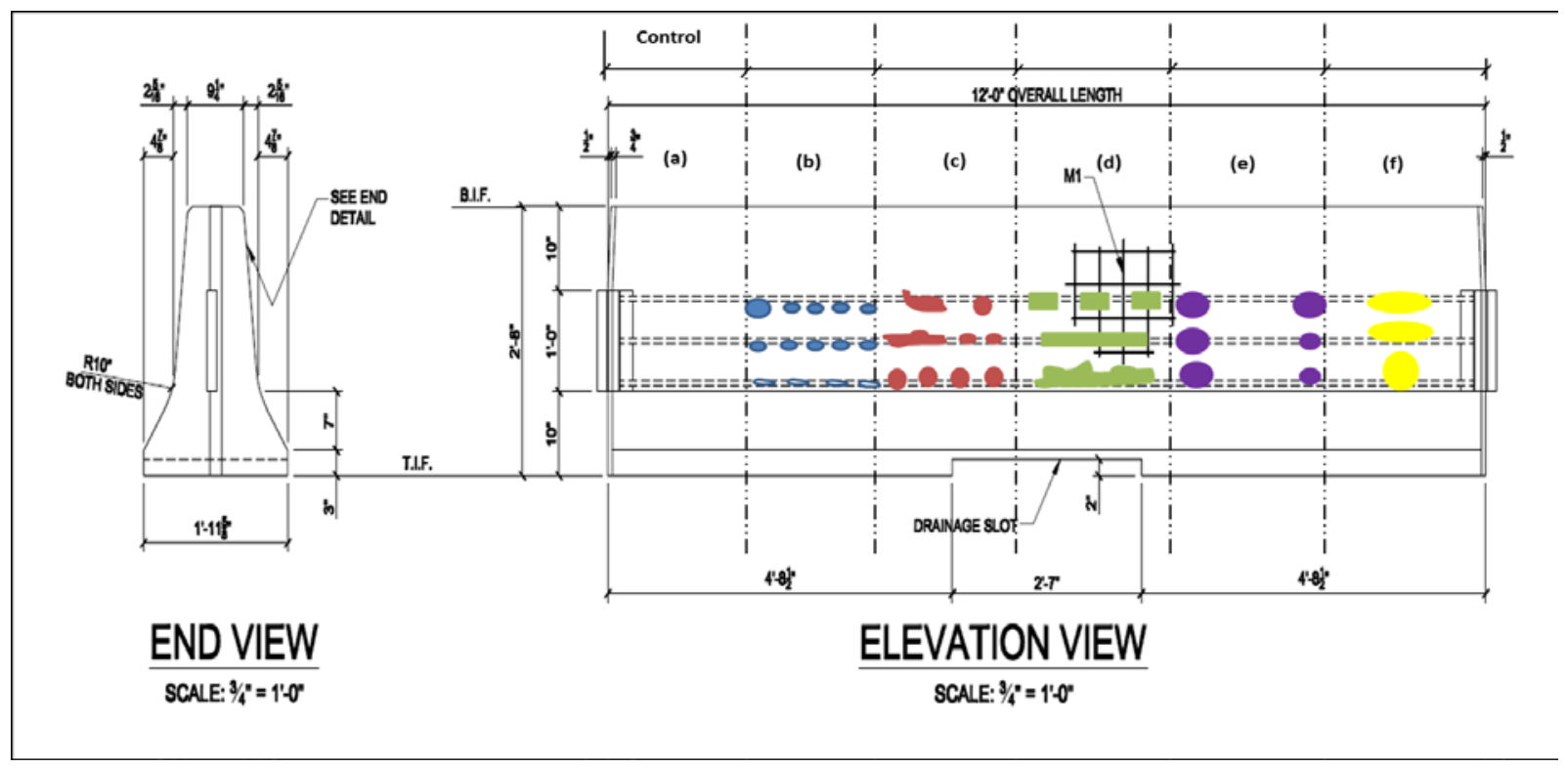

Fig. 18. F-shaped free standing portable barrier with simulated voids 


\subsubsection{Florida Department Of Transportation NDE Validation Facility}

The Florida Department of Transportation NDE Validation Facility in conjunction with the Department of Civil and Coastal Engineering Department University of Florida, Gainesville constructed various concrete specimens for the purposes of NDE comparisons and validation [9]. Six unique validation blocks were fabricated to evaluate the capabilities of instruments for reinforcing steel detection, elastic property estimation, post-tensioning duct investigation, internal void detection, and surface flaw evaluation. The six validation blocks, four of which are shown in Fig. 19, are:

- Control Block (monolithic concrete)

- Rebar Detection Block

- Internal Post-Tensioning (PT) Duct Block (galvanized steel ducts)

- Slab Thickness Block

- Asymmetric Internal PT Duct Block (polypropylene ducts)

- Void and Flaw Detection Block

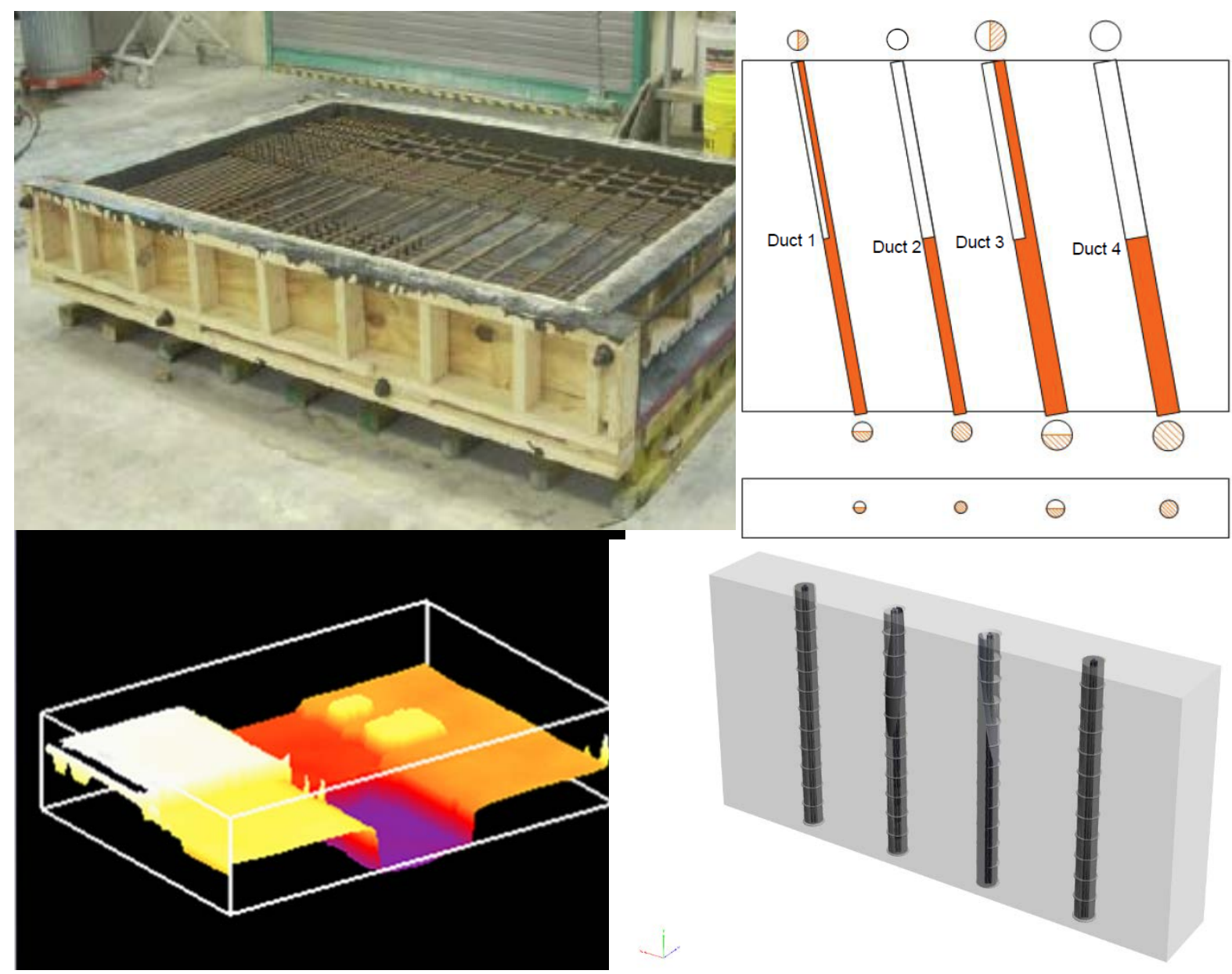

Fig. 19. Four concrete test specimens. Clockwise from top-left: rebar detection, steel post tensioning duct evaluation, polypropylene post tensioning duct evaluation, and slab thickness evaluation blocks in varying stages of design and construction [9]. 
Since Specimen 2 (Rebar Detection Block) is the most heavily reinforced with rebar and Specimen 6 (Void and Flaw Detection Block) represents several visible and hidden "defects" typical of aging concrete structures, these were evaluated as part of an ORNL study [8]. The Specimen 2 allowed for evaluation of the effectiveness of NDE instruments in locating rebar of various diameters with changing spacing and depths. The overall rebar mats can be observed in Fig. 20.

Front-x

Fig. 20. Orientation and relative location of rebar mats in Rebar Detection Block [5]

Specimen 6 was designed to evaluate defects such as the quality of consolidation in a completed concrete structure. Movement of rebar after initial set, over/under vibration, mix segregation, and development of bleed water pockets, and cracking were simulated in this specimen. This included a prism of pervious concrete placed at surface level during concrete placement along with two simulated angled cracks, which can be observed in Fig. 21. 


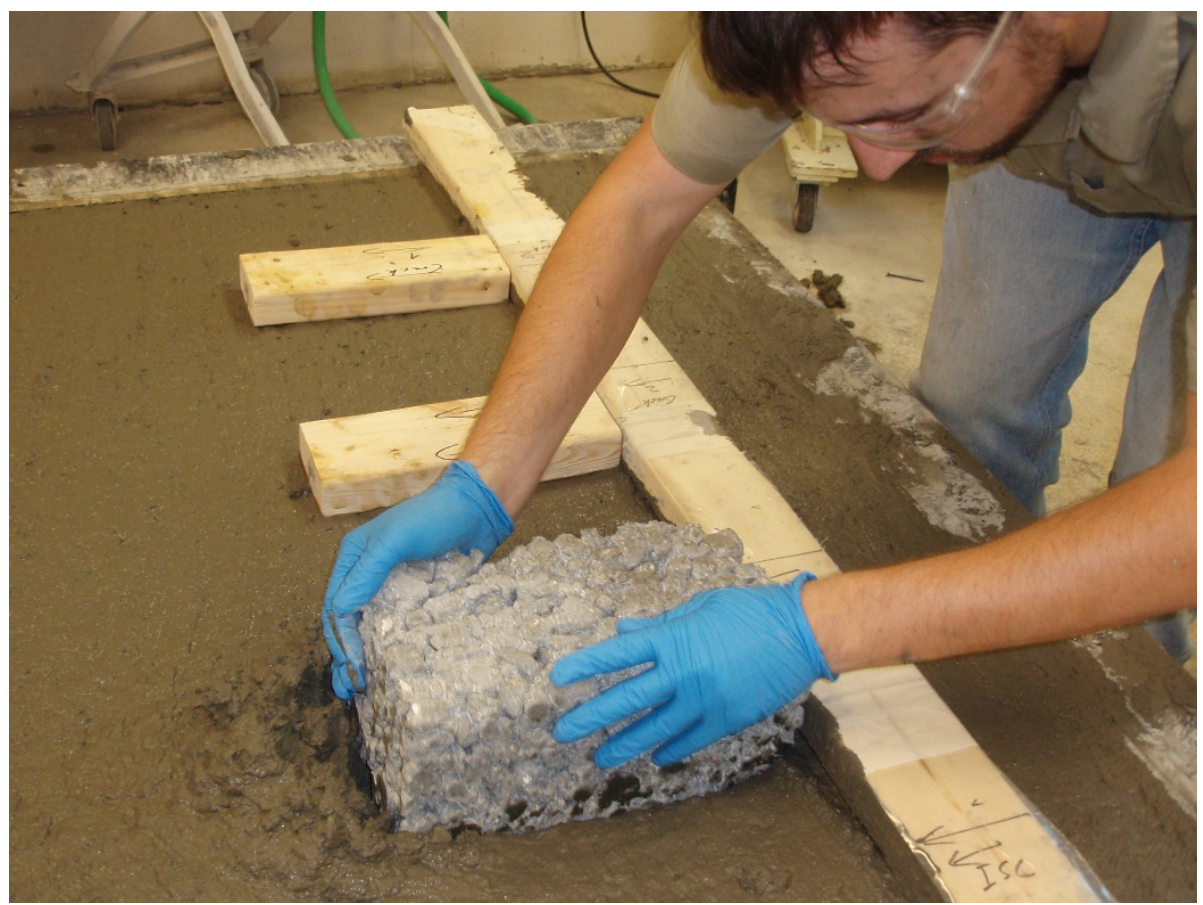

Fig. 21. Installing the surface level pervious concrete prism and two short boards holding the triangular plates used to make the simulated cracks [8]

The three sections of \#6 rebar, shown in Fig. 22 were suspended in-place by recessing the last 50mm of their length on either end into a layer of polymer coated form board. The rebar pieces to be moved after initial set of the concrete had one end moved in the mold after initial set of the concrete, through installation into a slot rather than a hole in the inner form board. In this manner, only one end of the rebar was moved after concrete placement, allowing for an increasingly severe "trail" of disturbed concrete behind the path of the rebar. The laterally moving rebar specimen had a more complicated cable system guided through a lubricated tube into the formwork itself. It should be noted that this system failed to move the rebar as desired and it was confirmed after measurement that this rebar piece moved only 8mm. 


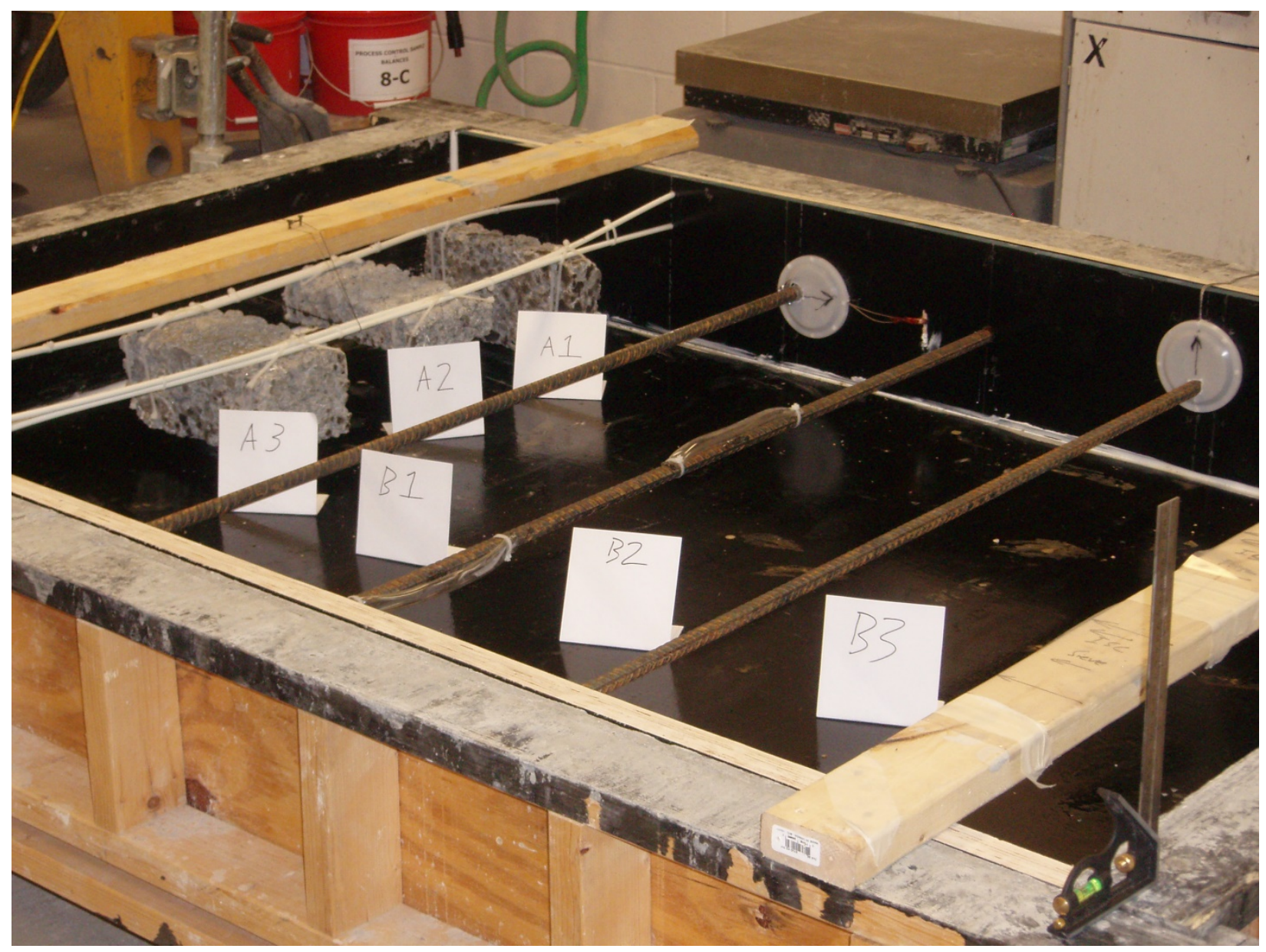

Fig. 22. Three rebar pieces including the two moving specimens in Void and Flaw Detection Block. The plastic caps marked with the black arrows both keep concrete out of the movement slot in the form boards and indicate which direction the rebar end is designed [8].

While the results of ORNL Report, "Evaluation of Ultrasonic Techniques on Concrete Structures," using these types of defects showed the promise of various techniques in determining the location and extent of these defects, the lack of required depth of penetration and heavy reinforcement creates a need for similar evaluations and comparisons on a larger more heavily reinforced specimen [8]. There is a need to design a new concrete specimen for qualifying NDE concrete instrumentation and evaluating the state of current NPP concrete structures characterization capabilities. The conceptual design in this study will do a more realistic job of adequately reflecting the existing large concrete structures for NPP containment and shielding. A recommendation from ORNL Report "Summary of Large Concrete Samples" is that at least one concrete test specimen representative of the cross section of a commercial NPP be fabricated for NDE [3]. A conceptual design based on the above summarized factors is proposed in this report. 



\section{DESIGN REQUIREMENTS FOR A SUITABLE REPRESENTATIVE NPP CONCRETE SPECIMEN FOR NDE EVALUATIONS.}

Suitable concrete specimens that are representative of NPP concrete cross sections are needed for NDE and testing of instrumentation and measurement techniques. Adequate test blocks/specimens play a key role, since they can provide defined conditions under which the different NDE concrete measurement methods can be evaluated. Material properties as well as the location of reinforcement, tendon ducts, and test flaws must be well documented. The artificial blocks can provide more defined conditions, since the critical parameters can be controlled during the block fabrication.

Due to the controlled conditions in the laboratory, the number of unknown variables can be decreased, making it possible to focus on specific aspects, investigate them in detail, and gain further information on the capabilities and limitations of the techniques. Comparative testing on the various NDE concrete measurement techniques will require concrete specimens with known material properties, voids, internal microstructure flaws and reinforcement locations. These specimens can be artificially created under laboratory conditions where the various properties can be controlled. Since no available large concrete specimens are representative of NPP concrete structures or available for forensic verification activities, a proposed design is presented in this section after two major concerns informing the specimen design are reviewed.

\subsection{BOUNDARY EFFECT CONCERNS}

To minimize artifacts caused by boundary effects discussed in the previous sections, the dimensions of the specimen should not be too compact. The minimum dimensions of the test specimen are directly related to the thickness of the specimen. If the ultrasonic wave is modeled as a spherical propagation from the point source (as shown in previous sections), the distance from the source location to the rear surface must be the minimum dimension. However, the exact size of the specimen needed to address boundary effects depends on the NDE technique used. For example, multiple ultrasonic transducers can be utilized to beamform the generated ultrasonic wave to give it more directional propagation properties (see Fig. 23) for a four-element beamformed wave, with no shading. If shading is applied, additional directionality is obtained.

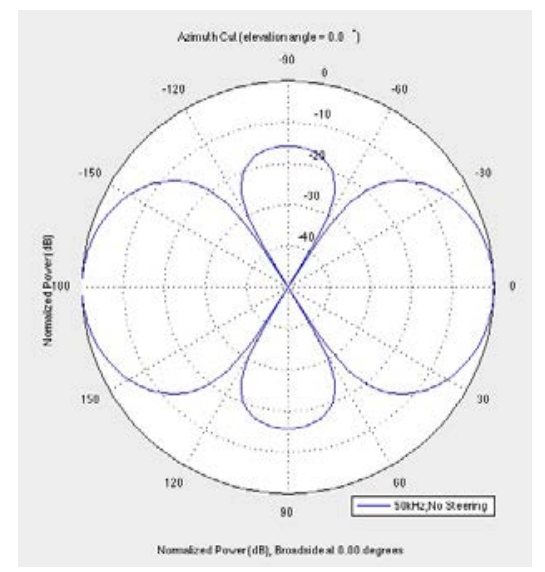

Fig. 23. Beam Pattern from a Four Element Ultrasonic Array 
This type of focusing can assist in both boundary effects and depth of penetration concerns. To illustrate this, a simple example scan was taken by an ultrasonic linear array system, MIRA (shown in Fig. 24[A]), at the University of Minnesota Theodore V. Galambos Structural Engineering Laboratory (UMN-TGL). The scan was taken for an approximately 1 meter thick reinforced concrete specimen with inclusions at approximately $0.15 \mathrm{~m}$ and $0.4 \mathrm{~m}$ depths, respectively. Fig. 24[B], Fig. 24[C], and Fig. 24[D] give cross-sectional imaging reconstructions of the same scan data showing the relative reflectivity throughout the depth using different inputs. It can be observed from Fig. 24[B] that the shallower inclusion (bordered by the solid black box) is properly represented by a round black increase in reflectivity, while the deeper inclusion and interface at the reinforced concrete structure thickness depth are underrepresented (bordered by the dashed box). It can be observed from Fig. 24[C] that the shallower inclusion (bordered by the dashed black box) is not properly represented due to a saturation in reflectivity, while the deeper inclusion and interface at the reinforced concrete structure thickness depth (bordered by the solid black box) are properly represented by a round black increase in reflectivity and oblong increase in reflectivity, respectively. By properly accounting for attenuating effects, the volumetric imaging and signal interpretation strategies can be adjusted accordingly. Fig. 24[D] shows how a volumetric reconstruction accounting for these types of effects might be applied to properly represent both shallow and deep characteristics, showing proper reflectivity at both inclusions and the back wall reflection at the thickness of the concrete structure.

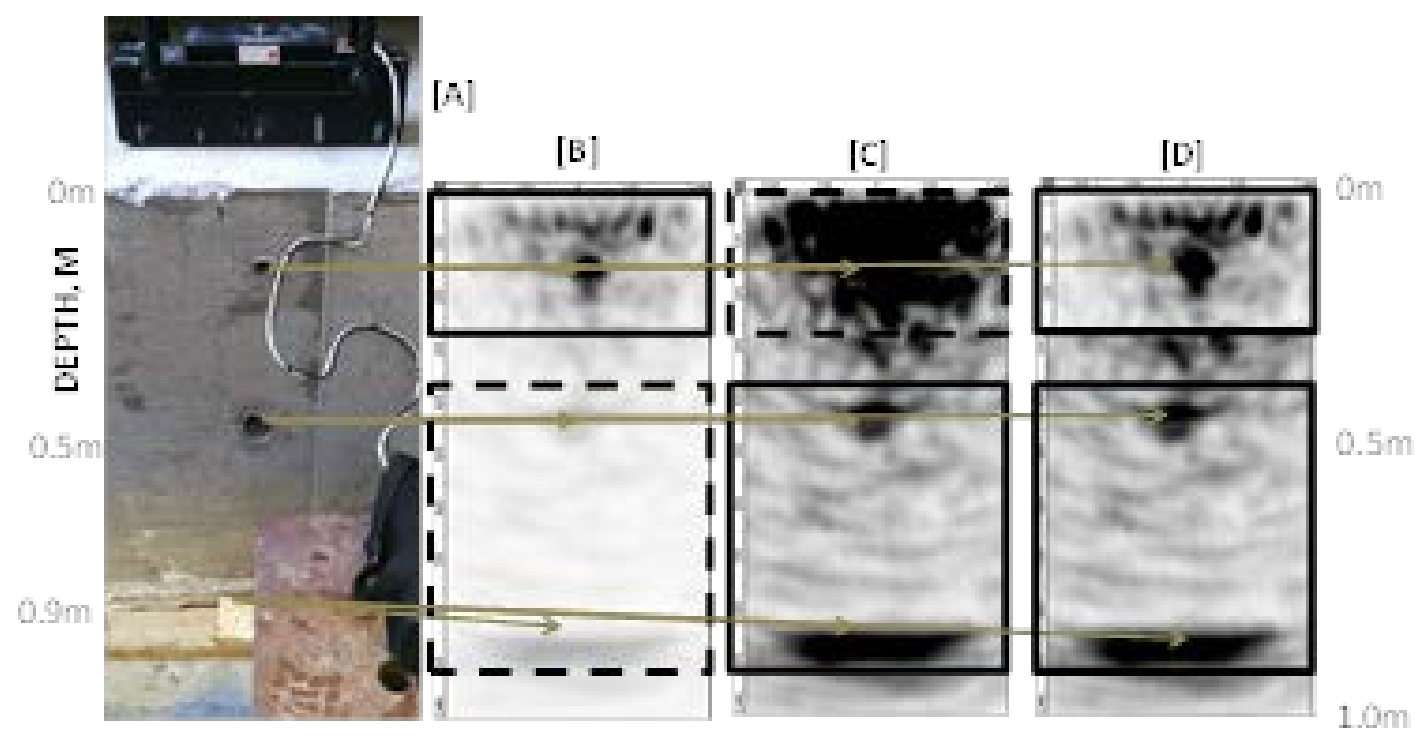

Fig. 24. [A] Picture of MIRA ultrasound scanner with an approximately 1 meter thick reinforced concrete specimen with corresponding reconstructions that indicate the $[B]$ shallow features [C] deep features, and [D] all features.

It is clear that using ultrasonic arrays for NDE with volumetric imaging techniques may reduce the necessary size of the concrete specimen - the lateral distance from the ultrasonic linear array is over 5 times smaller than the depth to the clear back wall reflection at the thickness of the specimen. However, since there are not a large number of vertical boundaries in aging concrete in NPP structures, an inability to handle boundary effects should not eliminate a technique from potential use for in-service inspection (also described in the "Need for Suitable Concrete Specimens" section). Therefore, the specimen should also be designed to evaluate techniques that do not have directional capabilities. A major design requirement is that the depth of the ROI in the specimen should be significantly larger than the remaining lateral dimensions. The ability of each technique to handle vertical boundary effects will not affect the validation activities if designed using this constraint, especially for defects near the center of the lateral boundaries of the specimen. 
It should also be noted that, while boundary effects from finite lateral structure dimensions are generally not a concern in NPP containment structures, this does not suggest that directional capabilities do not affect the ability of various NDE methods to evaluate thick reinforced structures, even at locations where no lateral vertical boundaries are present. Signal directionality can assist in evaluating defects near or below reinforcement, especially if the signal is focused along a plane of interest parallel and centered between adjacent reinforcement. Also, beyond mitigation of interference of internal structure characteristics, such as reinforcement patterns for evaluation of defects, the focusing can also allow for greater penetration depth by increasing the energy along the focused plane. Therefore, since focusing capabilities are of interest, defects will also be placed in locations that approach the lateral boundaries, in addition to the defects with no potential boundary effects near the center of the lateral dimensions of the various specimens. This will leverage the availability of an already cast specimen to increase the number and type of defects that can be tested by methods with directional capabilities and provide information about the extent of the focusing capabilities. Defects near a free vertical boundary provide the most controlled evaluation of the extent of directional focusing capabilities of the various techniques. In this case, care must be taken to separate the portion of the results that provide information on beam focusing capabilities of the various methods versus results that provide information about the ability of the methods to evaluate degradation assuming infinite lateral dimensions. It should be ensured that comparisons made near finite lateral dimensions do not lead to conclusions that negatively direct a realistic assessment of the current capabilities of each method to assess in-service NPP containment walls. To accommodate these factors, slabs with various defect locations in relation to the lateral dimensions are proposed.

\subsection{LARGE SPECIMEN CONCERNS}

While the design of the large concrete specimens mitigates some of the boundary effect concerns, it creates some additional complexities involved with forming such a large reinforced concrete specimen. Beyond the efforts required to cast and properly consolidate a large concrete specimen, the ability to maneuver and transport the specimen can be restrictive. Often specimens need to be tilted to allow for actuator loading at the correct orientation or in this case, NDE data collection access. Additionally, there are times where the specimen needs to be cast in a different location to mitigate concrete truck or other access issues. The weight of the specimen is a major factor in this regard, where reinforced concrete is typically $150 \mathrm{lbs} / \mathrm{ft}^{3}$ and $162 \mathrm{lbs} / \mathrm{ft}^{3}$ assuming a reported NPP 5\% steel by volume ratio [3]. This can be restrictive for the use of a typical structural laboratory crane 20-ton (40,000 lbs) load capacity. There can also be restrictions due to the large specimen dimensions even if the specimen is cast in the location and orientation necessary to conduct the testing. While infrastructure specimens can easily be cut to desired dimensions along the thickness cross section for disposal, this technique is not straightforward for disposal of the specimens meeting NPP containment structure thickness requirements. This can also create restrictions beyond the weight limits of crane operation. For example, the smallest dimension of the specimen and crane fixture mechanism is required to be less than the smallest dimension of clearance between the crane and floor along the path to the disposal site, assuming the specimen is instrumented to allow for rotation to the desired specimen orientation.

Fortunately, laboratories, such as the University of Minnesota (UMN) Department of Civil Engineering, have facilities that specialize in large concrete structure construction and testing. This includes the Theodore V. Galambos Structural Engineering Laboratory (UMN-TGL) and The Multi-Axial Subassemblage Testing (MAST) System Laboratory. These facilities frequently test various heavily reinforced concrete structures up to 28.75 feet $(8.7 \mathrm{~m})$ in height and 20x20 feet $(6.1 \times 6.1 \mathrm{~m})$ which provide large scale concrete specimens available for the proposed research that can be nondestructively evaluated and compared with forensics at various damage stages. 
The design for an abutment block cast in the UMN-TGL is presented here to illustrate how this type of facility can be used to construct the necessary large specimen for comparative NDE testing. The abutment block was also used to illustrate the directional and depth of penetration capabilities of ultrasonic linear arrays in Fig. 24 of this report. The design for the example large reinforced concrete specimen was part of a Minnesota Department of Transportation sponsored study "Investigation of Shear Distribution Factors in Prestressed Concrete Girder Bridges.” Fig. 25 shows a photograph of the abutment reinforced concrete specimen cast in the UMN Structures Laboratory. Fig. 26 shows the dimensions of the concrete slab as well as the embedded reinforcements and details of the various sectional views. Fig. 27 shows the formwork details required to cast the specimen in the laboratory. Fig. 28 shows the additional details required to move the specimen and lock it into place during loading. While the conceptual design presented in this report provides the critical details necessary for construction of the large reinforced PCC specimen, there are additional details for formwork and fixtures necessary in a detailed design to finalize the logistics of the construction operation. This includes mitigating the mobility and weight concerns discussed at the beginning of this sub-section. For example, the PVC holes in this specimen allow for movement of the specimen using the overhead crane. There are also threaded holes in the strong floor of the laboratory for specimen clamping purposes. These details were provided to a local company, Advance Shoring, who donated their forms for use during the specimen casting process.

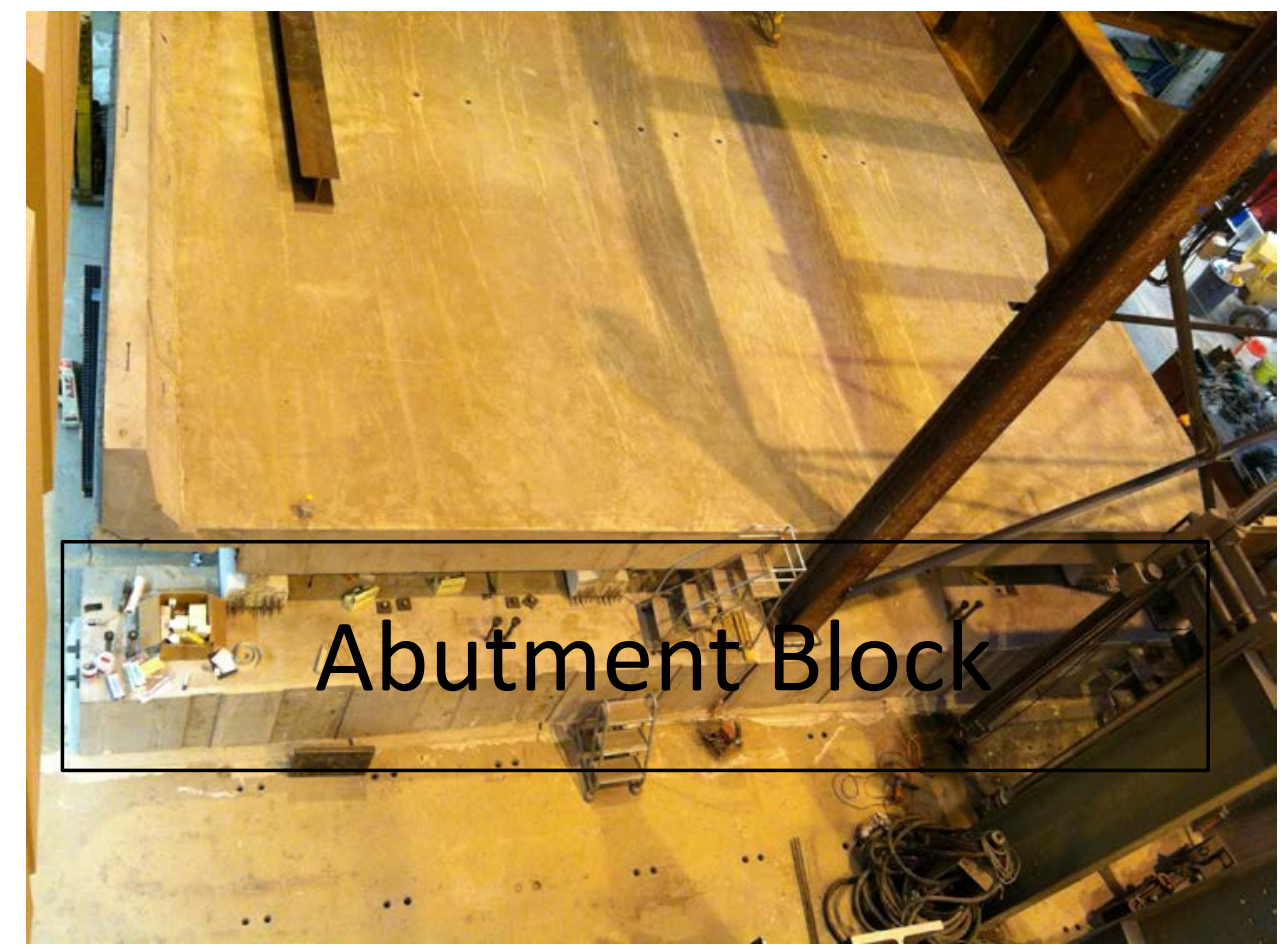

Fig. 25. Photograph of the abutment reinforced concrete specimen cast in the UMN Structures Lab 
$5 @ 3 "$

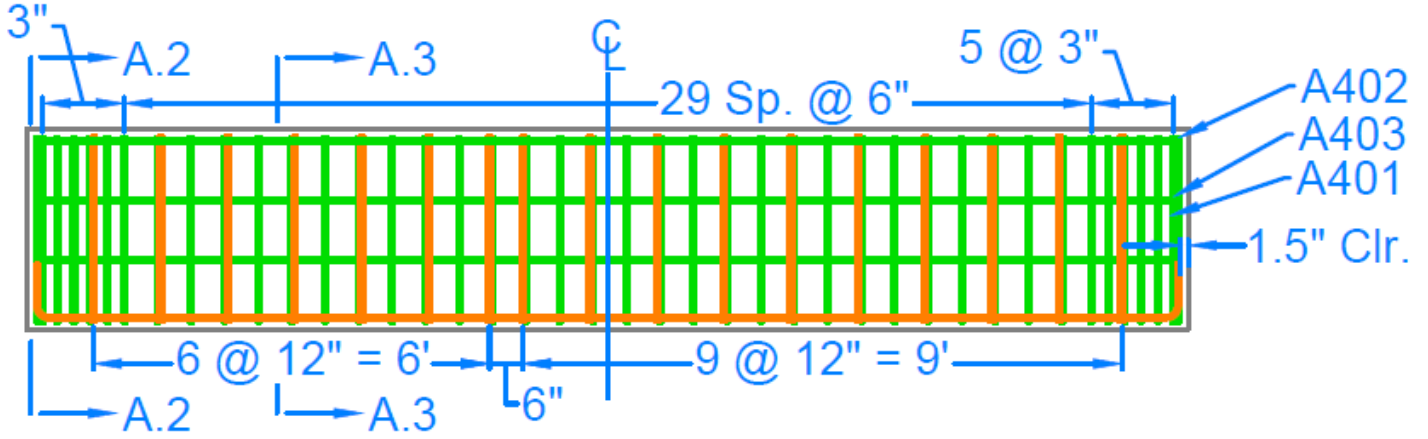

SECTION A.1

[A]

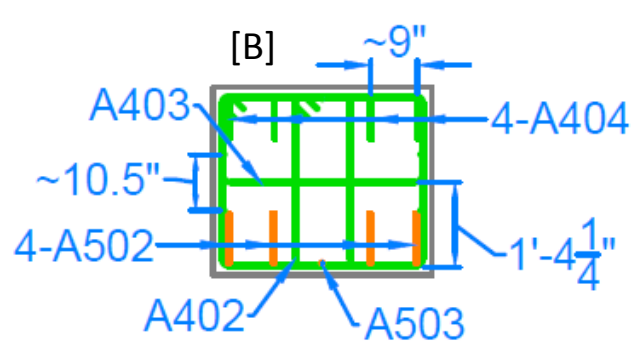

SECTION A.2

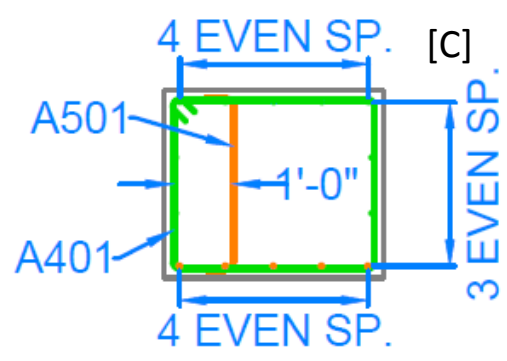

SECTION A.3

Fig. 26. Design for a large reinforced concrete specimen in the UMN structures lab illustrating the dimensions of the concrete and embedded reinforcements 

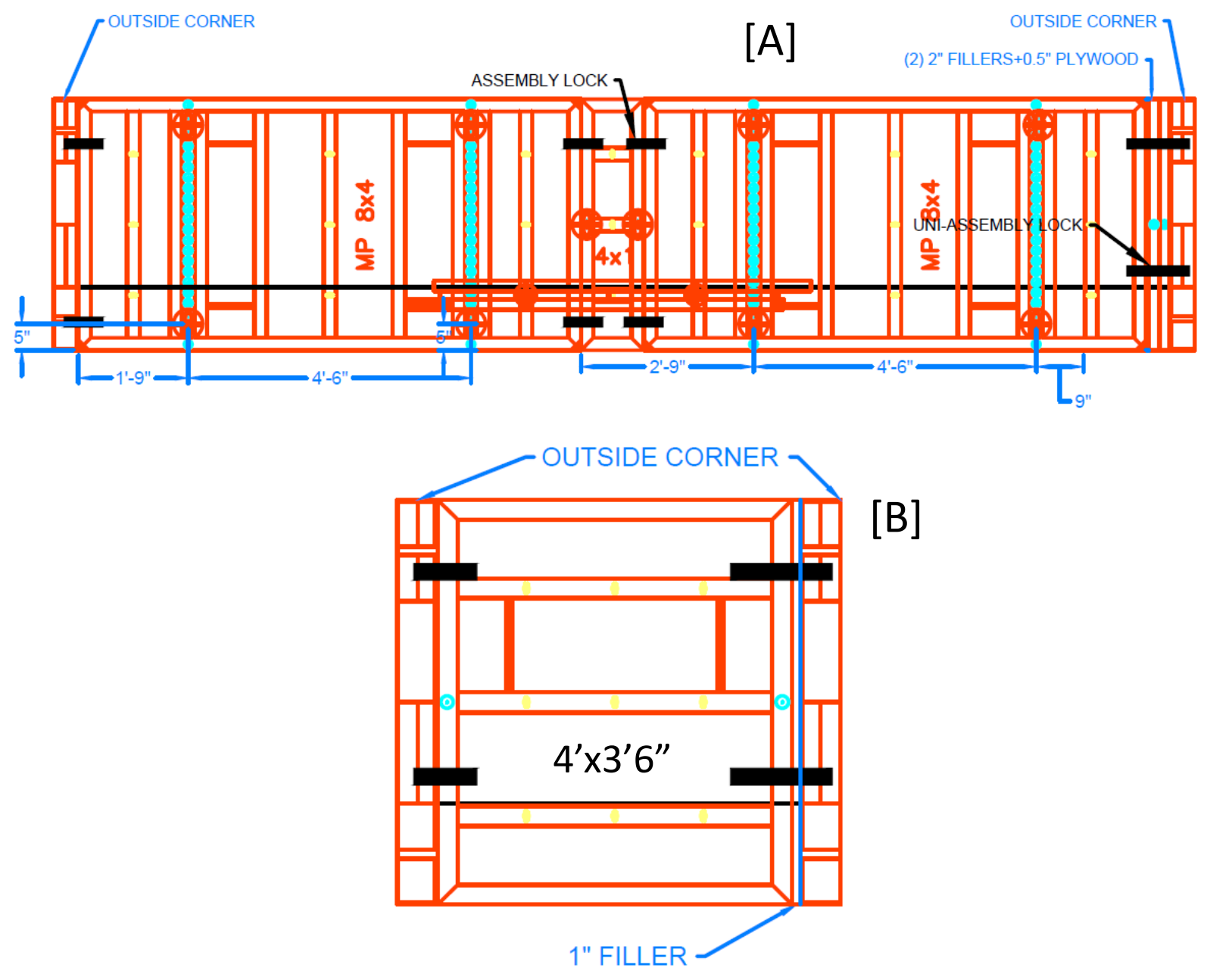

Fig. 27. Formwork required to cast the abutment structure.

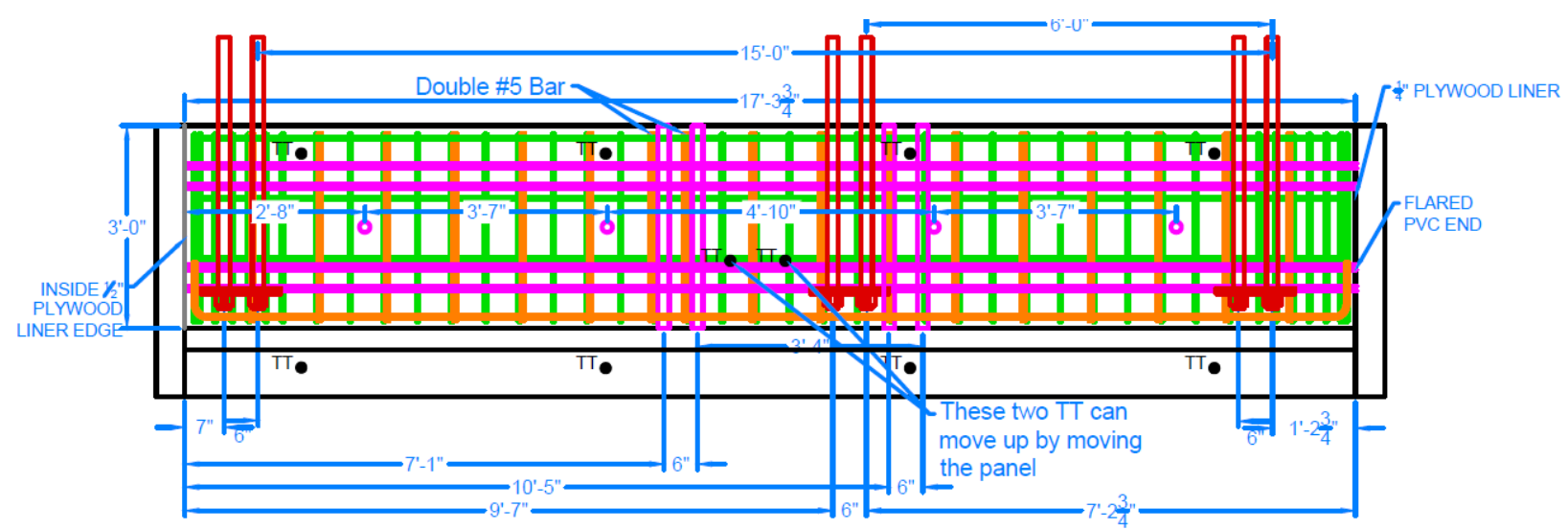

Fig. 28. Abutment block including details used to hold the block in place during loading and to crane the specimen to the desired location 


\subsection{PROPOSED REPRESENTATIVE SPECIMENS}

Concrete structures in NPPs are typically 3 to 4 feet thick along the wall and dome of the containment structure. Therefore, a specimen thickness of 3 feet 6 inches was chosen with various combinations of spacing and \#18 and \#10 rebar. This thickness is consistent with the example design constructed in the UMN-TGL and other similar laboratories. However, the $3 \mathrm{ft}$. height of the specimen constructed in the UMN-TGL causes boundary effects at deeper locations within the ROI for point source methods, regardless of the length of the specimen. Therefore, the height was increased to $9 \mathrm{ft}$. in the conceptual design to mitigate boundary effects. If the concrete wall conceptual design was the same $17 \mathrm{ft}$. length of the abutment block spanning the width of the UMN-TGL, this would maximize the specimen space allowing for multiple sections with different reinforcement types along with mitigation of boundary effects and embedment of different types and extents of simulated defects. However, the increase to a $9 \mathrm{ft}$ height creates a problem with load restrictions described in the "Large Specimen Concerns" section. Assuming a typical NPP reinforcement percentage of 5\%, the specimen will weigh over 80,000 lbs, requiring multiple cuts of a large cross section to allow for mobility using a typical crane load capacity. Rather than proposing construction of one large specimen with various sections that need to be cut for disposal, multiple specimens with various reinforcement, defect, and concrete types are proposed and prioritized in this report. The $17 \mathrm{ft}$ length was reduced to $7 \mathrm{ft}$ to accommodate use of a maximum 20-ton crane. This, along with mitigating mobility and disposal concerns, may allow the use of the initial specimen testing results to better inform the design or prioritization of specimens for subsequent testing.

To achieve the necessary NDE criteria, various specimens are proposed and prioritized. The potential design features include the reinforcement pattern (R), concrete type (C), and embedded defects (D). Each conceptual design section is proposed to have a height of 9 feet, a depth of 3.5 feet, and a length of 7 feet for mitigation of boundary effects when testing within the thickness of the specimen along the length/height surface. These dimensions allow for a representative type and extent of defects for each reinforcement pattern and spacing and concrete type proposed. Additionally, the use of smaller specimens allows for easier transport to locations where the specimens can be stored for future testing (structures grave sites) rather than demolished once they need to be removed from the laboratory. For example, a specimen of this size constructed and initially tested at the UMN-TGL could be transported to the Minnesota Road Research Facility (MnROAD) for storage and access to additional NDE testing as needed. This could provide a calibration and training site for any newly developed technique or newly available equipment. The various types of reinforcement patterns, concrete types, and embedded defects proposed are detailed in this section.

\subsubsection{Reinforcement Types}

NPP concrete is normally embedded with heavily reinforced cross sections using \#18 and \#8 rebar at 6 to 12 in spacing. The type and spacing of the reinforcement has a significant effect on shielding evaluation of defects below the level of reinforcements, especially when using GPR since electromagnetic waves are extremely sensitive to metal. While elastic wave-based methods are less sensitive to reinforcement than GPR, characterization of defects within heavily reinforced structures are more difficult than for less heavily reinforced structures. Since it is desirable to differentiate complexities caused by dense levels of reinforcement versus complexities caused by depth of penetration within concrete, various levels of reinforcement are proposed. The cross-sectional view shown in Fig. 29 gives the reinforcement pattern chosen to represent a typical NPP containment structure. The concrete wall is designed to have two vertical rebar, 7 inches from edge to center and horizontal rebar placed throughout the length of the wall with the first rebar starting 4 inches down from the top and stopping 4 inches from both ends to allow for proper concrete cover. One rebar on each side of the vertical rebar creates a shadowing effect test for the NDE methods while mimicking the reinforcement pattern of a typical NPP containment wall. 
Even though on-site testing of concrete in NPP structures typically only allows for one-sided access, the specimen is designed to allow for testing access on both sides of the wall with the understanding that the testing on each side of the wall should be treated as an independent measurement. The reinforcement pattern is similar for both sides of access, allowing evaluation of the effect of different depths using only one defect by comparing results of testing on both sides of the specimen. Although access to both sides would allow for test methods using two-sided access measurements, the testing should focus on one-side per measurement to simulate realistic containment wall access conditions.

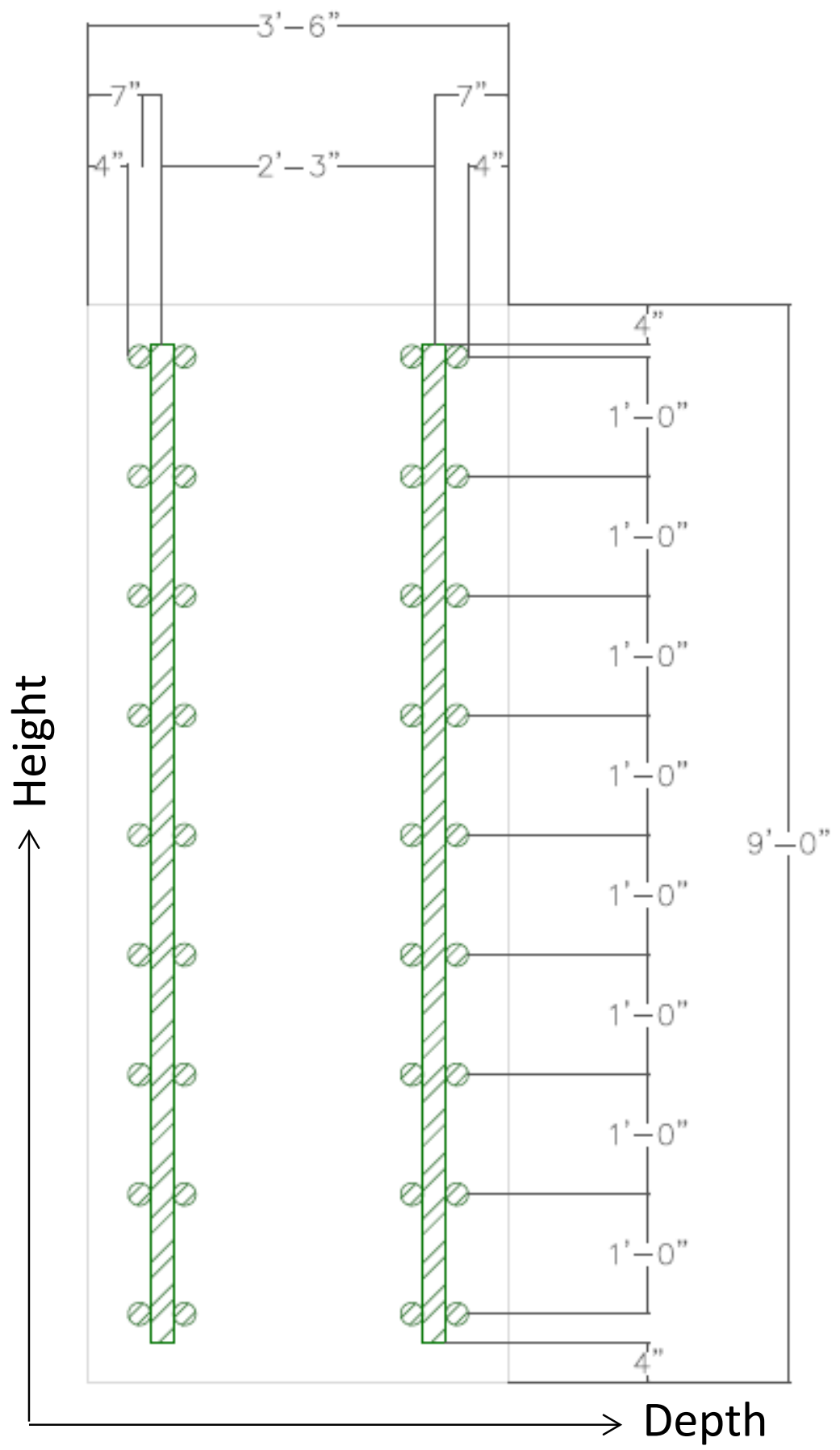

Fig. 29. Concrete dimensions and reinforcement cross-section to simulate a NPP containment wall 
The following reinforcement types were designed to allow for NDE assessment of defects in relation to reinforcement with different sizes, vertical and horizontal alignments, different spacing, and various depths:

- R1: No reinforcement - This provides a controlled specimen that allows for separation of the difficulties associated with defect depth from the effects of reinforcement density.

- R2: \#18 rebar at 12 in. spacing in both horizontal and vertical orientation - This provides a realistic reinforcement size that also allows for space between reinforcement for semicontrolled evaluation of the effects of concrete depth on defect characterization (see Fig. 30).

- R3: \#18 rebar at 6 in. spacing in both horizontal and vertical orientation - This provides a realistic reinforcement size that provides the most extreme density of reinforcement. This allows for evaluation of the effects of shadowing and scattering of heavily reinforced concrete specimens on defect characterization (see Fig. 31).

- R4: \#18 vertical rebar at 12 in. spacing and \#10 horizontal rebar at 6 in. spacing - This provides a realistic reinforcement size that also allows for evaluation of the effect of reinforcement spacing and variable reinforcement size, while providing some locations with greater spacing to evaluate the effects of specimen depth in the concrete (see Fig. 32).

Views along the length and height axes of the different types of reinforcements embedded in the conceptual design are illustrated in Fig. 30, Fig. 31, and Fig. 32.
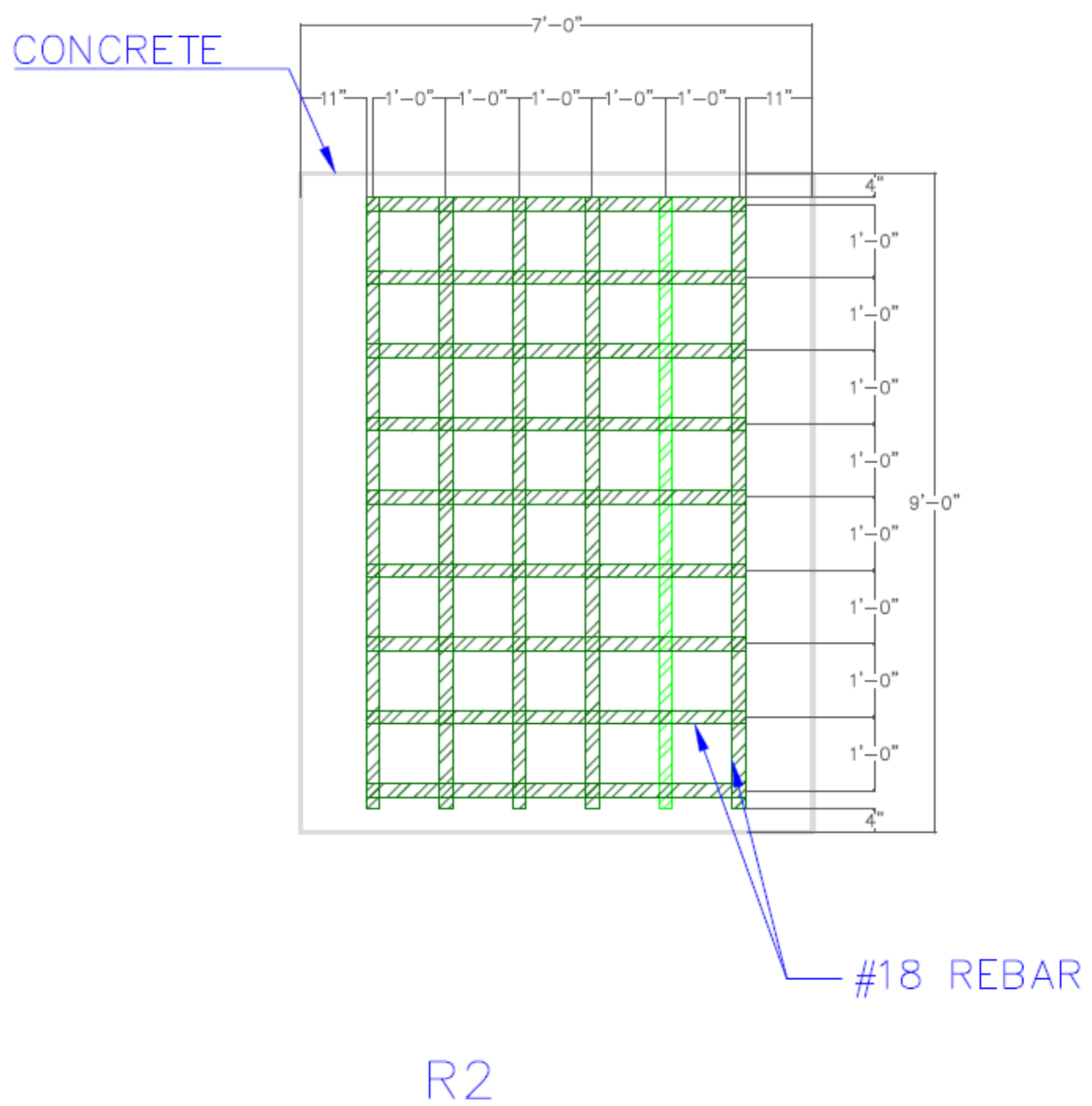

Fig. 30. Length/Height view of reinforcement type R2 


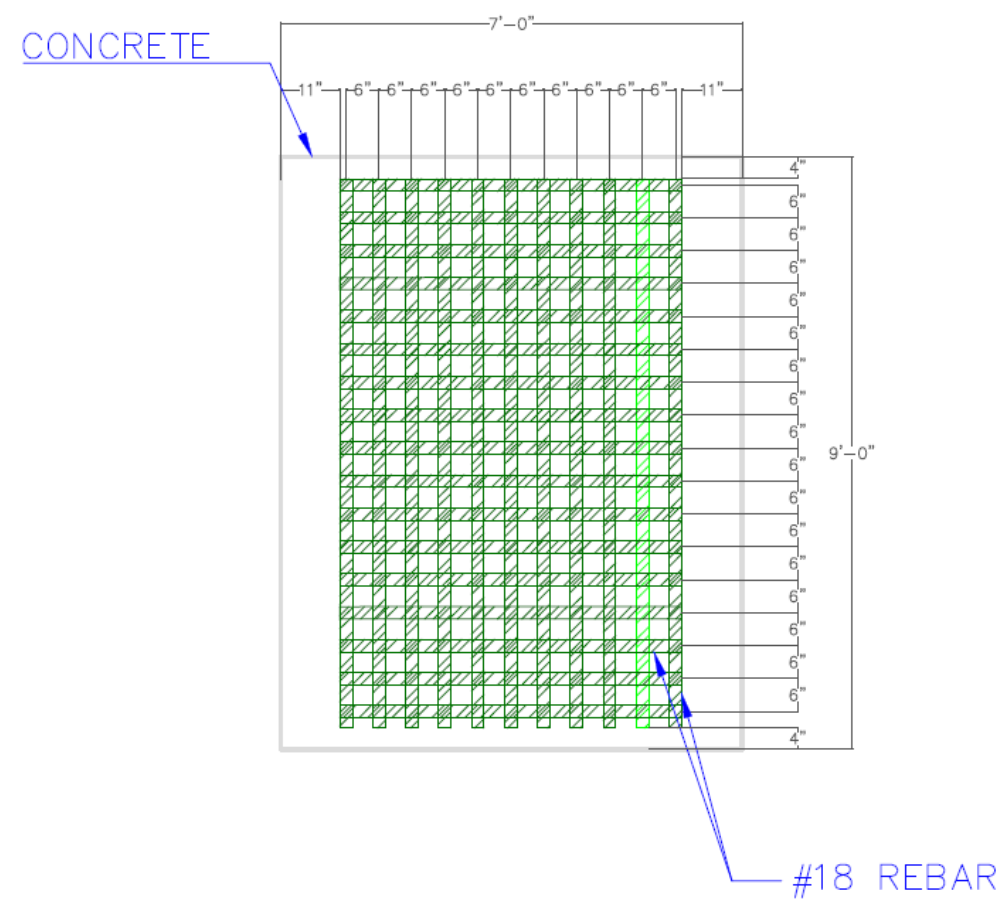

R3

Fig. 31. Length/Height view of reinforcement type R3

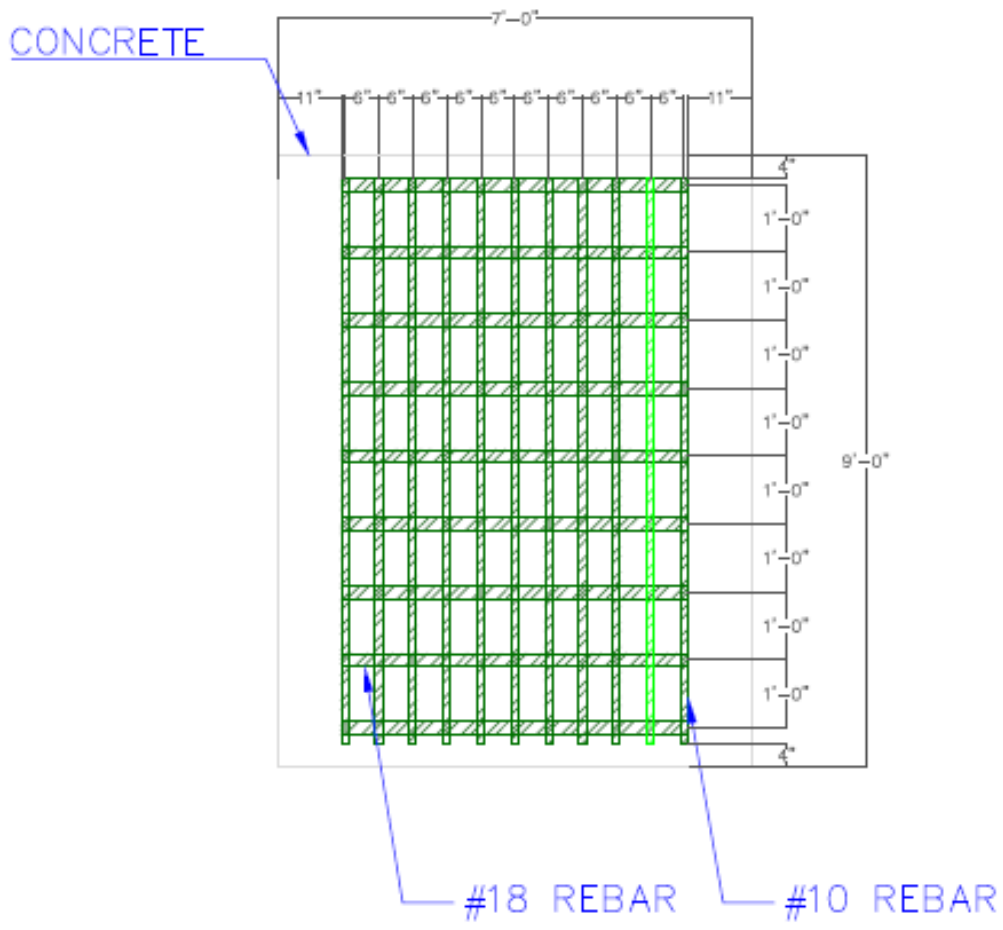

R4

Fig. 32. Length/Height view of reinforcement type R4 


\subsubsection{Concrete Material Properties}

Properties of the various NPP concrete structures depend on the materials used during construction of the specimen. Rather than attempting to replicate the mix design of the different NPP locations, material property variation methods are proposed by varying the water to cement ratio and aggregate type. These variations are better suited since NDE methods are generally more affected by macro properties of the specimen such as density, modulus, and strength. Additionally, these properties are more consistent from site to site than the material itself. For example a high slump mix was required at each site to allow for consolidation around a heavy percentage of reinforcement. The three basic types of concrete proposed for variation in material properties is given below:

- $\quad$ C1 - In this mix, the typical materials used for modern heavily reinforced concrete would be used with the goal of eliminating any unplanned defects and allow the evaluation to focus on the ability of the different methods to assess controlled defects in a larger more heavily reinforced structure. In this case any modern material or method will be used to ensure proper construction. For example, superplasticizer will be used to improve the consolidation of the concrete.

- $\quad$ C2 - In this mix, a higher water to cement ratio will be used to achieve the slump necessary to achieve proper consolidation of the concrete in a heavily reinforced structure. While the higher water to cement ratio may result in more unplanned and unquantified variability in the specimen, such as shrinkage and cracking, the paste portion of the mix will have a lower strength and modulus, which is more representative of the properties of NPP containment structures.

- $\quad$ C3 - In this mix, a lower strength and stiffness aggregate will be used to achieve the overall lower strength of the PCC caused by the higher water to cement ratio. This allows for a determination of the effect of cement paste versus aggregate property variability on the different NDE methods. This also gives a more fundamental understanding of how the different concrete materials from the various NPP may affect the various NDE techniques.

\subsubsection{Simulated Defects}

One of the critical purposes of the specimens for conceptual design in this report will be to determine how the current NDE techniques are able to determine various forms of degradation. This is a difficult task since, to date, limited comparisons of NDE techniques have been conducted at the size and reinforcement density of LWR containment structures on controlled specimens, or verified through forensic activities. There are two critical trade-offs to account for within the space constraints of the specimen when determining the simulated defects in the conceptual design. This includes determination of how realistic versus how controlled each defect should be as well as a determination of the detection/characterization difficulty each defect should achieve.

In the former trade-off, defects should be modeled to represent activities that may have legitimately happened during the construction process and/or cumulative deterioration and degradation of the concrete with time. Some of the aging related degradation mechanisms cannot be reproduced due to time constraints, while more realistic construction defect simulation can cause less repeatable results and can be difficult to quantify. However, designing the defects solely to be repeatable and not realistic can lead to the wrong conclusions when evaluating the various NDE techniques. For example, the NDE attributes determined to be desirable based on good performance on the test block may not be useful for evaluation of commercial concrete NPPs if the defects are not realistic enough.

With regard to the latter trade-off, the conceptual design should include sufficiently challenging defects that even the superior performing techniques cannot fully identify. This will ensure that limitations of even the most advanced methods are able to be quantified. At the same time, some of the defects should be identifiable by a majority of the methods. This will ensure that the methods that are not close to the desired achievement can be eliminated from consideration, while the baseline level of achievement of the methods performing well can be identified. 
The baseline level of performance on realistically large and densely reinforced specimens will allow for determination of the necessary improvements for effective NDE of real defects in in-service containment structures. Three different defect conceptual design types are proposed in this report with the goal of effective inspection of commercial NPP concrete degradation (note: all three designs contain some repeated defects from the previous ORNL study [8], for comparison purposes):

- D1: This type will be designed to have controlled defects that are repeatable, not only for multiple slabs, but also to compare with past studies. Since past studies have generally been performed on thinner, less heavily reinforced structures, these types of defects will be critical for separating the effect of specimen size and reinforcement density on the performance of the various NDE techniques. These defects include controlled delamination, consolidation, rebar disturbance, and voids.

- D2: This type will include defects that are designed to be as realistic as possible to the potential degradation conditions of a NPP's concrete. The defects in this slab do not need to be cited in journal publications or necessarily be controlled, but should either be included in previous reports. Combine multiple aspects of previously simulated defects, or replicate materials that may have fallen into the concrete during construction. These defects will include delamination, consolidation; rebar disturbance and realistic voids from construction debris or construction worker clothes or equipment.

- D3: This type will include a combination of D1 and D2 defects. This will be designed to give a realistic mix of defects with the controlled defects to allow for assessment of both the necessary measures needed to overcome the challenges with more heavily reinforced concrete structures, while also ensuring that the correct type of features for effective NPP NDE are achieved.

In the controlled defect (D1) block, void simulators based only on peer-reviewed studies were used to ensure a precedent for comparison. For example, the results of the NDE comparisons conducted on each of the voids from the peer reviewed studies on thinner, less heavily reinforced sections can be compared to the results on the proposed larger, more heavily reinforced section. This defect block contains forced honeycomb/non-consolidation/disturbed concrete (D1-1, D1-2, D1-14, D1-15), and voids (D1-3 to D1-8) using journal publications as a guide. A number of horizontal delamination defects (defects D1-9 to D113) are included at the level of reinforcements to evaluate the ability of the different techniques in determining defects similar to those observed at Crystal River and Davis-Besse NPPs. Defect D1-14 was designed to replicate the Defect D1-15 was designed to replicate disturbed concrete (B-1 from Fig. 22) from reference [8] where the rebar pieces were moved after initial set. This defect will be created by moving the rebar horizontally after concrete placement, allowing for an increasingly severe "trail" of disturbed concrete behind the path of the rebar. 
Table 6. Table detailing the defect type and locations for D1

\begin{tabular}{|c|c|c|c|c|c|c|c|c|c|c|}
\hline \multirow{2}{*}{$\begin{array}{c}\text { ID } \\
\text { D1-1 }\end{array}$} & \multirow{2}{*}{$\begin{array}{c}\text { Defect Type } \\
\text { Forced } \\
\text { Honeycombing }\end{array}$} & \multicolumn{4}{|c|}{$\begin{array}{l}\text { Dimensions, in. (X - } \\
\text { length, Y - height, Z } \\
\text { - depth, diameter) }\end{array}$} & \multicolumn{3}{|c|}{ Center Location (X, Y, Z) } & \multirow{2}{*}{$\begin{array}{c}\text { Material } \\
\text { Cast Beam }\end{array}$} & \multirow{2}{*}{$\begin{array}{r}\text { Ref. } \\
{[8]}\end{array}$} \\
\hline & & 20 & 6 & 6 & & 1'-9" & 7'-9" & 1'-2" & & \\
\hline D1-2 & $\begin{array}{c}\text { Forced } \\
\text { Honeycombing }\end{array}$ & 12 & & & 6 & 2'-1" & 1'-9" & 2'-4" & Cast Cylinder & {$[15]$} \\
\hline D1-3 & Void simulators & & & 2 & 12 & $2^{\prime}-5^{\prime \prime}$ & 6'-10" & 1'-0" & Styrofoam & [13] \\
\hline D1-4 & Void simulators & & & 6 & 4 & 3'-3" & 4'-3" & 1'-2" & Styrofoam & [13] \\
\hline D1-5 & Void simulators & $7^{\prime}$ & & & 0.5 & & 4'-0" & 1'-9" & PVC & {$[10]$} \\
\hline D1-6 & Void simulators & 7 ' & & & 1 & & 6'-1" & 1'-8" & PVC & [10] \\
\hline D1-7 & Void simulators & 4 & 4 & 4 & & 4'-9" & 3'-2" & 2'-1" & $\begin{array}{l}\text { Polystrene } \\
\text { Foam }\end{array}$ & {$[12]$} \\
\hline D1-8 & Void simulators & 8 & 8 & 4 & & $4^{\prime}-5^{\prime \prime}$ & $1^{\prime}-10^{\prime \prime}$ & 1'-1" & $\begin{array}{l}\text { Polystrene } \\
\text { Foam }\end{array}$ & {$[12]$} \\
\hline D1-9 & Forced Cracks & & & 0.2 & 20 & 1'-9" & 5'-1" & 0'-4" & Styrene plastic & [14] \\
\hline D1-10 & Forced Cracks & & & 0.2 & 12 & 3'-7" & 3'-0" & 2'-7" & Styrene plastic & [14] \\
\hline D1-11 & Forced Cracks & 6 & 6 & 0.04 & & 4'-4" & 7'-2" & 3'-2" & Plexiglass & {$[10]$} \\
\hline D1-12 & Forced Cracks & 6 & 6 & 0.08 & & 3'-10" & 5'-1" & 2'-7" & Plexiglass & [10] \\
\hline D1-13 & Forced Cracks & 6 & 6 & 0.12 & & 1'-10" & 2'-11" & 0'-4" & Plexiglass & {$[10]$} \\
\hline D1-14 & $\begin{array}{l}\text { Poor Surface } \\
\text { Finish/ } \\
\text { Consolidation }\end{array}$ & 4 & 8 & 4 & & 5'-8" & 5'-1" & 3'-4" & Form & {$[8][9]$} \\
\hline D1-15 & $\begin{array}{l}\text { Disturbed } \\
\text { Concrete }\end{array}$ & 1 & $9 *$ & 1 & & Vertic & $\begin{array}{l}\text { reinfor } \\
\text { nd to las }\end{array}$ & nent & $\begin{array}{c}\text { Disturbed } \\
\text { Reinforcement }\end{array}$ & {$[8][9]$} \\
\hline
\end{tabular}

The embedded defects arrangement for D1 can be observed in Fig. 33, Fig. 34, and Fig. 35. Reinforcement pattern R2 was included in each of the defect representations to show the defect relative location to the reinforcement. Fig. 33 shows the length and height view of the specimen. Fig. 34 shows the height and depth view of the defects, while Fig. 35 shows the length and depth face view of the defect arrangement. It can be observed that the defects are spaced to the extent possible to decrease the chance of adjacent distresses affecting the measurements. It should also be noted that none of the defects are overlapping, although some appear to be if the spacing between them is in the dimension not shown in the figure. The vertical reinforcement in the lighter green color denotes Defect D1-15, which is designated for movement during the casting process to simulate disturbed concrete. 


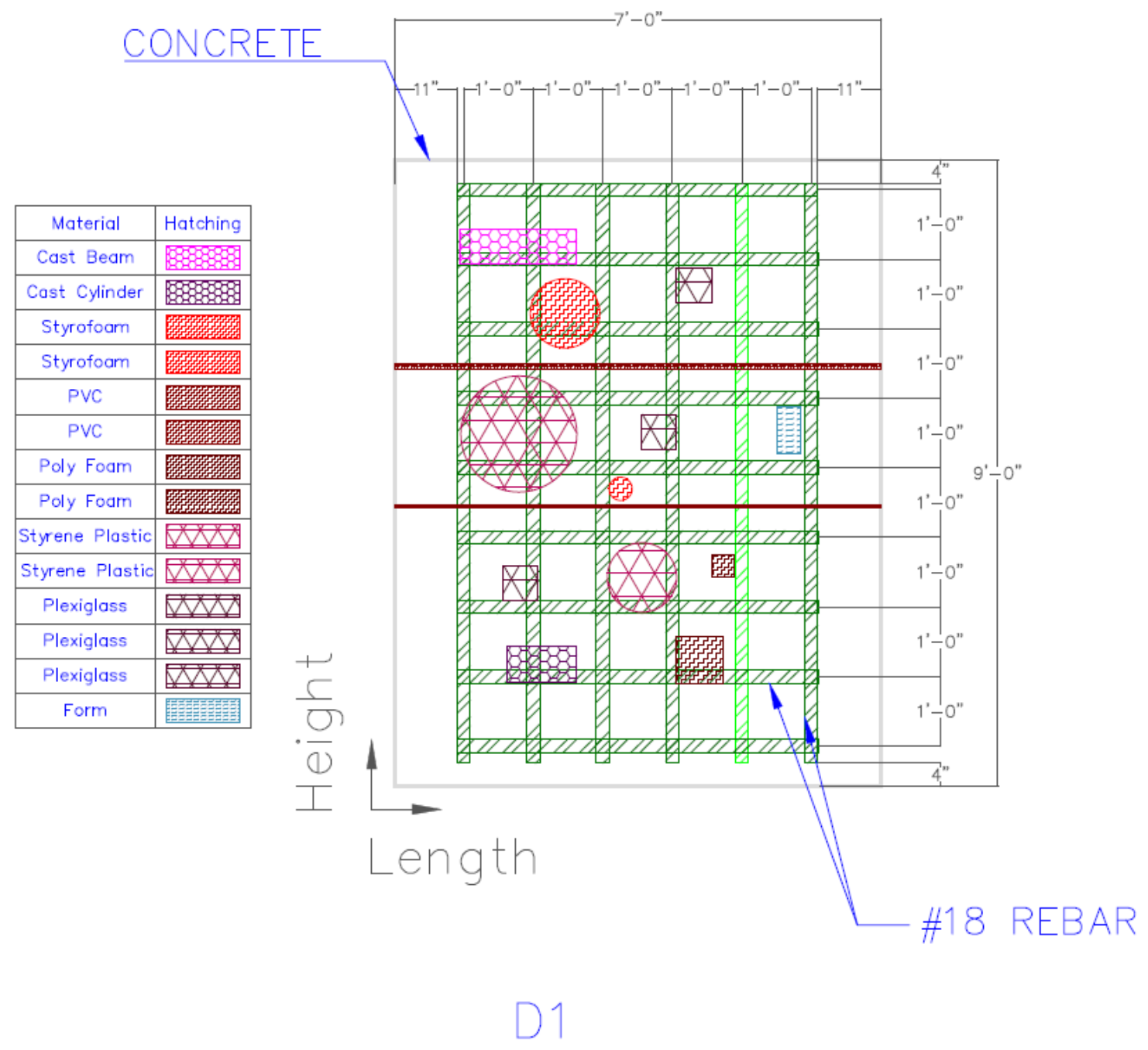

Fig. 33. Length/height view of the D1 defects outlined in Table 6 

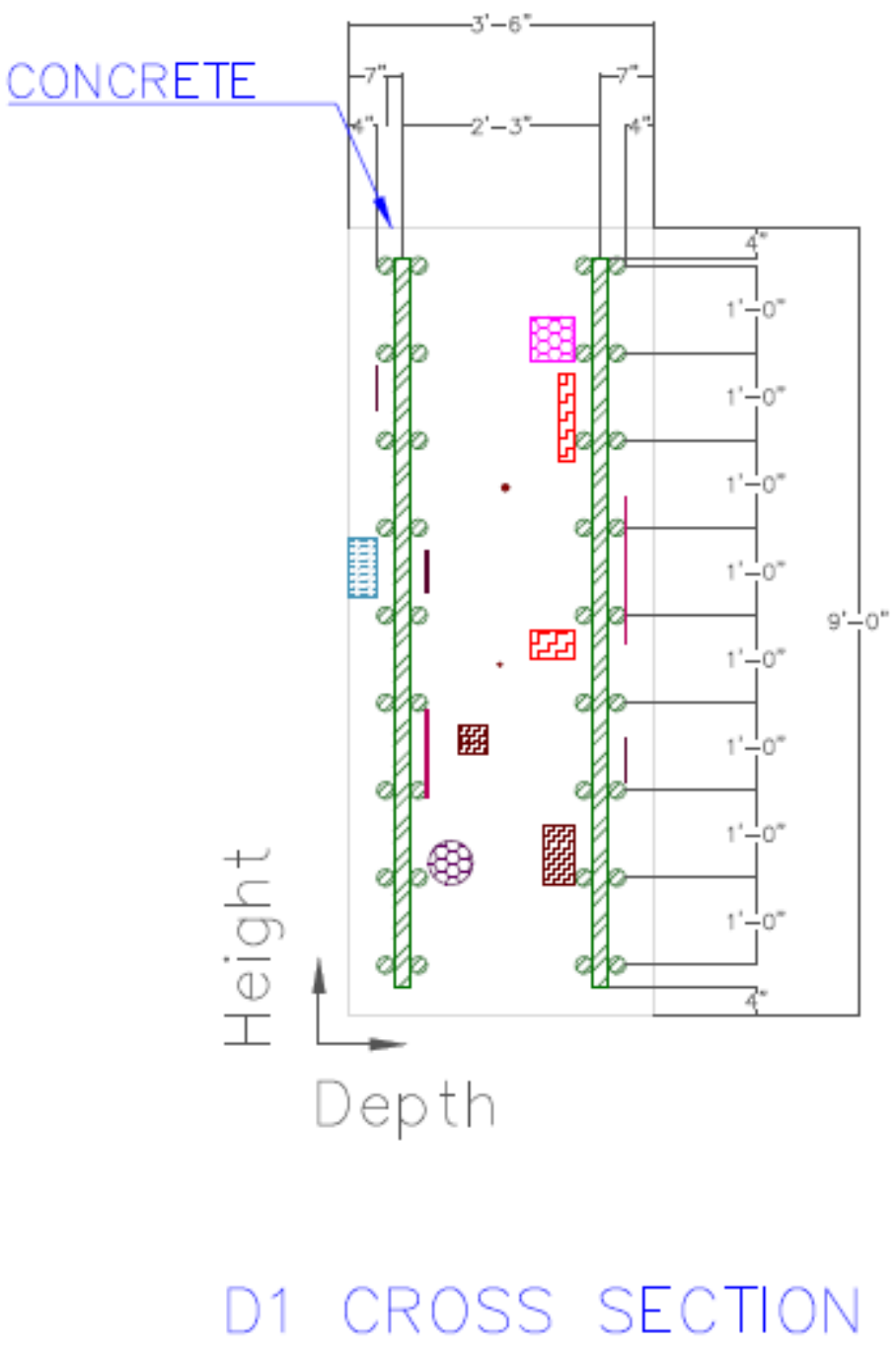

Fig. 34. Height/depth view of the D1 defects outlined in Table 6 


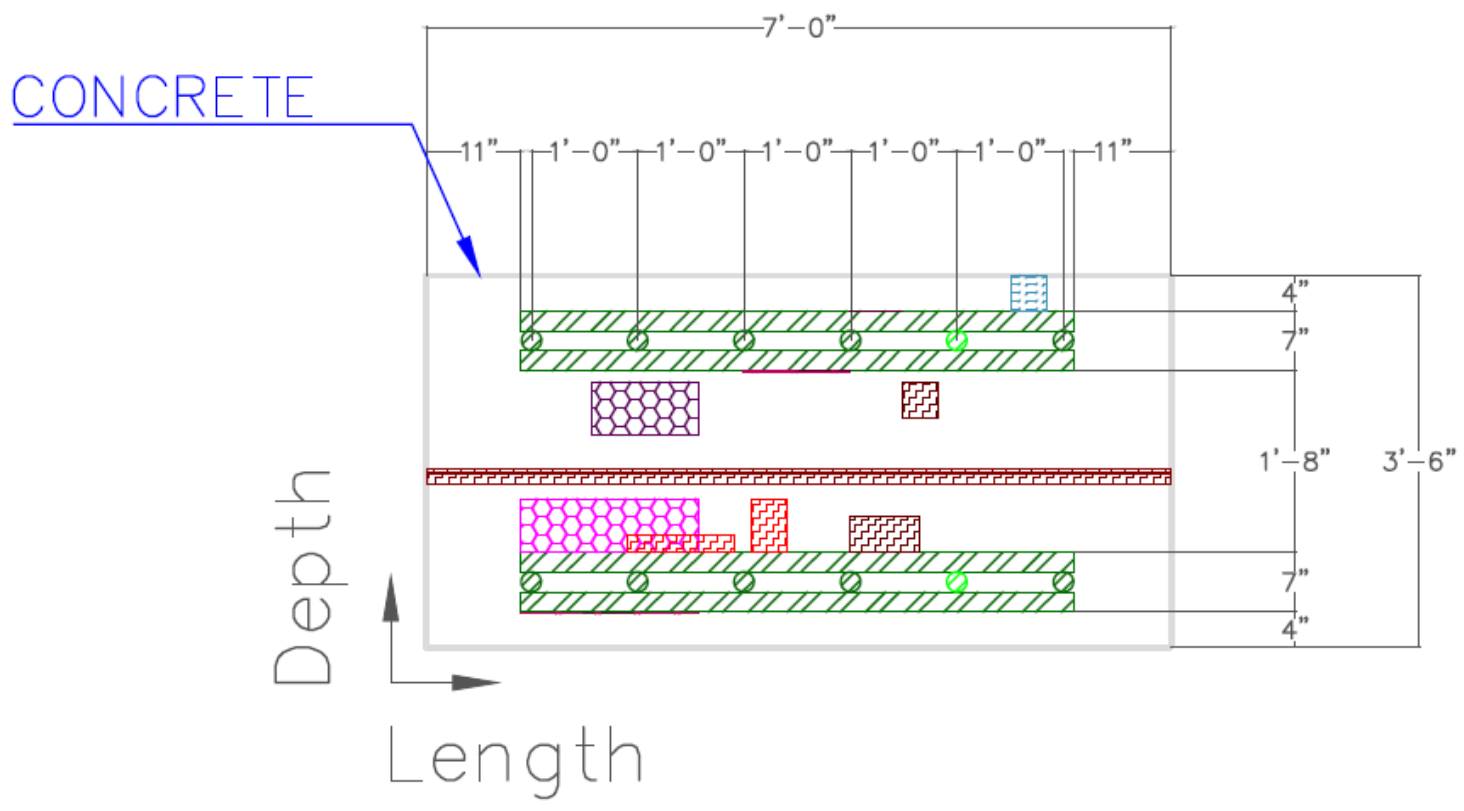

Fig. 35. Length/depth view of the D1 defects outlined in Table 6

In D2, forced honeycomb/non-consolidation/disturbed concrete (D2-1, D2-2, D2-14, D2-15) similar to that in D1 is proposed. This block also included defects that combine multiple aspects of previously simulated defects such as the dissolving Styrofoam defects that combine the delamination and void concepts from reference [8] and reference [10] to create a more realistic void embedded within a poor consolidation beam. In this case injection of acetone can be used dissolve Styrofoam at irregular shapes within beams and embedded in the specimen (D2-10, D2-11). Materials that may have fallen into the concrete during construction were also added in this specimen (D2-3, D2-4, D2-7, D2-8). Table 7 gives the location and type of defects for D2. 
Table 7. Table detailing the defect type and locations for D2

\begin{tabular}{|c|c|c|c|c|c|c|c|c|c|c|}
\hline \multirow{2}{*}{$\begin{array}{c}\text { ID } \\
\text { D2-1 }\end{array}$} & \multirow{2}{*}{$\begin{array}{c}\text { Defect Type } \\
\text { Forced } \\
\text { honeycombing }\end{array}$} & \multicolumn{4}{|c|}{$\begin{array}{c}\text { Dimensions, in. } \\
\text { (X - length, Y - } \\
\text { height, } \mathrm{Z} \text { - depth, } \\
\text { diameter) }\end{array}$} & \multicolumn{3}{|c|}{ Center Location (X, Y, Z) } & \multirow{2}{*}{$\begin{array}{c}\text { Material } \\
\text { Cast beam }\end{array}$} & \multirow{2}{*}{$\begin{array}{r}\text { Ref. } \\
\text { [8] }\end{array}$} \\
\hline & & 20 & 6 & 6 & & 1'-9" & 7'-9" & 1'-2" & & \\
\hline D2-2 & $\begin{array}{c}\text { Forced } \\
\text { honeycombing }\end{array}$ & 12 & & & 6 & $\begin{array}{l}1 '- \\
11 "\end{array}$ & 1'-7" & 2'-3" & Cast Cylinder & {$[15]$} \\
\hline D2-3 & $\begin{array}{c}\text { Construction } \\
\text { debris }\end{array}$ & & & 6 & 12 & 2'-5" & 6'-10" & 1'-0" & Hard Hat & none \\
\hline D2-4 & $\begin{array}{c}\text { Construction } \\
\text { debris }\end{array}$ & 10 & 5 & 2 & & 4'-3" & 4'-5" & 1'-1" & worker gloves & none \\
\hline D2-5 & Void simulators & $7^{\prime}$ & & & $\begin{array}{c}0 . \\
5\end{array}$ & & 4'-0" & 1'-8" & PVC & {$[10]$} \\
\hline D2-6 & Void simulators & $7^{\prime}$ & & & 1 & & 6'-1" & 1'-7" & PVC & {$[10]$} \\
\hline D2-7 & $\begin{array}{c}\text { Construction } \\
\text { debris }\end{array}$ & 4 & 4 & 2 & & 4'-5" & 3'-3" & 2'-4" & 2"X4" lumber & none \\
\hline D2-8 & $\begin{array}{c}\text { Construction } \\
\text { debris }\end{array}$ & 8 & 8 & 2 & & $4^{\prime}-5^{\prime \prime}$ & $1^{\prime}-10^{\prime \prime}$ & 1'-1" & 2"X8" lumber & none \\
\hline D2-9 & $\begin{array}{c}\text { Poor } \\
\text { consolidation / } \\
\text { Voids } \\
\end{array}$ & & & 1 & 20 & 1'-9" & 5'-1" & 0'-4" & Gravel Packs & [3] \\
\hline D2-10 & $\begin{array}{c}\text { Poor } \\
\text { consolidation / } \\
\text { Voids } \\
\end{array}$ & 20 & 6 & 6 & & $\begin{array}{l}3 '- \\
10^{\prime \prime}\end{array}$ & 7'-6" & $2^{\prime}-2^{\prime \prime}$ & $\begin{array}{l}\text { Dissolving } \\
\text { styrofoam }\end{array}$ & [10] \\
\hline D2-11 & $\begin{array}{c}\text { Poor } \\
\text { consolidation / } \\
\text { Voids } \\
\end{array}$ & 6 & 6 & 1 & & 3'-0" & 2'-8" & $1^{\prime}-0 " *$ & Gravel Packs & [3] \\
\hline D2-12 & $\begin{array}{c}\text { Poor } \\
\text { consolidation / } \\
\text { Voids } \\
\end{array}$ & 8 & 4 & 4 & & $\begin{array}{l}1 '- \\
10^{\prime \prime}\end{array}$ & 2'-11" & $1^{\prime}-8 " *$ & $\begin{array}{l}\text { Dissolving } \\
\text { styrofoam }\end{array}$ & [10] \\
\hline D2-13 & $\begin{array}{c}\text { Poor } \\
\text { consolidation / } \\
\text { Voids }\end{array}$ & 6 & 6 & 1 & & 3'-7"' & 6'-1" & 2'-7" & Gravel Packs & [3] \\
\hline D2-14 & $\begin{array}{l}\text { Poor Surface } \\
\text { Finish/ } \\
\text { Consolidation } \\
\end{array}$ & 4 & 8 & 4 & & 5'-8" & 5'-1" & 3'-4" & $\begin{array}{l}\text { Hand trowel } \\
\text { disturb }\end{array}$ & [8][9] \\
\hline D2-15 & $\begin{array}{l}\text { Disturbed } \\
\text { Concrete }\end{array}$ & 1 & 9 '* & 1 & & Verti & $\begin{array}{l}\text { al reinfo } \\
2^{\text {nd }} \text { to la }\end{array}$ & ement & $\begin{array}{c}\text { Reinforcement } \\
\text { disturb }\end{array}$ & {$[8][9]$} \\
\hline
\end{tabular}

The embedded defects arrangement for D2 can be observed in Fig. 36, Fig. 37, and Fig. 38. Fig. 36 shows the length and height view of the specimen. Fig. 37 shows the height and depth view of the defects, while Fig. 38 shows the length and depth face view of the defect arrangement. It can be observed that the defects were spaced in a similar manner to defects arrangement D1. 


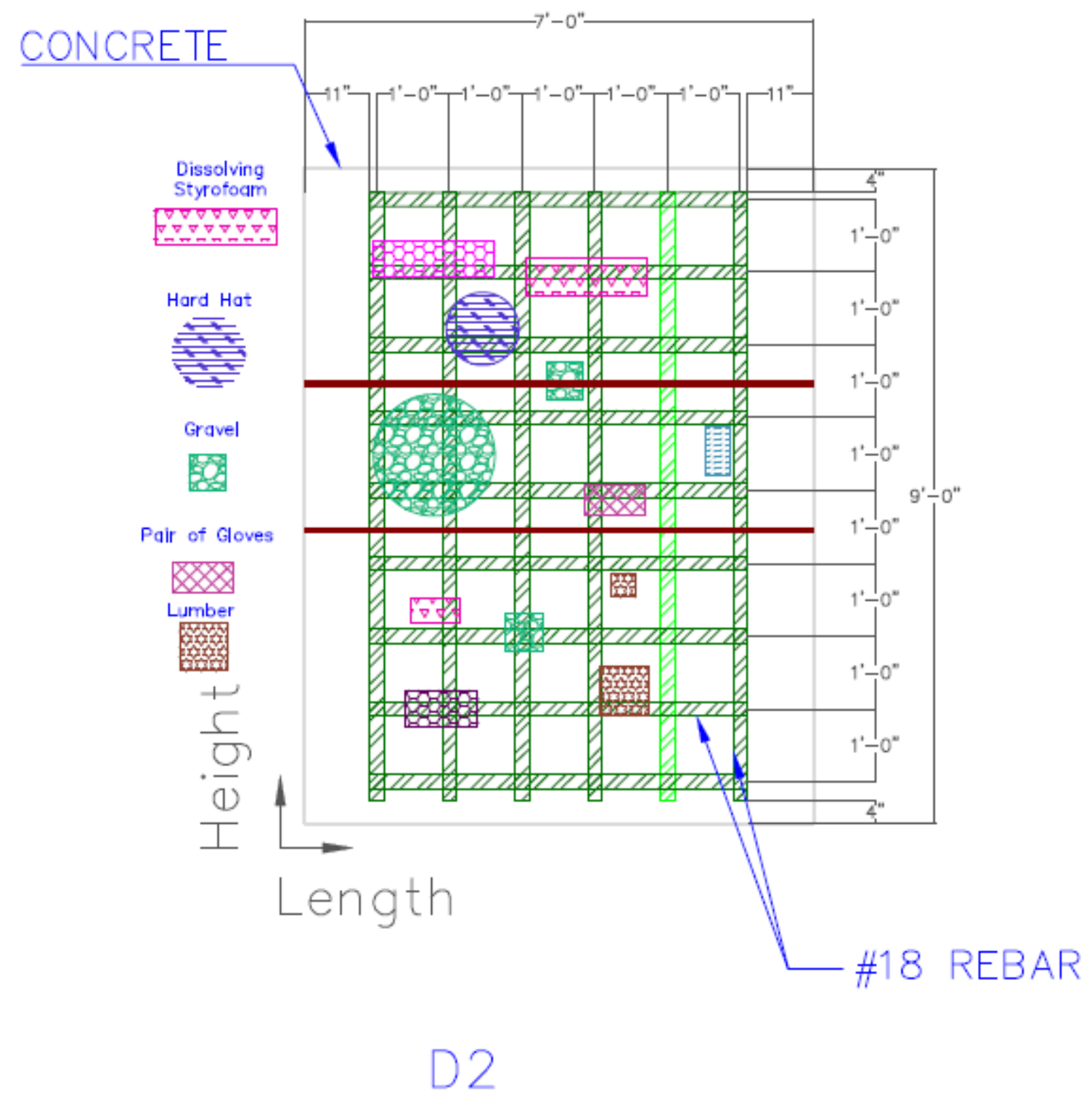

Fig. 36. Length/height view of the $D 2$ defects outlined in Table 7 

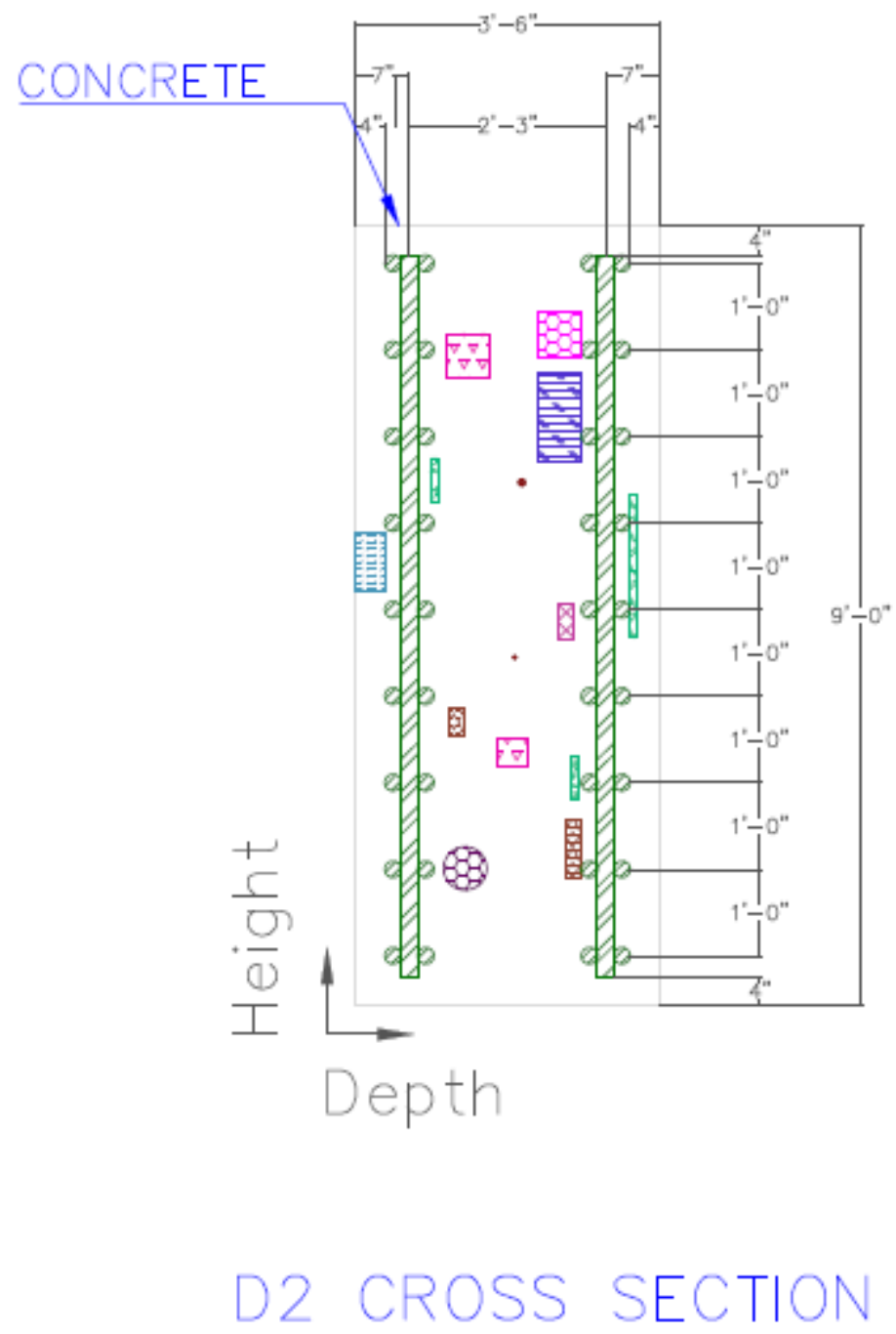

Fig. 37. Height/depth view of the D2 defects outlined in Table 7 

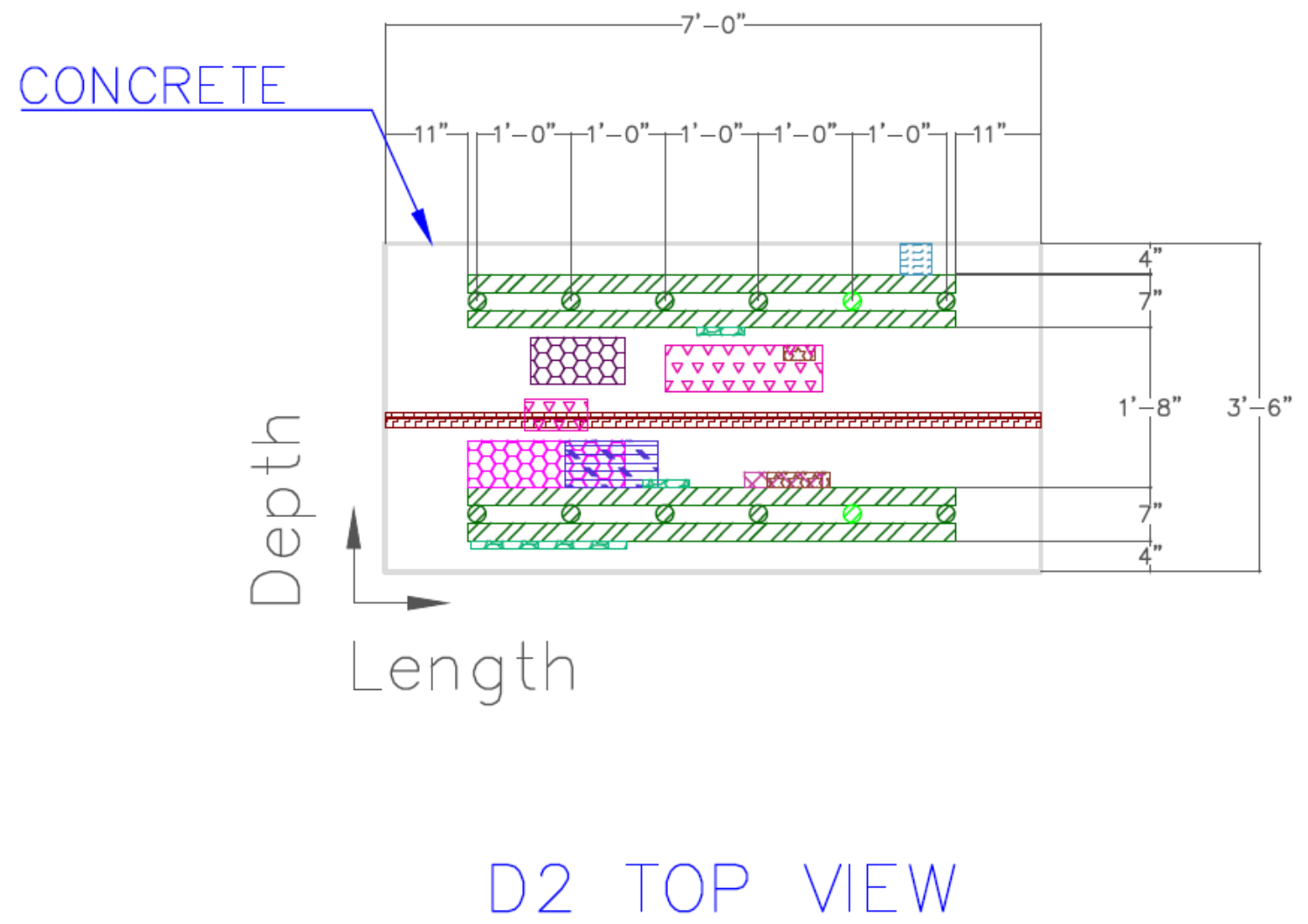

Fig. 38. Length/depth view of the $D 2$ defects outlined in Table 7

The combination block (D3) gives a mix of realistic and controlled defects from D1 and D2 to allow for assessment of both the necessary measures needed to overcome the challenges with more heavily reinforced concrete structures, while also ensuring that the correct type of features for effective NPP evaluation. 
Table 8. Table detailing the defect type and locations for D3

\begin{tabular}{|c|c|c|c|c|c|c|c|c|c|}
\hline \multirow{2}{*}{$\begin{array}{c}\text { ID } \\
\text { D2-1 }\end{array}$} & \multirow{2}{*}{$\begin{array}{c}\text { Defect Type } \\
\text { Forced } \\
\text { honeycombing }\end{array}$} & \multicolumn{4}{|c|}{$\begin{array}{c}\text { Dimensions, in. } \\
\text { (X - length, Y - } \\
\text { height, } \mathrm{Z} \text { - depth, } \\
\text { diameter) }\end{array}$} & \multicolumn{3}{|c|}{ Center Location (X, Y, Z) } & \multirow{2}{*}{$\begin{array}{r}\text { Material } \\
\text { Cast Beam }\end{array}$} \\
\hline & & 20 & 6 & 6 & & 1'-9" & 7'-9" & $1^{\prime}-2^{\prime \prime}$ & \\
\hline D2-2 & $\begin{array}{c}\text { Forced } \\
\text { honeycombing }\end{array}$ & 12 & & & 6 & $\begin{array}{l}1- \\
11 "\end{array}$ & $1^{\prime}-7^{\prime \prime}$ & 2'-3" & Cast Cylinder \\
\hline D1-3 & Void simulators & & & 2 & 12 & 2'-5" & 6'-10" & 1'-0" & Styrofoam \\
\hline D2-4 & $\begin{array}{l}\text { Construction } \\
\text { debris }\end{array}$ & 10 & 5 & 2 & & 4'-3" & 4'-5" & 1'-1" & worker gloves \\
\hline D2-5 & Void simulators & $7^{\prime}$ & & & $\begin{array}{r}0 . \\
5\end{array}$ & & 4'-0" & 1'-8" & PVC \\
\hline $\mathrm{D} 2-6$ & Void simulators & $7^{\prime}$ & & & 1 & & 6'-1" & 1'-7" & PVC \\
\hline D2-7 & $\begin{array}{l}\text { Construction } \\
\text { debris }\end{array}$ & 4 & 4 & 2 & & 4'-5" & 3'-3" & 2'-4" & 2"X4" lumber \\
\hline D1-8 & Void simulators & 8 & 8 & 4 & & 4'-5" & 1'-10" & $1^{\prime}-1 "$ & $\begin{array}{l}\text { Polystrene } \\
\text { Foam }\end{array}$ \\
\hline D1-9 & Forced Cracks & & & $\begin{array}{l}0 . \\
2 \\
\text { in. }\end{array}$ & 20 & 1'-9" & $5 '-1 "$ & $0^{\prime}-4^{\prime \prime}$ & Styrene plastic \\
\hline D2-10 & $\begin{array}{l}\text { Poor } \\
\text { consolidation / } \\
\text { Voids }\end{array}$ & 20 & 6 & 6 & & $\begin{array}{l}3 '- \\
10^{\prime \prime}\end{array}$ & 7'-6" & $2^{\prime}-2 "$ & $\begin{array}{l}\text { Dissolving } \\
\text { styrofoam }\end{array}$ \\
\hline D2-11 & $\begin{array}{l}\text { Poor } \\
\text { consolidation / } \\
\text { Voids }\end{array}$ & 6 & 6 & 1 & & 3'-0" & 2'-8" & $1^{\prime}-0 " *$ & Gravel Packs \\
\hline D1-12 & Forced Cracks & 6 & 6 & $\begin{array}{r}0 . \\
08\end{array}$ & & 3'-7"' & 6'-1" & 2'-7" & Plexiglass \\
\hline D1-13 & Forced Cracks & 6 & 6 & $\begin{array}{r}0 . \\
12\end{array}$ & & $\begin{array}{l}1 '- \\
10^{\prime \prime}\end{array}$ & 2'-11" & $0^{\prime}-4 "$ & Plexiglass \\
\hline D2-14 & $\begin{array}{l}\text { Poor Surface } \\
\text { Finish/ } \\
\text { Consolidation }\end{array}$ & 4 & 8 & 4 & & 5'-8" & 5'-1" & 3'-4" & $\begin{array}{l}\text { hand trowel } \\
\text { disturb }\end{array}$ \\
\hline D2-15 & $\begin{array}{l}\text { Disturbed } \\
\text { Concrete }\end{array}$ & 1 & 9 '* & 1 & & & & & \\
\hline
\end{tabular}

The embedded defects arrangement for D3 can be observed in Fig. 39, Fig. 40, and Fig. 41. Fig. 39 shows the length and height view of the specimen. Fig. 40 shows the height and depth view of the defects, while Fig. 41 shows the length and depth face view of the defect arrangement. 


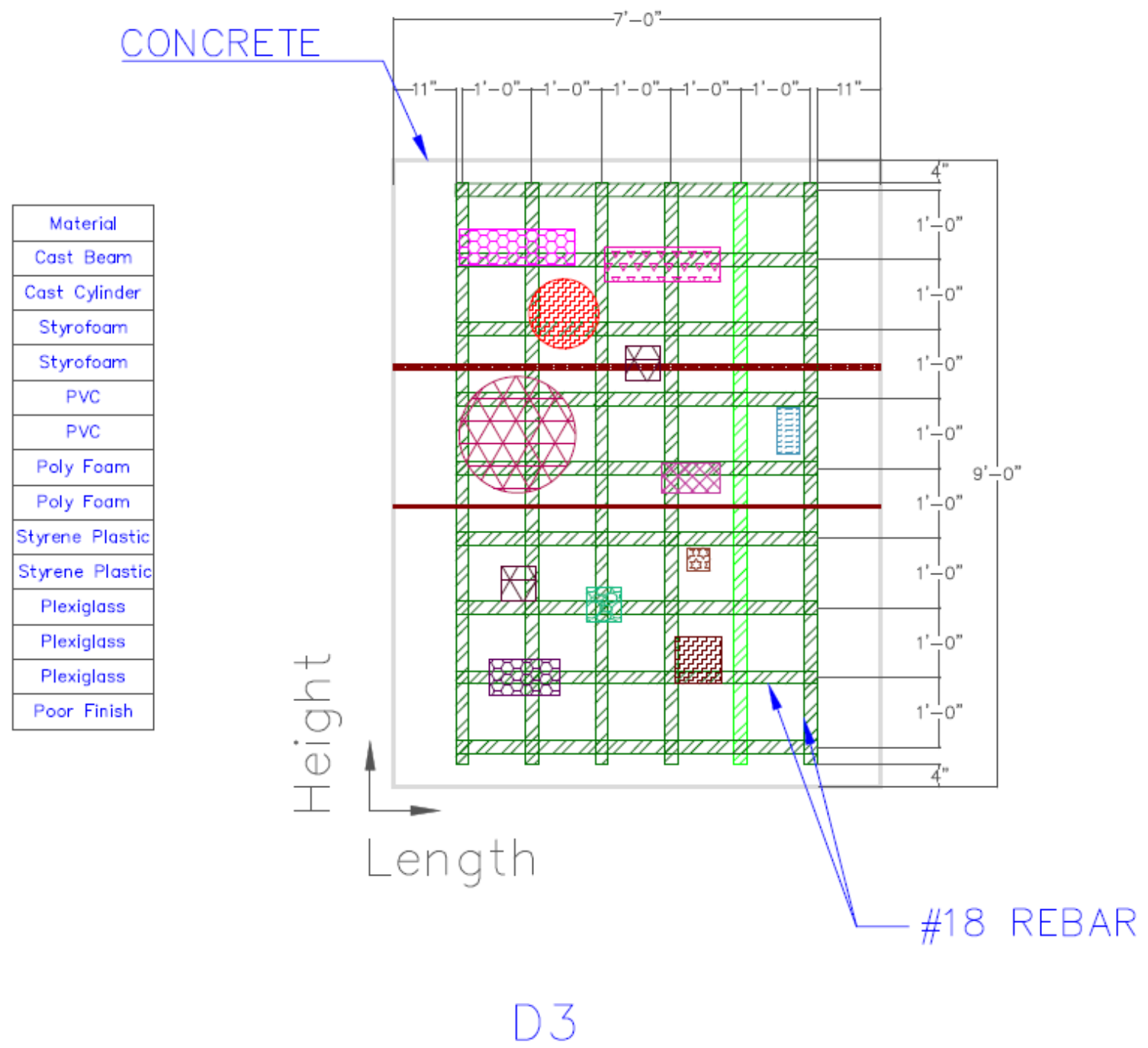

Fig. 39. Length/height view of the D3 defects outlined in Table 8 

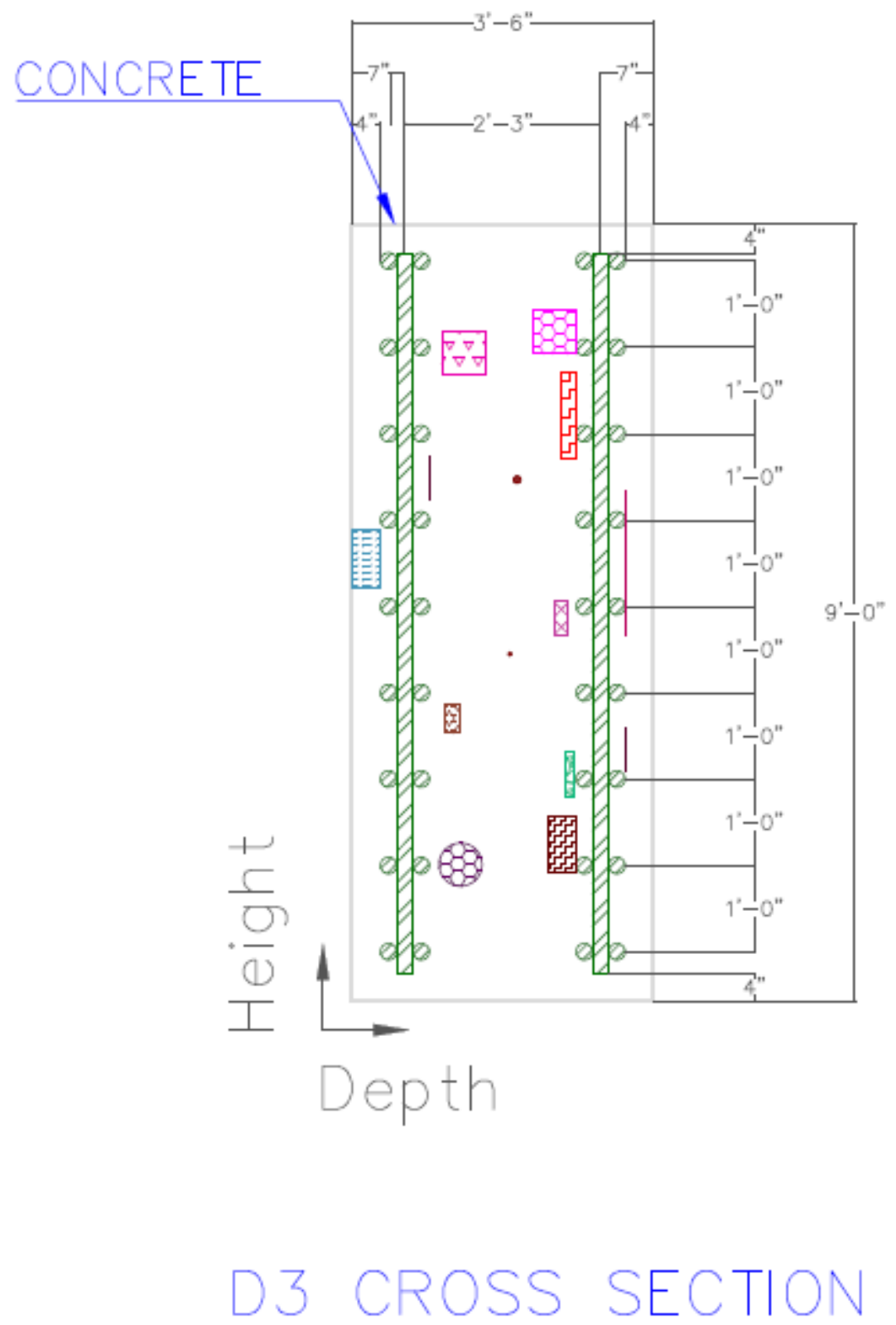

Fig. 40. Height/depth view of the D3 defects outlined in Table 8 

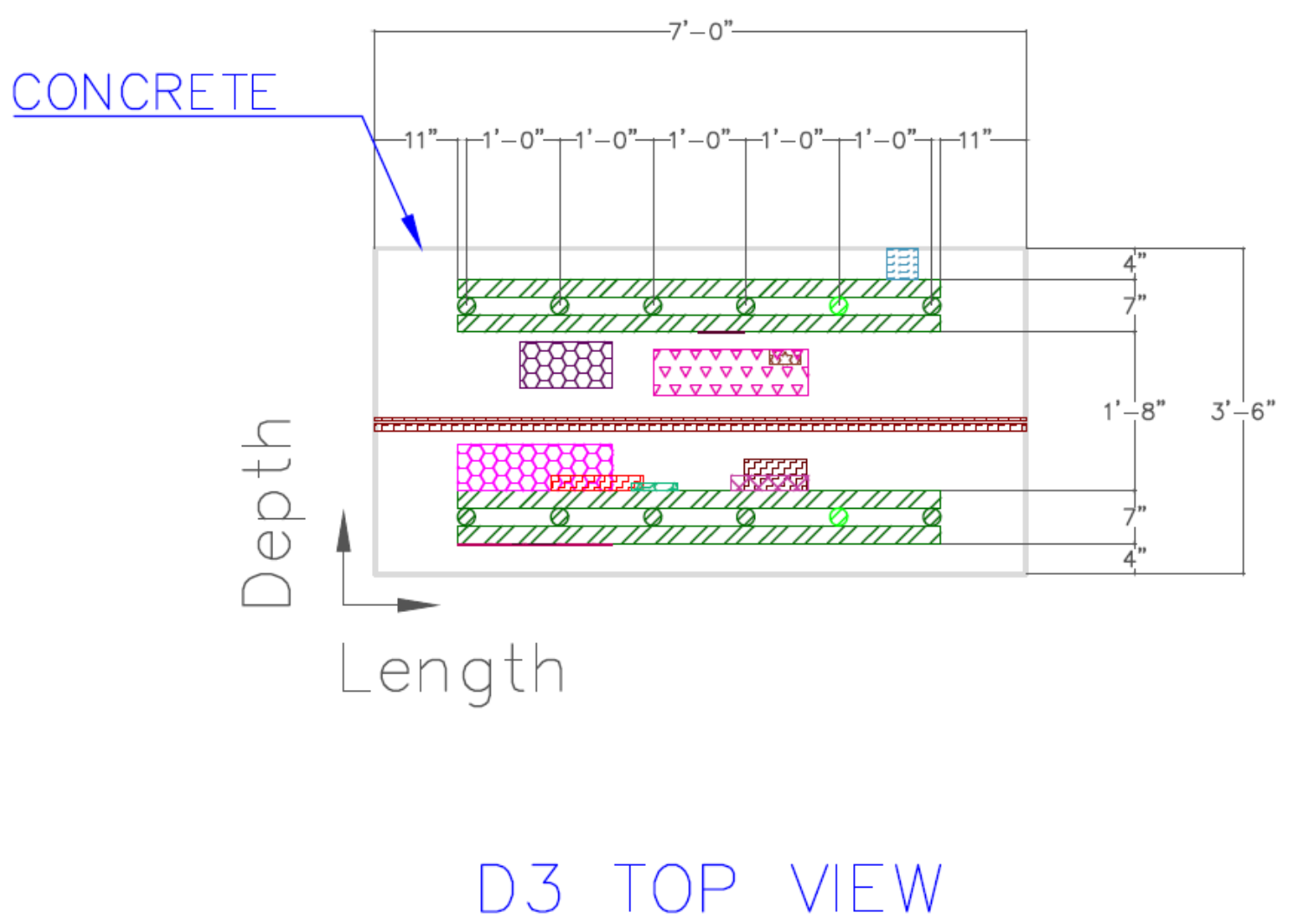

Fig. 41. Length/depth view of the D3 defects outlined in Table 8

\subsection{Prioritized Specimen List}

The potential design features for each of the specimens include the reinforcement pattern (R), concrete type (C), and embedded defects (D) outlined in the previous paragraphs. These options are combined to provide a prioritized list of potential conceptual design specimens for comparative nondestructive evaluation. One advantage of forming a prioritized list of conceptual designs to be tested in series includes the ability to use the results from testing of the previous specimens to modify the designs or priorities based on the newly available information. For example, the reinforcement density may be increased or decreased based on the ability of the different techniques in evaluating defects. Each of the conceptual design specimens are proposed to lead to the validation of a combination of techniques that can be applied for NDE of commercial NPP concrete degradation. The proposed specimen dimensions allow for a representative evaluation of a thick concrete structure with various types and extents of defects for each reinforcement pattern and spacing. While smaller lateral dimensions can be chosen to mitigate cost or mobility issues if need be, the thickness of the specimen would also need to be reduced to account for boundary effects. The smaller option may be attractive when the test specimen is designed to evaluate the effect of a specific material property, defect, or reinforcement pattern. However, smaller specimens are not recommended in most cases, as the cost of casting a specimen should be leveraged to allow for evaluation of as many factors as possible. The prioritized list of conceptual designs proposed to evaluate multiple defects within various reinforcing and concrete types is given here ending with the evaluation of the most realistic NPP concrete specimen combination: 


\subsubsection{First Specimen (R2-C1-D3)}

This combination of reinforcement, concrete, and defect types is designed to provide a large variety of information. The chosen defect type (D3) includes both realistic and controlled distresses at various sizes and difficulties of detection. This also allows for a diverse enough defect set to ensure that some defects will be difficult to detect, while some of the defects will be feasible for detection through various techniques. This will also provide feedback on which types of detects are best suited for thick and heavily reinforced concrete specimens, since the defects were mainly determined from studies involving thinner specimens. The reinforcement type (R2) was chosen to allow for an examination of how NDE techniques respond to the uniquely large diameter of typical NPP containment structure reinforcement (\#18 rebar). At the same time, the 12 in. spacing will allow sufficient space to collect information between reinforcements that focus on the ability of different techniques to deal with further propagation distances associated with detecting defects at greater depths. Since the defects provide a large amount of variables when combined with the added complexities of an increased specimen thickness and reinforcement type for NDE comparative testing, the PCC properties were chosen to be the most controllable concrete type (C1) in the first specimen.

\subsubsection{Second Specimen}

Depending on the results of testing the first specimen, the level and type of reinforcement will either be increased or decreased. If the techniques methods are proven to be relatively proficient in identifying and characterizing defects in the first specimen, the reinforcement will be adjusted to include shorter spacing ( 6 in.) between bars and a different reinforcement type will be included (\#10 bar) using reinforcement type R4. If the increased size and reinforcement density of specimen 1 causes more difficulty than anticipated, the reinforcement will be removed. Assuming the first round of testing identifies the most effective defect combinations, D3, can also be adjusted accordingly.

- $\quad$ R4-C1-D3: This combination was chosen to provide a controlled analysis of the effect of reinforcement on defect analysis. Since the concrete and defects are proposed to be constant with added reinforcement variability in the size and spacing, a comparison of the same NDE techniques on both specimens 1 and 2 will detail the sensitivity to reinforcement, which is a critical factor in evaluating 5\% reinforcement by volume NPP concrete structures. This will also provide repeatability testing at locations between the 6 in. spaced \#10 reinforcements, since most of the other parameters should be constant. Since these comparisons are only valid assuming fairly consistent PCC characteristics, the most consistent concrete (C1) will be used to replicate the first specimen.

- $\quad$ R1-C1-D3: This combination will check the sensitivity of the NDE techniques to increased size without the complexities caused by increased reinforcement size and density. This will assist in determining the cause of the difficulties in detection identified from the first specimen. The most consistent concrete (C1) will be used to replicate the first specimen to focus on the ability of the techniques to identify defects at large depths. 


\subsubsection{Third Specimen (R2-C2-D3)}

This specimen will be constructed with a higher water to cement ratio to better characterize the effect of material properties on the ability of the NDE techniques to identify the various defects, while keeping the reinforcement and defects similar to the first specimen.

\subsubsection{Fourth Specimen (R3-C2-D2)}

This specimen will be constructed to most closely resemble the necessary features for NDE of concrete degradation in commercial NPP structures. The most realistic defects will be embedded, in the most dense realistic reinforcement pattern with concrete using a water to cement ratio that represents inservice NPP structures. The effectiveness of developments made to address issues identified in testing of previous specimens will be validated on this realistically large and densely reinforced concrete specimen. 


\section{CONCLUSION}

Comparative NDE of various defects in reinforced concrete specimens is a key component in identifying the most promising techniques and directing the research and development efforts needed to characterize concrete degradation in commercial NPPs. This requires access to the specimens for data collection using state-of-the-art technology. Validation data is needed to properly evaluate the effectiveness of the techniques. In this case, the various defects should be created, well defined, and/or feasible to be evaluated forensically. It is also critical that the evaluation specimen and embedded defects is representative of in-service NPP structure concrete. Past studies have shown that it is not feasible to meet all of these needs through field removal or evaluation of currently available fabricated specimens.

Conceptual designs representative of the cross section of a commercial NPP and available for comparative NDE testing are proposed in this study to address the issues identified in the previous paragraph. Multiple comparative NDE studies have been conducted on reinforced concrete structures that are not as thick or heavily reinforced as typical commercial NPP reinforced concrete structures. Results of the comparative studies on these specimens showed the promise of various techniques in evaluating concrete degradation, providing the basis of the conceptual designs from this study. The results from the comparative testing on the thinner structures must be validated under NPP reinforced concrete conditions where difficulties such as a lower signal-to-noise ratio with greater depth of penetration need to be resolved. The lateral dimensions of the specimen were also chosen to mitigate unrealistic boundary effects that would not affect the results of field NPP concrete testing.

An evaluation of the basic restrictions and potential complexities involved with construction of large reinforced concrete specimens was conducted with a focus on how different NDE techniques may interact with the proposed structures. These factors were taken into account when determining specimen size and features to ensure a realistic design. Various reinforcement, concrete, and defect types were detailed, with the advantages and drawbacks of each conceptual design outlined, resulting in a proposed conceptual design for comparative NDE testing. Additional conceptual design combinations were also prioritized allowing for modification based on initial testing results and ending with a realistic conceptual design that could be used to validate NDE techniques for use in NPP inspections. 



\section{REFERENCES}

[1] “Light Water Reactor Sustainability Program Integrated Program Plan”, Revision 1, INL/EXT-1123452, http://www.energy.gov/sites/prod/files/2013/05/f0/LWRS_IPP_R1\%20April\%202013.pdf.

[2] D. A. Clayton and M. S. Hileman, "Light Water Reactor Sustainability Non-Destructive Evaluation for Concrete Research and Development Roadmap,” ORNL/TM-2012/360, Oak Ridge National Laboratory, 2012.

[3] D. A. Clayton and C. M. Smith, "Summary of Large Concrete Samples,” ORNL/TM-2013/223, Oak Ridge National Laboratory, 2013.

[4] Naus, D. J., et al. "Summary and conclusions of a program addressing aging of nuclear power plant concrete structures." Nuclear engineering and design 194.1 (1999): 73-96.

[5] Naus, D. J., C. B. Oland, and E. G. Arndt. "Ageing management of safety-related concrete structures to provide improved bases for continuing the service of nuclear power plants." Materials and Structures 24.4 (1991): 308-316.

[6] Braverman, J. I., Miller, C. A., Ellingwood, B. R., Naus, D. J., Hofmayer, C. H., Bezler, P., \& Chang, T. Y. (2001, March). Structural performance of degraded reinforced concrete members. In Transaction 17th International Conference on Structural Mecha

[7] Naus, D. J., C. B. Oland, and E. G. Arndt. "Ageing management of safety-related concrete structures to provide improved bases for continuing the service of nuclear power plants." Materials and Structures 24.4 (1991): 308-316.

[8] Clayton, Dwight A., Cyrus M. Smith, Christopher Ferraro, Jordan Nelson, Lev Khazanovich, Kyle Hoegh, Satish Chintakunta, John Popovics, Hajin Choi, and Suyun Ham. "Evaluation of Ultrasonic Techniques on Concrete Structures.” ORNL/TM-2013/430. Oak Ridge National Laboratory, 2013

[9] D. Algernon, D. Hiltunen, and C. Ferraro, "Validation of Nondestructive Testing Equipment for Concrete," University of Florida Department of Civil and Coastal Engineering, 2010.

[10] Yehia, Sherif, et al. "Detection of common defects in concrete bridge decks using nondestructive evaluation techniques." Journal of Bridge Engineering 12.2 (2007): 215-225.

[11] Sansalone, Mary, and Nicholas J. Carino. "Detecting delaminations in concrete slabs with and without overlays using the impact-echo method." ACI Materials Journal 86.2 (1989).

[12] Asano, Masanori, et al. "Impact acoustics methods for defect evaluation in concrete." NDT-CE 2003, Proc., BB 85-CD, DGZIP (2003).

[13] Zhu, Jinying, and John S. Popovics. "Imaging concrete structures using air-coupled impactecho." Journal of engineering mechanics 133.6 (2007): 628-640.

[14] Weritz, F., et al. "Investigation of concrete structures with pulse phase thermography." Materials and Structures 38.9 (2005): 843-849.

[15] Beutel, Ralf, et al. "Comparative performance tests and validation of NDT methods for concrete testing." Journal of Nondestructive Evaluation 27.1-3 (2008): 59-65.

[16] Maierhofer, Christiane, et al. "Complementary application of radar, impact-echo, and ultrasonics for testing concrete structures and metallic tendon ducts."Transportation Research Record: Journal of the Transportation Research Board1892.1 (2004): 170-1

[17] Taffe, Alexander, Kerstin Borchardt, and Herbert Wiggenhauser. "Specimen for the improvement of NDT-methods-Design and construction of a Large Concrete Slab for NDT methods at BAM." International Symposium Non-Destructive Testing in Civil Engineering ( 
[18] Schubert, Frank, and Bernd Köhler. "Ten lectures on impact-echo." Journal of Nondestructive Evaluation 27.1-3 (2008): 5-21.

[19] Fellinger, P., et al. "Numerical modeling of elastic wave propagation and scattering with EFITelastodynamic finite integration technique." Wave motion 21.1 (1995): 47-66.

[20] Schubert, Frank, and René Marklein. "Numerical computation of ultrasonic wave propagation in concrete using the elastodynamic finite integration technique (EFIT)." Ultrasonics Symposium, 2002. Proceedings. 2002 IEEE. Vol. 1. IEEE, 2002.

[21] Schubert, Frank, Herbert Wiggenhauser, and Regine Lausch. "On the accuracy of thickness measurements in impact-echo testing of finite concrete specimens-numerical and experimental results." Ultrasonics 42.1 (2004): 897-901.[22] G. Zacher, C. Kohl, J. Wostmann, and C. Maierhofer, "Evaluation of radar and complementary

[23] Schurr, Dennis P., et al. "Damage detection in concrete using coda wave interferometry." NDT \& E International 44.8 (2011): 728-735.

[24] International Atomic Energy Agency, "Guidebook on non-destructive testing of concrete

[25] Popovics, J., "Ultrasonic and X-ray Imaging," in Short Course on NDE for the Infrastructure, (2011).

[26] Schubert, F., Lausch, R. \& Wiggenhauser, H. “Geometrical effects on impact-echo testing of finite concrete specimens. Proceedings of International Symposium .” Non-Destructive Testing in Civil Engineering (NDT-CE), 2003. 16-19.

[27] K.J. Langenberg, R. Marklein, K. Mayer (2002). “Applications to nondestructive testing with ultrasound”, R. Pike, P. Sabatier (Eds.), Scattering \& Inverse Scattering in Pure and Applied Science, Academic Press, 594-617.

[28] M. Spies, W. Jager (2003). "Synthetic aperture focusing for defect reconstruction on anisotropic media”, Ultrasonics, 41, 125-131.

[29] C. Engstrand, R. Kline (2005). “Application of SAFT to layered, anisotropic, media”, Rev QNDE, 24B, 1151-1158.

[30] A. Shlivinski, K.J. Langenberg (2007). "Defect imaging with elastic waves in inhomogeneousanisotropic materials with composite geometries." Ultrasonics, 46, 89-104.

[31] Marklein (2002). "Linear and nonlinear inversion algorithms applied in nondestructive evaluation.” Inverse Problems. 18,1733-1759.

[32] Schickert, M., Krause, M. \& Müller, W. (2003). "Ultrasonic imaging of concrete elements using reconstruction by synthetic aperture focusing technique.” Journal of Materials in Civil Engineering, 15, 235-246.

[33] Mayer, K., Langenberg, K. J., Krause, M., Milmann, B. \& Mielentz, F. 2008. Characterization of reflector types by phase-sensitive ultrasonic data processing and imaging. Journal of Nondestructive Evaluation, 27, 35-45.

[34] Shokouhi, P. \& Wiggenhauser, H. (2012) “Multiprobe Ultrasonic Testing for Detection of Delamination in Concrete Bridge Decks.” Transportation Research Board 91st Annual Meeting.

[35]Hoegh, K., Worel, B., Yu T., and Khazanovich, L. (2013) “Detection of Subsurface Joint Deterioration” Transportation Research Record: Journal of the Transportation Research Board. Volume 2367. Issue 1: p. 3-12. 
[36] Hoegh, K. and L. Khazanovich (2012). "Correlation Analysis of 2D Tomographic Images for Flaw Detection in Pavements,” Journal of Testing and Evaluation. American Society for Testing and Materials Paper ID: JTE103765, Volume 40, Issue 2. 9 pages.

[37] Braverman, J. I., Miller, C. A., Hofmayer, C. H., Ellingwood, B. R., Naus, D. J., \& Chang, T. Y. (2004). Degradation assessment of structures and passive components at nuclear power plants. Nuclear engineering and design, 228(1), 283-304.

[38] Chiu et al. Performance Improvement International. "Root Cause Assessment Crystal River Unit 3 Containment Concrete Delamination.” CRYSTAL RIVER NUCLEAR PLANT-SPECIAL INSPECTION REPORT 05000302/2009007. US Nuclear Regulatory Commission (NRC) Special Inspection at Crystal River Unit 3 Nuclear Plant (2010).

[39] Ashar, H., and G. Bagchi. Assessment of inservice conditions of safety-related nuclear plant structures. Washington, DC: US Nuclear Regulatory Commission, 1995.

[40] Moreadith, Frederick L., and Richard E. Pages. "Delaminated prestressed concrete dome: investigation and repair." Journal of Structural Engineering109.5 (1983): 1235-1249.

[41] Wang, Shen, and Javeed A. Munshi. "Design of radial reinforcement for prestressed concrete containments." Nuclear Engineering and Design 255 (2013): 153-161.

[42] S.A. Reynolds, "Davis-Besse Nuclear Power Station - Inspection to Evaluate the Root Cause Evaluation and Corrective Actions for Cracking in the Reinforced Concrete Shield Building Of The Containment System.” Nuclear Regulatory Commission Inspection Report 05000346/2012009(DRS) (2012).

[43] "Non-Destructive Inspection Protocol for Reinforced Concrete Highway Barriers and Bridge Railings.” Federal Highway Administration NDE Validation Center, McLean, VA, 2013 